
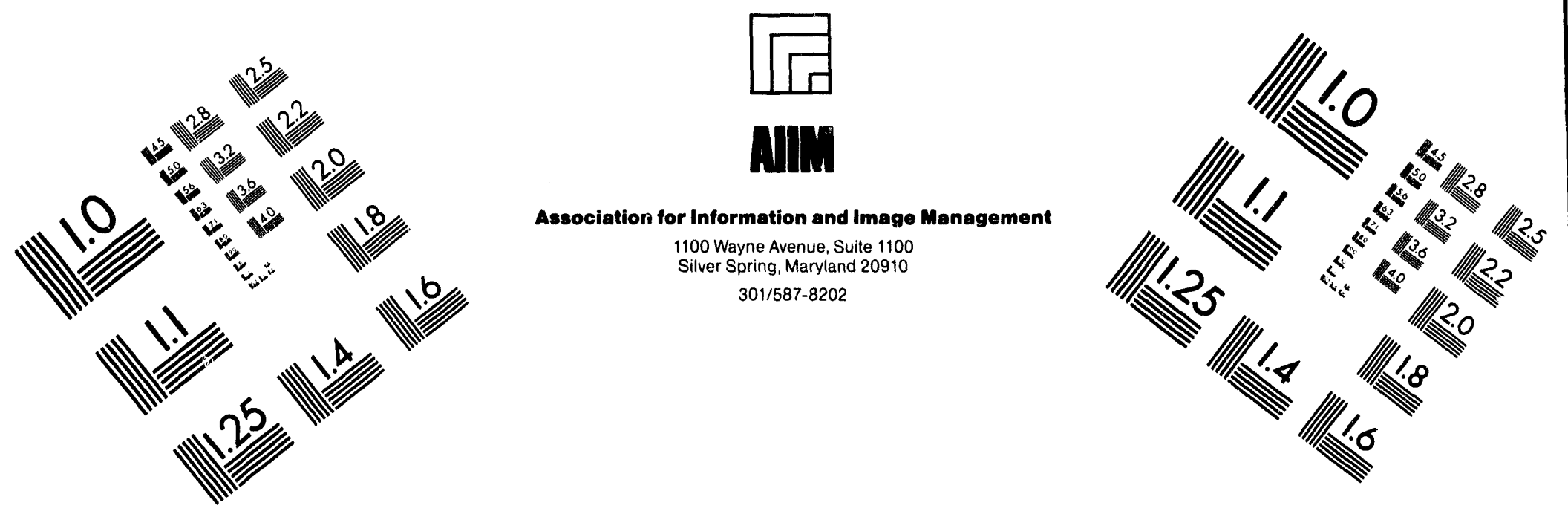

Centimeter

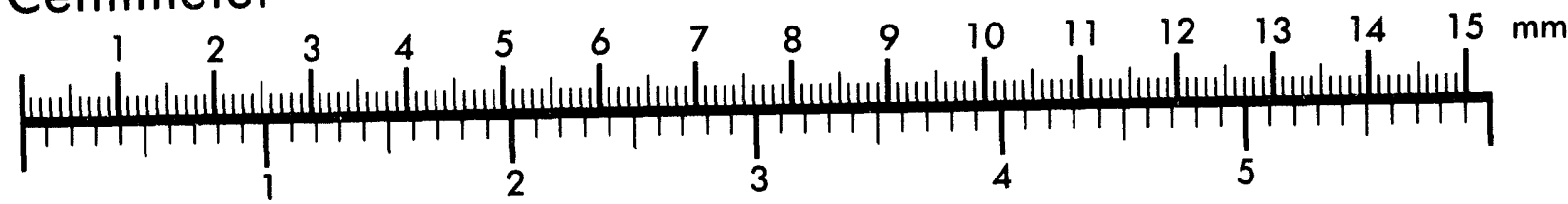
Inches
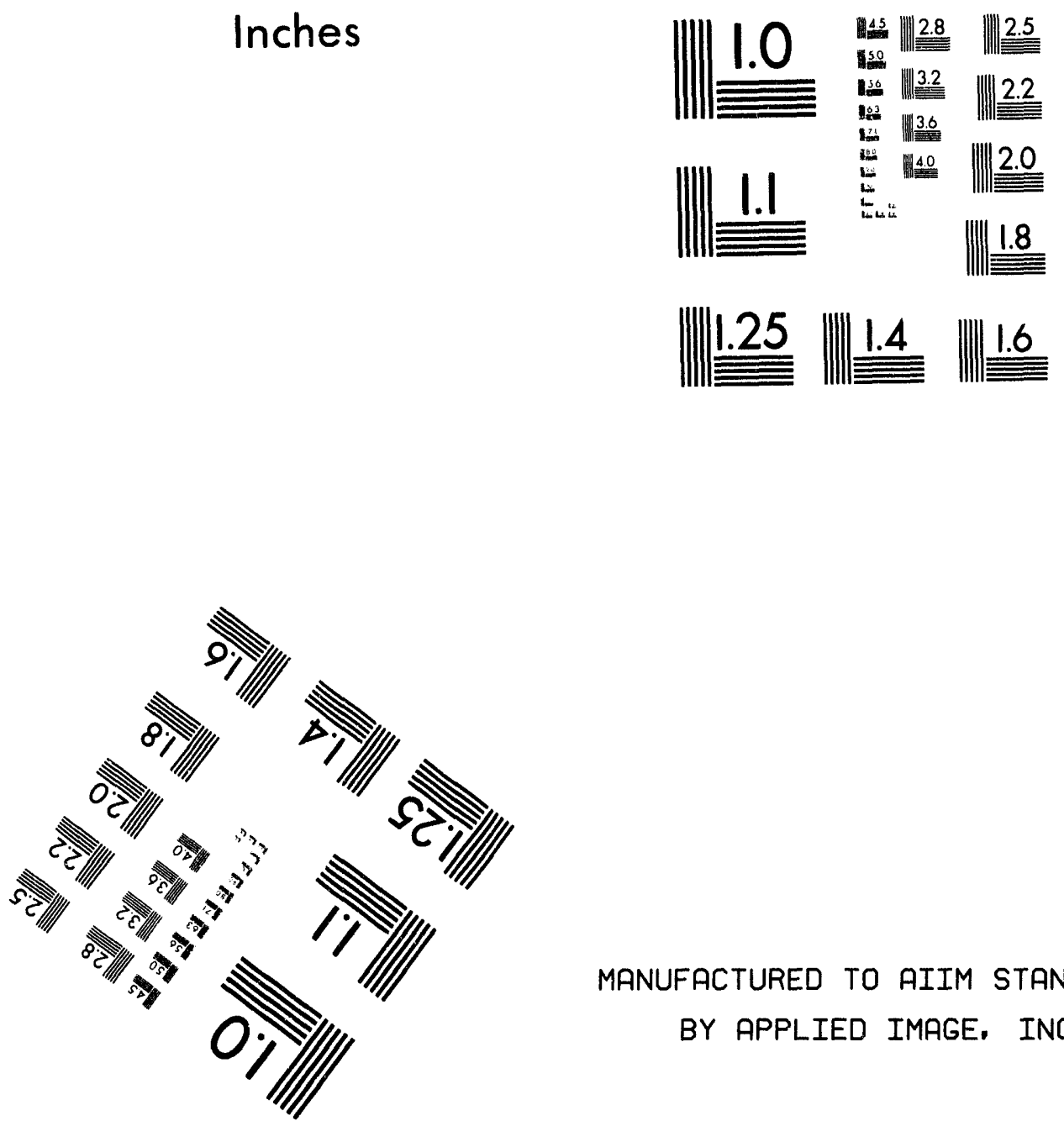

MANUFACTURED TO AIIM STANDARDS

BY APPLIED IMAGE, INC.

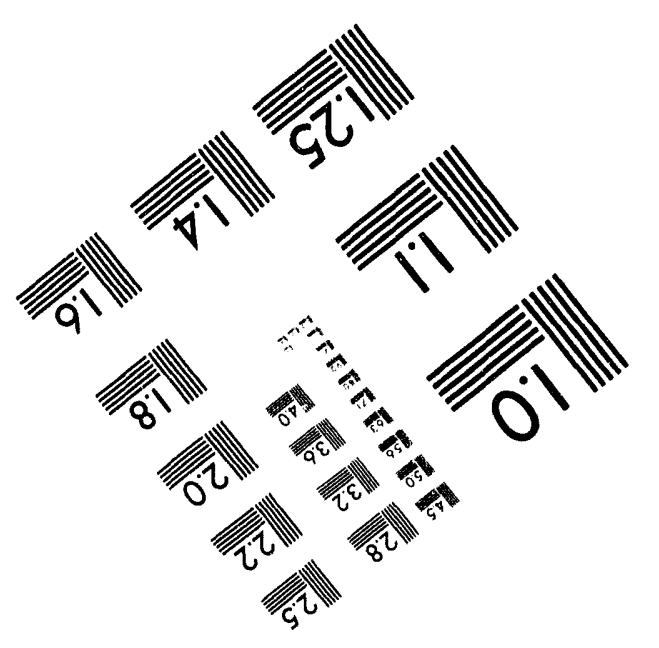



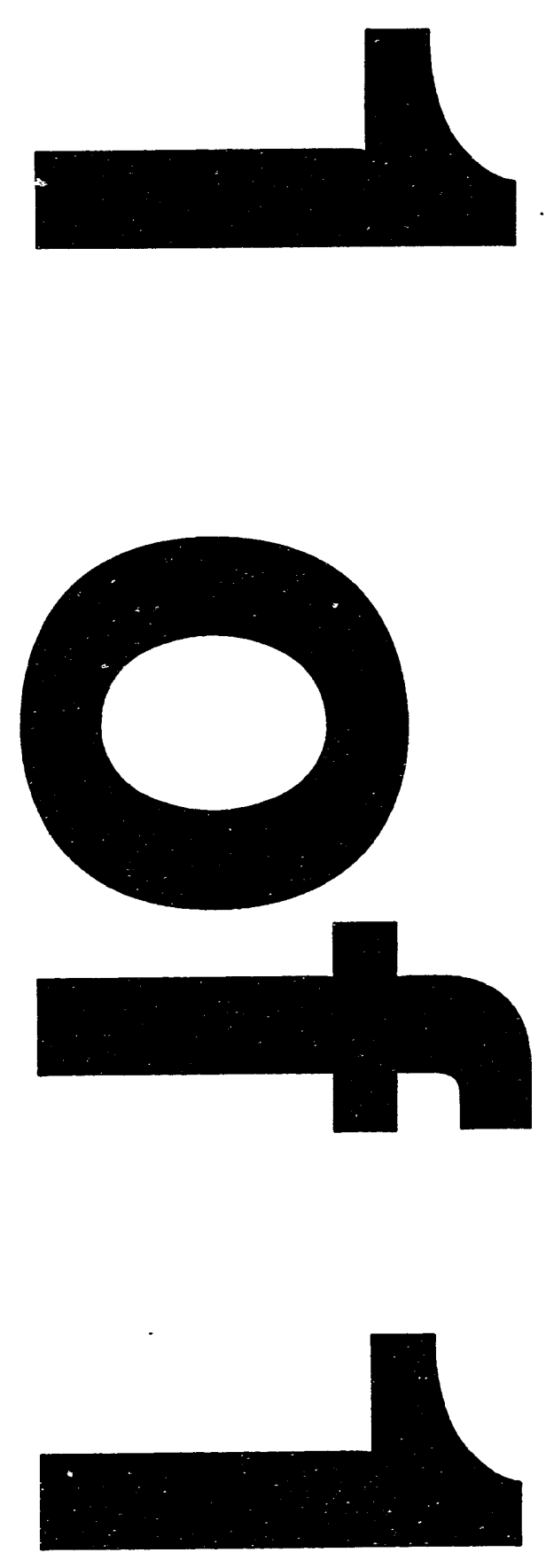


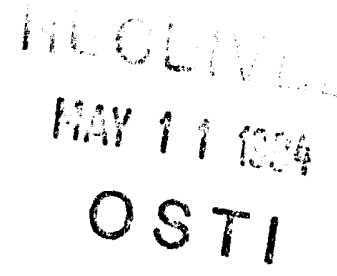

\section{Real-Time Radiography of Titan IV Solid Rocket Motor Upgrade (SRMU) Static Firing Test QM-2}

Kenneth W. Dolan, Gary M. Curnow, Dwight E. Perkins, Daniel J. Schneberk, Bart W. Costerus, Mark J. La Chapell, Donald E. Turner, Phinas W. Wallace

March 1994

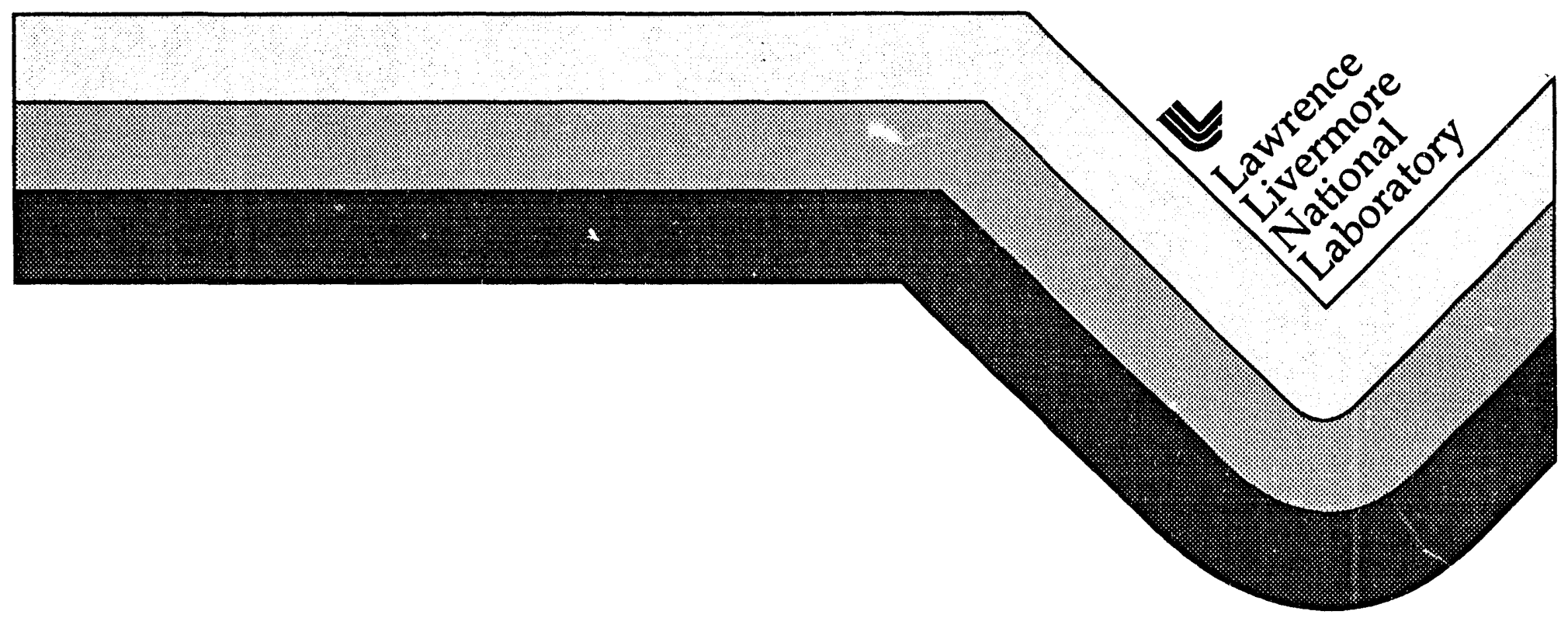




\section{DISCLAIMER}

This document was prepared as an acccount of work sponsored by an agency of the United States Government. Neither the United States Government nor the University of California nor any of their employees, makes any warranty, express or implied, or assumes any legal liability or responsibility for the accuracy, completeness, or usefulness of any information, apparatus, product, or process disclosed, or represents that its use would not infringe privately own rights. Reference herein to any specific commercial products, process, or service by trade name, trademark, manufacturer, or otherwise, does not necessarily constitute or imply its endorsement, recommendation, or favoring by the United States Government or the University of California. The views and opinions of authors expressed herein do not necessarily state or reflect those of the United States Government or the University of California, and shall not be used for advertising or product endorsement purposes.

This report has been reproduced directly from the best available copy.

Available to DOE and DOE contractors from the Office of Scientific and Technical Information P.O. Box 62, Oak Ridge, TN 37831

Prices available from (615) 576-8401, FTS 626-8401

Available to the public from the National Technical Information Service

U.S. Department of Commerce 5285 Port Royal Rd. Springfield, VA 22161 


\title{
Real-Time Radiography of Titan IV Solid Rocket Motor Upgrade (SRMU) Static Firing Test QM-2 *
}

\author{
prepared for \\ United State Air Force \\ Solid Propulsion Division \\ Space and Missile Center (SMC/MES) \\ Skynet Street Suite 1508 \\ Los Angeles AFB, CA 90245-4659
}

by
Kenneth W. Dolan, Gary M. Curnow, Dwight E. Perkins, Daniel J. Schneberk,
Bart W. Costerus, Mark J. La Chapell, Donald E. Turner, and Phinas W. Wallace

Lawrence Livermore National Laboratory

Livermore, CA 94550

March 8, 1994

- Work performed under auspices of the U.S. Department of Energy by the Lawrence Livermore National Laboratory under contract No. W-7405-ENG-48. 
Section

TABLE OF CONTENTS

1.0 EXECUTIVE SUMMARY

2.0 INTRODUCTION 2

$2.1 \quad$ Background

2.2 Objectives

3.0 DATA ACQUISITION

3.1 Equipment Description

3.1.1 Linac Source

3.1.2 RTR Imager

3.1.3 Data Acquisition System

3.1.4 Shock and Acoustic Mitigation

3.1.5 Test Environment Measurements

3.2 Equipment Layout

3.3 Field of View

3.4 Image Reference Dimensions

3.5 Image Quality Assurance

4.0 EQUIPMENT PERFORMANCE

4.1 Linac System

4.2 Imager System

4.3 Data Acquisition System

4.4 Test Environments Measurement System

4.5 Post Test Equipment Condition

5.0 TEST RESULTS

5.1 Slag Accumulation

5.2 Slag Dynamics

5.3 Slag Ejection

5.4 Slag Density

5.5 Test Article Effects

5.6 Test Environment Measurements

5.7 Motor Lift-Off

6.0 DATA ANALYSIS

6.1 RTR Data Reduction Methods

6.1.1 Image Processing

6.1.2 Dimensional Calibration

6.1.3 Pool Level Determination

6.1.4 Geometric Projections

6.2 Pool Level Uncertainty

6.2.1 Order Statistic Analysis

6.2.2 Strip length Comparisons

6.2.3 Strip Average Comparisons

6.2.4 Projection Uncertainties

6.2.5 Combined Uncertainties

7.0 CONCLUSIONS

8.0 ACKNOWLEDGMENTS 


\section{APPENDICES}

Al PROCEDURES FOR PROCESSING DATA A1

A2 GEOMETRIC CONVERSION OF SCREEN IMAGE TO POOL LEVEL A7

A3 GEOMETRIC PROJECTIONS AND PATH LENGTHS A14

A4 LINAC RADLATION EXPOSURE LOG A16

$\begin{array}{lll}\text { A5 } & \text { STATEMENT OF WORK } & \text { A18 }\end{array}$

$\begin{array}{lll}\text { A6 ORDER OF EVENTS AND TASK PLANNING A19 } & \text { A }\end{array}$

$\begin{array}{lll}\text { A7 SUPPORTING DOCUMENTATION A21 } & \text { A }\end{array}$

$\begin{array}{lll}\text { A8 } & \text { RTR TEAM MEMBERS } & \text { A22 }\end{array}$

Table

\section{LIST OF TABLES}

Table 1. Broad beam half-value layers at $9 \mathrm{MeV}$ Linac energy 9

Table 2. Test environment measurements maximum acceleration results. $\quad 14$

Figure

\section{LIST OF FIGURES}

3.1-1 Linac equipment layout showing trailer, $x$-ray tube head and console. 21

3.1-2 Screen layout showing nine each 14 by 17 inch standard screens laid 22 up in a mosaic array with fiducials at interstices.

3.1-3 Data acquisition system block diagram.

3.2-1 Equipment layout in test stand - side view. 24

3.2-2 Equipment layout in test stand - overhead view.

3.3-1 RTR and Titan SRMU aft dome cross-section plan view. 26

3.3-2 RTR and Titan SRMU aft dome cross-section elevation view. $\quad 27$

3.3-3 RTR Field of view - centerline area projection. 28

3.3-4 Image screen with nozzle and slag pool images represented together 29 with pixel strip locations used for pool depth analysis.

5.1-1 Time history of slag pool depth, 40 to 160 seconds, from 330-strip 3\% 30 order statistic analysis, average of strips 2 thru 4, as referenced to datum-A of aft dome cavity. 
Figure

\section{LIST OF FIGURES (continued)}

5.1-2 Time history of slag pool depth, 160 to 260 seconds, from 330-strip 3\% 31 order statistic analysis, average of strips 2 thru 4 , as referenced to datum-A of aft dome cavity.

5.1-3 Time history of slag pool depth, comparing LLNL 5-frame average order statistic result (330-strip, 3\%) with Aerospace Corporation (AC) 45-frame average gradient filter result.

5.1-4 Time history of slag pool depth compared the Thrust Vector Control (TVC) duty cycle for yaw axis.

5.2-1 Time history of slag pool depth for strips 1 thru 3 from 330-strip 3\% order statistic analysis.

5.2-2 Time history of slag pool depth for strips 3 thru 5 from 330-strip 3\% order statistic analysis.

5.2-3 Amplitude spectrum from Fourier analysis of strips 1, 2, and 3 for the time period 80 to 140 seconds.

5.2-4 Amplitude spectrum from Fourier anaiysis of strips 4 and 5 for the time period 80 to 140 seconds.

5.2-5 Bar chart time sequence of slag pool depth for strips 1 thru 5 (left to right in each chart), indicating slosh and wave modes, from $T+124$ to $T+130$ at $1 / 6$ second intervals.

5.2-6 Bar chart time sequence of slag pool depth for strips 1 thru 5 (left to right in each chart), indicating slosh and wave modes, from $T+130$ to $T+136$ at $1 / 6$ second intervals.

5.2-7 Bar chart time sequence of slag pool depth for strips 1 thru 5 (left to right in each chart), indicating slosh and wave modes, from $T+136$ to $T+142$ at $1 / 6$ second intervals.

5.7-1 Motor liftoff measurement from RTR data compared to test data.

6.2-1 Difference in slag pool depth results for different order statistic analyses, 330 -strip $3 \%$ analysis minus 330 -strip $10 \%$ analysis, average of strips 2 thru 4.

6.2-2 Comparison of slag pool depth results for different strip length analyses, 270 -strip and 330-strip 10\% order statistic analysis.

6.2-3 Difference in slag pool depth results for different strip lengths, 270-strip $10 \%$ analysis minus 330-strip 10\% analysis, average of strips 2 thru 4 .

6.2-4 Difference in slag pool depth results for different strip averages, average of strips 2 thru 4 minus average of strips 1 thru 5, for 330-strip length $3 \%$ order statistic analysis. 
Figure

\section{LIST OF FIGURES (continued)}

6.2-5 Standard deviation of slag pool depth result for averages of strips 2-4 and 1-5 from 330-strip 3\% order statistic analysis.

6.2-6 Attenuation vector (top) and cumulative attenuation vector (bottom) vs. pixel number from average of strips 2 thru 4 at $T+50$ seconds indicating pool level results for zero intercept, $3 \%$ and $10 \%$ order statistic.

6.2-7 Attenuation vector (top) and cumulative attenuation vector (bottom) vs. pixel number from average of strips 2 thru 4 at $T+60$ seconds indicating pool level results for zero intercept, $3 \%$ and $10 \%$ order statistic.

6.2-8 Attenuation vector (top) and cumulative attenuation vector (bottom) vs. pixel number from average of strips 2 thru 4 at $T+70$ seconds indicating pool level results for zero intercept, $3 \%$ and $10 \%$ order statistic.

A1-1 Five-frame RTR image showing two regions which are candidates for performing the scaling operation between the background image and the image to be converted.

A1-2 Vector plots from the 270-strip analysis: a) upper plot - attenuation vectors for different strips as a function of vertical pixel location, and b) lower plot - integrated attenuation vectors.

A1-3 Example of background corrected image: a) upper left - background image at $69 \mathrm{sec}$ ), b) upper right - RTR image at $100 \mathrm{sec}, \mathrm{c})$ lower left background corrected image at $100 \mathrm{sec}$.

A2-1 Source-to-strip centroid projections in beam centerline plane showing intercepts with inner insulator contours corresponding to pool depths of $0,4,8,12,16,20,24$ inches.

A3-1 Representation of projection in vertical beam centerline plane showing intercept with slag pool level at inner contour of insulator and bottom of screen image defining minimum detectable pool level.

A3-2. Representation of projection in vertical beam centerline plane showing top-of-prol projection and through-pool projection. 


\subsection{EXECUTIVE SUMMARY}

Real-time radiogranhy was successfully applied to the Titan-IV Solid Rocket Motor Upgrade (SRMU) static firing test QM-2 conducted February 22, 1993 at Phillips Laboratory, Edwards AFB, CA. The real-time video data obtained in this test gave the first incontrovertible evidence that the molten slag pool is low (less than 5 to 6 inches in depth referenced to the bottom of the aft dome cavity) before $T+55$ seconds, builds fairly linearly from this point in time reaching a quasi-equilibrium depth of 16 to 17 inches at about $T+97$ seconds, which is well below the top of the vectored nozzle, and maintains that level until $T+125$ near the end motor burn. From $T+125$ seconds to motor burn-out at $T+140$ seconds the slag pool builds to a maximum depth of about 20 to 21 inches, still well below the top of the nozzle. The molten slag pool was observed to interact with motions of the vectored nozzle, and exhibit slosh and wave mode oscillations. A few slag ejection events were also observed.

A high energy ( $9 \mathrm{MeV}$ ) and high output linear accelerator $\mathrm{x}$-ray source customized for this application, and a large area real-time imager were mounted in the test stand within inches of the motor to capture video $x$-ray images of the molten slag build-up and dynamics. As the propellant in the aft dome burned away reducing the material thickness between $x$-ray source and imager, increasing $x$-ray penetration of the motor resulted in image formation at about $T+35$ seconds, with full image definition by $T+40$ seconds. Video image data was obtained through the entire motor burn and water quench events until the linear accelerator was turned off at $T+360$ seconds. The imaging geometry allowed us to observe molten slag activity and slag pool levels to within 5 to 6 inches of the bottom of the aft dome cavity from $T+40$ seconds. After loss of pressure and motor burnout at $T+140$ seconds, followed by water quench at $T+155$ seconds, the molten slag material was observed to become very active in what appeared to be a boiling mode with solidification of slag material on the exhaust nozzle beginning at about $T+180$ seconds. Post test video the day following the test also showed the nozzle encased in slag material.

Test environment measurements showed that maximum acceleration at equipment attachments to test stand snubbers were much greater than expected, e.g. 6.4 g-peak vertical and $7.1 \mathrm{~g}$-peak East-West on the North snubber where the $\mathrm{x}$-ray source was mounted. These levels were mitigated to less than 1 g-peak by shock absorbing mounts. Sound levels inside the sound mitigation enclosure of the $x$-ray source were measured at $149 \mathrm{~dB}$. Using the design theoretical mitigation factor of the enclosure, sound levels outside the enclosure were estimated to be $164 \mathrm{~dB}$, about as expected. 


\subsection{INTRODUCTION}

\subsection{Background}

The accumulation of molten slag material in the aft dome of two-phase solid propellant motors with a submerged nozzle has been a concern not only for Titan IV SRMU, but also for the Shuttle Booster and early designs of the Small Intercontinental Ballistic Missile (SICBM). Over 4000 lbs of solidified slag material was removed from the aft dome segment of the Titan IV SRMU during post test disassembly in each of the previous successful test firings, PQM-1' and QM-1. Although the amount of residual material and an indication of pool height (from slag marks on the interior motor case wall) are obtained from post test disassembly analysis, the time history of slag accumulation and maximum pool height during test firing were unknown. Reduced pressure in the motor case at burnout, and water quench of the motor case following burnout (water injected through the exhaust nozzle) obscure direct correlation of post test residual slag analysis with time history and maximum slag accumulation. The time history is important for guidance and control, vehicle dynamics, and performance calculations. At least two different approaches have been used to calculate the time history of slag accumulation, but the results of the different approaches do not agree. Real-time radiography was needed to provide an empirical basis for time history and slag accumulation estimates.

\subsection{Objectives}

The goal of real-time radiography (RTR) was to image slag accumulation in the aft donne region of the Titan IV SRMU during static test firing in order to characterize the slag pool. The primary objective was to determine slag pool height versus time, including maximum pool height, in a representative field of view. From the pool height information, pool volume and mass can be determined with height-to-volume conversion factors and best estimates of molten slag mass density. Since molten slag density is an unknown, an estimate of slag density was to be obtained from the data if possible. Slag ejection events were to be recorded and an estimate of amount of material ejected in any event. A correlation between the measured post test slag mass and the accumulation history was desired. Since total accumulation may differ from the post test measurement due to overflow of slag through the nozzle, any periods where slag height exceeds the top of the nozzle were to be documented. An estimate of the accuracy of the height measurement was to be given and uncertainties associated with the accumulation rate assessment and accumulation heights were to be discussed.

A secondary objective was to determine the dynamic behavior of the molten slag pool. The amplitudes and frequencies of any slosh modes were to be identified along with the time occurrence. Specific times of interest were between 46 and 52 seconds, 94 and 100 seconds, and 115 seconds to end of test. Each of these periods begins with a $0.5 \mathrm{~Hz}$ half sine wave movement of the nozzle with a 2 degree amplitude. The sine wave movement is followed by 5 seconds of dwell with the nozzle at the null position. Any slosh dynamics observed at other times were also to be documented.

A third objective was to measure the test environment conditions, e.g. shock and acoustic levels, to provide data that could be used in assessment of RTR system performance and to determine possible causes of RTR system failure should it occur.

\subsection{DATA ACQUISITION}

\subsection{Equipment Description}

The RTR equipment was comprised of the following major components: (1) linear accelerator (Linac) x-ray source; (2) RTR imaging system; (3) data acquisition and 
recording system; (4) shock and vibration isolation system: and (5) test environment measurement system. The Linac tube head. Linac trailer, and RTR imager incorporated shock and vibration isolation mounts. An acoustic mitigation enclosure surrounded the Linac tube head, and acoustic mitigation design features were incorporated into the RTR imager.

\subsubsection{Linac Source}

The $x$-ray source was a Varian Linatron $3000 \mathrm{~A}$ (Linac) previously modified by LLNL for mobile operation. Although this machine was intended for fixed medical and industrial applications by the manufacturer, our modifications provide a fully transportable unit capable of most field radiography applications. This unit has been used for other field applications over the last 15 years at Warren AFB, Vandenberg AFB, and the Tonopah Test Range. The Linac operates at an accelerating voltage of 9 million volts and produces dose rates up to 3000 rads per minute at 1 meter. The pulse rate is nominally 300 per second with pulse duration of a few microseconds. The high energy and high output dose rate provided by this machine were essential for $x$-ray penetration of the motor case and propellant with sufficient intensity to light up the RTR imaging screen.

The tube head contains a freon filled wave guide and an evacuated accelerator tube with tungsten anode. A proportional counter insi te the tube head measures actual $x$-ray output and provides feedback to stabilization and control circuits. The wave guide must be kept at constant temperature to operate properly (e.g., constant physical dimensions must be maintained). This is accomplished by circulating $96^{\circ} \mathrm{F}$ wates through cooling coils in both the waveguide and accelerator tube. A tuning fork inside the wave guide is adjusted to tune the cavity for stable operation and maximım sutput. The pulse rate is also adjustable. Once the tuning fork is adjusted and the rnichine set for a specified output, an automatic control circuit and motor drive controls th: tuning fork. Shock and vibration affect the tuning fork, and the automatic adjustnient circuit provides continuous adjustment to maintain the preset output. It was known that the control circuits and motor drive would not respond to tuning fork displacements at the vibration frequencies anticipated for this test, but it was our prediction that t.e controls would respond to overall displacements of the tuning fork to constantly bring the Linac back to the preset conditions.

The transportable Linac system layout for test QM-2 is shown in Figure 3.1-1. The modulator pulse forming network, line voltage regulator, water heater/chiller, and cable reels are contained in the trailer. The $x$-ray tube head was located approximately 40 feet above the trailer level, and the console was located in bunker 1-C-T below the test stand. Not shown in this figure is the auxiliary generator used to supply line voltage to the trailer to decouple the Linac unit from house power.

Test QM-2 placed new requirements on the operation of the LLNL transportable Linac unit. The distance between the trailer and operating console, the extreme environment for the $\mathrm{x}$-ray head, and the required single point failure mitigation of the control electronics were all $n \in W$ requirements for this test.

Extending the Control Console The mobile $x$-ray system trailer has the capability of operating 100 feet from the console. For QM-2 we were obligated to extend the existing $100 \mathrm{ft}$ limitation to $1500 \mathrm{ft}$. To satisfy this requirement, we implemented a portion of the control logic at an extended operating point. In addition to an abbreviated, remote set of controls, we used a video link to confirm the status of control commands and monitor other indicators on the front panel of the main console. In addition, this video signal was recorded for assessment of Linac operation during the test. 
Operating Environment One of our first and foremost concerns was the survivability of the $x$-ray system in the hostile environment of a rocket motor static firing test. The $x$-ray head in the test stand had to survive projected accelerations beyond original design considerations. To mitigate the projected accelerations, we designed an insulating system and structural members to support and cushion the unit.

The Varian 3000A employs a radio-frequency (RF) linear accelerator and other high voltage, high power technologies. The controls were originally designed with a complex interlock logic system which provides orderly, nondestructive shutdown in the event of an internal fault or breach of personnel safety functions. As designed, this interlock logic detects a comprehensive, but subtle array of machine health parameters in the modulator and $\mathrm{x}$-ray head.

With the expected severe test environment conditions (greater than $1 \mathrm{~g}$ shock and nominal $160 \mathrm{~dB}$ sound), and given the relatively delicate nature of the Linac machine and our experience operating this unit, we believed that one or more internal fault conditions were likely to occur during QM-2. The most likely time for faults to occur was expected to be during the peak acceleration, at the instant of motor ignition. Should these internal fault conditions occur, they would cause machine shutdown.

The realization that shutdown could occur before the critical data could be acquired lead to an interesting engineering dilemma. We had to afford crucial machine protection while maintaining operability through the test with likely interlock logic faults. Our approach had to take into consideration our operating experience with the machine and a realistic appraisal of what was important and what was less important. We decided to prioritize the various interlocks. Those interlocks which protected against immediate destructive internal failure of critical components were left functional. We felt that a shutdown condition caused by one of these crucial interlocks would allow a relatively quick recovery to "Beam On" operation. Other interlock functions such as personnel access (microswitches on the tube head panel access doors) and cooling water overtemperature were either longer term concerns or controlled adequately with administrative controls. A bypass circuit was then designed for the non-crucial interlocks. Further, we decided the bypass function would be under operator control, and procedurally be applied only for short periods during pretest function verification runs and during the actual rocket motor test firing from $\mathrm{T}-35$ seconds to planned shut down of the Linac at $\mathrm{T}+360$ seconds.

Single Point Failure Concern The possible failure of one power contactor during late stages of the operating sequence was identified as a potential single point failure mode that could cause inadvertent $x$-ray output. This single point failure needed to be addressed and dealt with adequately for personnel protection on the QM-2 event.

A year previous to QM-2, a design change was implemented on the high voltage modulator and power supply. This modification afforded greater safety for those performing maintenance on the high voltage portions of the machine by providing a visible, redundant, direct short for high energy storage components. This was accomplished with the addition of crowbar relays.

To mitigate the single point failure concern, a control circuit design change was made for QM-2. The existing shorting, fail safe function provided by the crowbar relays was moved to the latest possible portion of the operating sequence. As designed, these crowbar relays prevented any possible application of high voltage until the final operator key sequence. In affect, this modification prevented $x$-ray output even with the failure of the power contactor in question. 


\subsubsection{RTR Imager}

The RTR imager consisted of a large area phosphor screen, two each (redundant) intensified-CCD cameras with wide angle lenses, a 45 degree front-surface silvered mirror, a light tight enclosure, camera and mirror mounts, lead shielding for the cameras, and shock mounts. The size of the screen was dictated by the area desired to be imaged. The imager was designed so that the screen could be positioned as close as possible to the rocket motor case to maximize the projected image area and minimize image unsharpness. The design of the light enclosure was dictated by the space available for mounting imager hardware above the South snubber in the test stand. Features such as flexible fabric coupling and plywood panels were used in construction of the light-tight imager enclosure to minimize acoustic levels.

Screen The large area screen, 42 by 51 inches, consisted of a mosaic array of 9 rare earth phosphor screens, each 14 by 17 inches, of the type used as intensifier screens in film radiography. The phospt.or screen was selected for its high brightness at $9 \mathrm{MeV} x$-ray energy, peak light output in the green for compatibility with the cameras, and short persistence for compatibility with dynamic events. Comparison studies previously done at LLNL had shown that thick gadolinium oxysulfide (GOS) screens satisfied these criteria. Commercially available Trimax 12-B ${ }^{\circledR}$ (DuPont NDT, McKinney, TX) screens were selected. The screens were epoxy bonded to a sheet of 0.063 inch thick copper to provide a stiff backing, to convert some of the incident $\mathrm{x}$-rays to electrons to improve screen efficiency, and to attenuate some of the lower energy scattered x-rays. Epoxy was chosen to be compatible with the low temperature $-4^{\circ} \mathrm{C}\left(25^{\circ} \mathrm{F}\right)$ air blown into the test stand. No precautions were made to prevent moisture condensation on the screens since the air in the test stand was very dry. The screens were mounted in a mosaic array as shown in Figure 3.1-2. The corners of the screens come from the manufacturer already trimmed, and no attempt was made to square the corners which would have reduced overall screen dimensions. Instead the diamond-shaped blank areas at the screen interstices were used as fiducials to obtain exact measurements in the recorded image, and light-emitting diodes (LEDs) were mounted at the four interior screen interstices to check camera operation, focusing and alignment. The copper sheet with screens attached was mounted on a 0.5 inch thick aluminum plate for attachment to the imager structure.

Cameras Criteria for camera selection were high sensitivity, high gain, high resolution, anti-blooming, automatic gain, and rugged design. The cameras chosen for this test were intensified-CCD video cameras (Model ISS-255, Xybion Electronic Systems, San Diego, CA) with a sensitivity of better than 10-6 foot-candles, overall gain of $10^{+6}$, operational through $5 \mathrm{~g}$ shock ( 5 to $200 \mathrm{~Hz}$ ), and operational temperature range 0 to $50^{\circ} \mathrm{C}$ with storage at -20 to $+50^{\circ} \mathrm{C}$. Scan rate was 59.94 fields per second interlaced. The intensifier element of this camera is a microchannel plate (MCP) electron multiplier. The automatic gain feature of the camera is accomplished by automatic continuous adjustment of the voltage to the MCP element. The voltage is adjusted to limit the current on the MCP element. The voltage can change within the scanning time of a single frame, but the gain is the same for all lines in the frame. This means that frame to frame comparisons require normalization, but that image features within a single frame can be used for calibration within that frame. The charge-coupled device (CCD) has 756 horizontal by 485 vertical usable elements, providing the standard $3 / 2$ video aspect ratio. The non-blooming feature in the readout electronics of the CCD prevents charge from bleeding from next neighbor elements on readout. Output from the camera is standard RS-170. The image was framed to contain the screen plus a border. Although the camera has 756 usable elements in the long screen dimension (51 inches) and 485 in the narrow screen dimension ( 42 inches), digitization was done at 512 by 512 so that inherent spatial 
resolution was approximately $0.1 \mathrm{inch} / \mathrm{pixel}$. Although the digitization and resampling were done to obtain approximately 0.1 inch/pixel, the calibration conversion for pixel dimension as a function of screen position was obtained directly from analysis of screen fiducials in the image (see Section 6.1).

Optics The cameras were lens coupled to the imaging screen with a wide angle lenses and a 45 degree turning mirror. The lens for each camera was $25 \mathrm{~mm}$ diameter, with 12.5 $\mathrm{mm}$ focal length, f-stop of $\mathrm{fl} .4$, and provided a large depth of field at the camera-toscreen distance of 66.8 inches. The mirror was 9 by 9 by 1 inch glass, front surface silvered, and robust enough to survive shock and acoustic levels. The cameras were mounted on their side to utilize the $3 / 2$ camera aspect ratio to obtain maximum resolution in the vertical screen dimension. Because the cameras were mounted on their side, all of the video images when displayed on video monitors appear rotated $90^{\circ}$. This is corrected in digitized images (i.e. digitized images are rotated $90^{\circ}$ ), so that the vertical imager screen dimension is displayed vertically.

Light Enclosure A customized light tight box was fabricated from $3 / 4$ inch plywood at the test site to conform to the structural members of the test stand that were in close proximity to the imager. A spacing of $3 / 8$ to $1 / 2$ inch was provided between the box and test stand structural members to prevent direct vibration transmittal during the static firing. The inside of the light tight box housing cameras and mirror was painted black and lined with black cloth. Black tape was applied to the cloth near the camera mount to hold the cloth in place, and this provided a reflection in the video image below the screen image. The reflection does not affect image quality. The screen assembly was mounted on a rectangular tapered horn. The covering of the horn was made of perforated sheet metal. The horn was mounted on the South snubber independent of the light box housing cameras and mirror, so that vibrations associated with the horn would not be directly transmitted to camera and mirror assemblies. Black cloth was fitted to the outside of the horn, and provided light tight coupling of the horn/screen assembly to the camera/mirror enclosure box.

Shielding The CCD element and other solid state components in the camera are susceptible to electronic noise and intrinsic damage from $\mathrm{x}$-ray exposure. Lead shielding consisting of 8 lead plates, each 1 by 12 by 12 inches, was positioned on the source side of the camera to eliminate direct exposure to $x$-rays. Lead plate, 1 inch thick, protected the cameras on all other sides except for the lens side. We opted not to use lead glass protection on the lens side of the camera enclosure because of our uncertainty regarding fragility of the lead glass relative to the anticipated shock and acoustic environments.

\subsubsection{Data Acquisition System}

Block diagrams of the data acquisition system (DAS) are shown in Figure 3.1-3. Signals from the RTR imager cameras to the $1-C-T$ room were carried by regular coaxial cable. House power was used for the camera power supplies in the test stand. Because of the long cable runs $(1500 \mathrm{ft}$ ) between the $\mathrm{I}-\mathrm{C}-\mathrm{T}$ room and the $1-\mathrm{E}-\mathrm{T}$ control room, a fiber optic data transmission link was used to ensure video signal quality. Redundant power supplies and automatic switching were provided for the fiber optic repeaters on each end of fiber optic data transmission link. Video recording was done on each of the two video channels with both an optical video disk recorder (VDR) and an S-VHS video cassette recorder (VCR). The IRIG-B timing signal was recorded on the audio channels of the VDRs and VCRs. A third S-VHS VCR recorded video from a CCD camera focused on the Linac control console in the 1-C-T room. Power for the recording systems was house power. A control panel was provided in the RTR-DAS electronic rack in the 1-E-T room to activate and adjust light intensity of the LEDs mounted in the fiducial locations on the 
imager screen. These lights were used to verify RTR camera and data link operational status, and to check RTR camera focusing and alignment.

\subsubsection{Shock and Acoustic Mitigation}

Shock and vibration mitigation for the Linac tube head and camera platform in the test stand, the modulator electronics rack in the trailer, and the trailer jack stands was accomplished by isolating these systems with air spring mounts. The isolation mounts selected for this application were Stabl-Levl ${ }^{\circledR}$ pneumatic spring mounts (Barry Controls, Brighton, MA), Models SLM-1A through 12A. The modulator electronics rack in the trailer had previously been fitted with Stabl-Level ${ }^{\circledR}$ air springs, Model SLM-6A, for vibration isolation during trailer transport. The air springs were selected for their convenient height and load distribution adjustment by means of air pressure, as well as their low natural frequency $(3$ to $5 \mathrm{~Hz}$ ). The natural frequency of the air springs is in range where the excitation was expected to be low and avoided magnification of accelerations at resonance. The air springs operate at zero deflection under load, and the stiff elastomer side walls provide one-to-one horizontal to vertical stiffness ratio. For most vibration applications, the air pressure in the center body provides a significant portion of the isolation. For shock applications, the mount initially deflects against the centerbody, and then after a minimum deflection is exceeded, the shock loads are smoothly transferred to the outer wall. The nominal design pressures of the mounts are 20 to 80 psi. For our application, the air springs were pressurized to provide a gap of $3 / 16$ inch between the top of the elastomer bag and the top mounting plate. This resulted in a nominal pressure of 60 psi for all the air springs except the one supporting the heaviest curner of the Linac, under the collimator set, which was pressurized to approximately $80 \mathrm{psi}$. A manifold with pressure guages provided readouts for daily and pretest checks, and a convenient method for filling and adjusting pressure for individual air shocks. Shock and vibration accelerations associated with the snubber were unknown, but were expected to be greater than $1 \mathrm{~g}$.

Acoustic mitigation was provided for the Linac tube head only. The mitigation consisted of a $3 / 4$ inch thick plywood enclosure box with up to 6 internal layers of 1 inch thick $584 \times x$ Series foam/barrier composites (Tech Products Corp, Dayton, OH). A total of 9 layers had been the design plan to reduce sound levels from the anticipated $160 \mathrm{~dB}$ to an acceptable level of $120 \mathrm{~dB}$. But space limitations reduced the thickness to 6 layers, and the acoustic mitigation enclosure had to be cut to fit between structural components of the test stand and to allow for connections to the Linac tube head resulting in a less than a perfect enclosure for sound mitigation.

\subsubsection{Test Environment Measurements}

Twelve channels of vibration data, one channel of acoustic data, and one dummy accelerometer channel were recorded during QM-2. Triaxial accelerometers were installed on the $x$-ray tube head (above air springs), on the tube head support frame attached to the North snubber (below air springs), on the camera platform on the South snubber (above air springs), and inside the Linac trailer on the isolation support structure enclosing the modulator electronics (above air springs). The microphone for the acoustic channel was placed inside the sound mitigation enclosure for the $x$-ray tube head near the lower rear surface of the tube head. The dummy (low sensitivity) accelerometer was used to verify data integrity.

\subsection{Equipment Layout}

Equipment layout in the test stand is shown in Figures 3.2-1 and 3.2-2. The Linac tube head was mounted above the North snubber. A 2 inch thick aluminum plate attached to the North snubber provided a level mounting surface. An aluminum framework provided 
the necessary height, and a plate on top of the framework provided mounting locations for the air springs. The Linac was attached to the air springs and enclosed in an acoustic mitigation box. The Linac tube head requires circulation air drawn in by an internal fan, so a 12 inch square was cut out of the enclosure box exposing the intake plenum to allow air from a warm air blower to be circulated in the tube head. Openings in the enclosure were also cut out to allow for connection of power, control cables, and water hoses to the tube head. A door cutout in the enclosure allowed access to a side panel doors in the Linac tube head for daily and pretest checks of freon waveguide pressure and accelerator tube vacuum. Water hoses from the trailer to the test stand were wrapped with thermal insulation material to avoid severe drop in water temperature in the lines.

The imager system was mounted above the South snubber. A 2 inch thick leveling plate was mounted on the snubber and a pedestal was attached to the leveling plate to provide proper height. The base of the camera housing is attached to the pedestal, and air shocks are attached to this base. The camera platform is attached to the air shocks and includes the camera and mirror mounts, and lead shielding. The light coupling horn with screen is independently attached to the base plate with struts, so that there was no direct vibration coupling between the horn and camera housing.

The screen was located as close as possible to the SRMU motor case to reduce image unsharpness and maximize projected image area. Positioning of the Linac $x$-ray source was a compromise involving several considerations, e.g. dose rate at the imager screen, image unsharpness, field of view, and test stand structural restrictions. The Linac was positioned inside the test stand to provide $x$-rays at sufficiently high intensity to penetrate the SRMU motor case and produce image on the screen. The Linac was mounted to the snubber as the most structurally robust and possibly most stable member of the test stand. It was positioned above the snubber inside the test stand as far away as possible from the SRMU motor case, allowing for test stand structural constraints, to reduce image unsharpness and maximize the projected image area.

\subsection{Field of View}

The desired field of view was to contain the top of the exhaust nozzle in order to image the highest possible slag accumulation levels, and was also to contain as much of the lower portion of the aft dome as possible. The plan view in Figure 3.3-1 shows the envelope of ray paths projected onto the imager screen in the horizontal plane of the beam centerline for the positions selected for the imager screen and Linac $x$-ray source. The elevation view in Figure 3.3-2 shows the envelope of ray paths projected onto the imager screen in the vertical plane of the beam centerline, and provides a perspective of motor components projected onto the screen. Both the top of the exhaust nozzle (near the $x$-ray source) and nearly the bottom of the aft dome region (near the imager) are projected onto the screen. Objects near the $x$-ray source, e.g. pins, rivets. joints, etc., appear enlarged in the RTR image due to projection magnification, while objects near the imager screen are projected onto the screen with very little magnification. The field of view represented in Figure 3.3-3 shows the area (cross-hatched) in the plane of the SRMU vertical centerline, normal to the beam centerline, that is projected onto the imager screen. This field of view was used in determining an appropriate location for the beam centerline, and was also used as a reference representation of beam centerline. It should be noted that an infinite number of such areas (as cross-hatched in Figure 3.3-3) for all planes through the motor case normal to the beam line are projected onto the imager screen. A representation of the composite projection onto the mosaic array image screen is given in Figure 3.3-4, where the contour edges of the nozzle and the slag pool are prominent features. Also shown in Figure 3.3-4 are superimposed areas enclosed by dashed lines and labeled strips 1 through 5 , which are the projection areas analyzed for pool level as discussed in Section 5.1. 


\subsection{Image Reference Dimensions}

The Linac $\mathrm{x}$-ray source is a point source, less than $2 \mathrm{~mm}(0.08$ in) diameter, located in the $0-270^{\circ}$ quadrant referenced to the motor case (northwest quadrant of the test stand), 90.0 inches from the $0-180^{\circ}$ centerline, 34.6 inches from the $90-270^{\circ}$ centerline, and 46.6 inches above the top surface of the North snubber (see Figure 3.2-1). The $\mathrm{x}$-ray beam is projected onto a 42 by 51 inch screen with center located in the $0-90^{\circ}$ quadrant (southwest quadrant of the test stand), 70.0 inches from the $0-180^{\circ}$ centerline, 34.6 inches from the $90-270^{\circ}$ centerline and 46.6 inches above the top surface of the South snubber. The angle subtended by the imaging screen is 15.0 degrees in the horizontal, and 18.1 degrees in the vertical. The square collimator set on the Linac $\mathrm{x}$-ray source was opened to 24 degrees to include the screen in the projected beam and provide a margin. The Linac $x$-ray source was leveled and then trued North and South using the self-contained laser alignment source and auxiliary mirrors. The Linac laser alignment beam was targeted at a point 0.75 inches above the centerline of the single band of 1 inch diameter fasteners on the aft dome and skirt (see Figure 3.3-2). To confirm the location of the $x$ ray beam centerline, the circumferential distance was measured on the outside of the motor case from the $270^{\circ}$ motor case mark to the laser spot bulls eye. This arc distance was 36.5 inches and agrees with the calculated arc distance, given an outside diameter of 128.66 inches for the motor case at this location.

\subsection{Image Quality Assurance}

The dose rate to provide definable image was determined to be approximately $2 \mathrm{rad} / \mathrm{min}$ by measurement at the LLNL High Energy Radiography Facility using a clone of the large area imager fielded for the static firing test. The same screen material, camera type, optics, and camera-to-screen distance were used with the facility's $9 \mathrm{MeV}$ Linac $\mathrm{x}$-ray source for this measurement. The dose rate to produce detectable light on the screen was measured as approximately $1 \mathrm{rad} / \mathrm{min}$. Given the thickness of the solid propellart in the motor case, we predicted that a usable RTR image would be produced approximately 40 seconds into the motor firing when sufficient burn back of the solid propellant had occurred. These calculations were based on half-value thicknesses for the materials in the motor case as given in Table 1 .

Table 1. Broad beam half-value layers at $9 \mathrm{MeV}$ Linatron energy

\begin{tabular}{|l|c|c|c|c|}
\hline Material & $\begin{array}{c}\text { Density } \\
\left(\mathrm{g} / \mathrm{cm}^{3}\right)\end{array}$ & $\begin{array}{c}\text { Density } \\
\left(\mathrm{lb} / \mathrm{ft}^{3}\right)\end{array}$ & $\begin{array}{c}\text { Half-Value } \\
\text { Layer (in) }^{*}\end{array}$ & $\begin{array}{c}\text { Half-Value } \\
\text { Layer (in) }\end{array}$ \\
\hline Steel & 7.85 & 490 & 1.2 & 1.2 \\
Aluminum & 2.70 & 169 & 3.8 & 3.8 \\
Solid Propellant & 1.76 & 110 & 5.8 & 6.3 \\
Molten Slag & $1.44 \dagger \dagger$ & $90^{\dagger \dagger}$ & $7.2^{* *}$ & -- \\
Insulation & 1.11 & 69 & 9.6 & 8.5 \\
\hline
\end{tabular}

* "High Energy X-Ray Applications for Nondestructive Testing", Varian Inc., Palo Alto, CA 94303, May 1988.

** Interpolated from Varian data based on least squares logarithmic fit of half-value layer vs density (independent of atomic number).

$\dagger$ Provided by Aerospace Corp., El Segundo, CA.

$\dagger^{\dagger}$ Density of molten slag is best estimate of possible values ranging from 80 to 120 $\mathrm{lb} / \mathrm{ft}^{3}$. 


\subsection{EQUIPMENT PERFORMANCE}

All RTR and test environment measurement systems functioned successfully throughout the static firing test. Reports on major component systems are given as follows.

\subsection{Linac System}

The Linac system operated from $\mathrm{T}-360 \mathrm{sec}$ through $\mathrm{T}+280 \mathrm{sec}$ as planned. The interlock bypass function switch was engaged at $\mathrm{T}-35$ seconds as planned and was left engaged until $x$-rays were beamed off at $T+280$. Linac output was fairly constant at 3000 rads during the beam on period. There were two short periods when output fell to 2400 rads and then recovered to 3000 rads. This is normal as the automatic frequency control (AFC) locks on and automatically retunes the waveguide for 3000 rads output. The Linac support structure on the North snubber saw significantly more acceleration than expected (see Section 4.2. Test Environment Data). Shock and vibration mitigation mounts provided about a factor of 5 reduction in acceleration to the Linac . The trailer also experienced significant accelerations. Sound levels at the Linac were about as expected (approximately $160 \mathrm{~dB}$ ). Because we were not able to install the full 9 layers of acoustic foam around the Linac as planned due to cut-out outs in the box resulting from closeness of the test stand structure, the acoustic box provided mitigation of only $20 \mathrm{~dB}$ rather than the originally planned $40 \mathrm{~dB}$.

\subsection{Imager System}

Before the static firing test and during the T-5 min planned hold, the DAS operator reported that one of the two redundant camera channels, video channel no. 1, did not have video. The problem was traced to the camera itself, and the channel no. 1 camera (serial no. 6233) and power supply were replaced with spares. The replacement camera (serial no. 6231) was known to have degraded resolution as compared to the other cameras, but it was our judgment that the resolution was still of sufficient quality to allow useful data to be obtained. The replacement camera had operated properly during Firing Mode Sequence Test (FMST)-1C, and was on-line for FMST-2 when the degraded performance was discovered. It was swapped out just prior to FMST-2 and then swapped back in, as noted, in video channel no. 1 at T-5 min. The higher quality image of the redundant data channels, i.e. both cameras image the same area on the screen, was obtained from data channel no. 2. The two cameras that had difficulties were returned to the manufacturer after the test for assessment of problems and repair. In the case of the failed camera, serial no. 6233, the manufacturer reported failure of a power supply in the camera. In the case of the camera with degraded resolution, the manufacturer reported that the focus ring was slightly out of adjustment for the optical path length we were using, 66.8 inches screen to camera, but actually in focus for the optical path of 96 inches which they normally use in setting up the camera.

\subsection{Data Acquisition and Recording System}

The data acquisition system performed flawlessly before, during, and after the static firing test. Both video channels (nos. I and 2) were recorded on S-VHS Video Cassette Recorders (VCRs) and also on optical Video Disk Recorders (VDRs) in real time. The IRIG-B signal was recorded on the audio channel of each unit (both VCRs and both VDRs). Signal output from the cameras is standard RS-170. The RS-170 analog signal is transmitted over the optical data links and recorded on the S-VHSs and VDRs as analog data. Digitization of the data was accomplished post test (see Section 6.1). In addition to the RTR Imager System video data, real-time video of the Linac control console showing the Rad Output analog meter and oscilloscope traces of the Automatic Frequency Control (AFC) wave forms were recorded on an S-VHS VCR. 


\subsection{Test Environment Measurement System}

Test environment data system performed as planned through the test. Thirteen data channels were recorded which included data from twelve accelerometers and one microphone. One of the data channels recorded output from a dummy (insensitive) accelerometer to verify data integrity. It showed no spurious signals due to the x-ray beam, sound, or vibration beyond the noise of the data processing and recording system. On post test inspection, it was found that the acoustic cable was damaged. This might explain why the gain of the microphone amplifier had to be increased significantly during the final pre-test and end-to-end calibration (using a piston-type microphone calibrator). Consequently, the measured sound levels are suspect and may be in error.

\subsection{Post Test Equipment Condition}

The equipment survived the test environment remarkably well. The Linac was powered up two days after the static firing test and real-time radiography images were successfully recorded of the post test condition of the aft dome. The trailer was coated with residue from the static firing test and required washing. No residue entered the trailer, but all of the exterior hinged panels had to be removed, container cargo areas cleaned, and hinges replaced. The acoustic microphone cable was damaged, but this may have occurred pretest since, as noted above, the acoustic channel had to be recalibrated just before the test.

\subsection{TEST RESULTS}

\section{$5.1 \quad$ Slag Accumulation}

Slag accumulation as a function of time is shown in Figures 5.1-1 and 5.1-2 from the start of image definition at $T+40$ seconds to the end of image definition at $T+260$ seconds. The slag pool level is reference to datum-A of the aft dome cavity (see Fig. 3.33 ), and includes correction for motor lift-off during the static firing. The lowest slag pool level that can be imaged is geometrically defined by the lowest point on the inner contour of the aft dome insulation nearest the RTR imager screen as projected onto the bottom of the imager screen (see Figure 3.3-2). This minimum observable level corresponds to a slag pool depth of approximately 6 inches. The early time information, before $T+55$ seconds, shows excursions above the minimum observable level only, and is not a true representation of average pool depth. A large excursion is observed between $T+55$ and $T+65$ seconds, peaking at $T+61$ seconds. At times greater than $T+65$ seconds, slag accumulation increases from approximately $9.0 \pm 1$ inches to an equilibrium value of approximately $16.5 \pm 1$ inches at $T+97$ seconds. The equilibrium level persists at $16.5 \pm$ 1 inches from $T+97$ seconds to $T+115$ seconds, and then decreases slightly to $16.0 \pm 1$ inches from $T+115$ to $T+127$ seconds. Beyond $T+127$ seconds, as internal pressure decreases, the slag pool becomes very active and apparent pool level increases, to a peak value of $23 \pm 1$ inches at $T+150$ seconds. The end of motor burn occurs during this time period at $T+140$ seconds. Beyond $T+150$ seconds, pool level is less well defined, but appears to decrease to a local minimum of $17 \pm 2$ inches at $T+195$ seconds. Beyond $\mathrm{T}+195$ seconds, the pool volume again appears to be very active as water from the water quench fills the aft dome. Slag material appears to solidify on the nozzle beginning at approximately $\mathrm{T}+180$ seconds, and continues to grow until image definition is degraded beyond $\mathrm{T}+260$ seconds.

Results given in Figures 5.1-1 and 5.1-2 are based on 5-frame ( $1 / 6$ second) digitized averages using 330 -length by 30 -wide pixel strips and a $3 \%$ order statistic analysis (see Section 6.1 for an explanation of the order statistic analysis method), averaging the middle 3 strips. The 330-long vertical pixel strip extends from 18 inches above the screen centerline (pixel no. 75) to within 1 inch of the bottom of the image (pixel no 405). The middle 3 strips, i.e. strip nos. 2 through 4 (see Figure 3.3-4), were averaged to obtain 
the pool level time history. By using the average of the inner 3 strips only, the shadow image of the vectored nozzle was not included in any portion of the time history analysis, nor were pool oscillations imaged near the edge of the screen. In addition to the 330-strip $3 \%$ analysis, a 330-strip 10\% analysis and a 270-strip (pixel nos. 75 to 345 ) $10 \%$ analysis were also done, as were 3-strip averages and 5-strip averages. Comparison of analysis results for the different choices of order statistic, pixel strip length, and strip average are presented in Section 6.2, together with an estimate of uncertainties associated with the pool level results .

A number of checks were done to add confidence to the pool level results determined by the order statistic analysis. These included visual screen analysis on still frame video images, and line traces and differential filter analysis on digitized images. All comparisons generally confirmed the resulis obtained by the order statistic method. An independent analysis of the RTR video data performed by Aerospace Corporation (AC) used a 45-frame (1.5 second) average of digitized images and a gradient filter method to determine pool level at 5 second intervals from $T+065$ to $T+160$ seconds. ${ }^{1}$ A comparison of the AC independent assessment with our 330-strip 3\% order statistic result is shown in Figure 5.1-3. The $A C$ results in this figure are corrected for a 1.9 second time difference where $A C$ used the video frame at which screen check lights were turned off as a time zero indicator (per our suggestion before IRIG-B timing information on the video was available). Post test analysis showed that check lights out actually occurred 58 frames ( 1.9 seconds) before time zero. As corrected for this timing difference, the AC results are in very good agreement of our results (within \pm 1 inch) at early times, $T+65$ and $T+70$ seconds, are slightly lower than our results ( 1 to 2 inches) between $T+75$ and $T+90$ seconds, and approximately 2 inches lower than our results in the time interval T+95 seconds to $\mathrm{T}+135$ seconds. At the end of burn, $\mathrm{T}+140$ seconds, the $\mathrm{AC}$ result is considerably lower than our result, while at $T+150$ to $T+165$ seconds the results are again in good agreement (within \pm 1 inch). It is to be expected that the gradient filter method would give pool level values that are generally lower than the order statistic method since the gradient filter method determines location of steepest slope of the approximate step change in attenuation, while the order statistic method determines an approximate onset location for the attenuation change. We used the order statistic analysis method after trying various gradient filter methods because of our need to do automated analysis of large data sets, given the observed superposition in the image of motor case structural features with the pool level image particularly at early times (less than 90 seconds).

A number of pool level excursions and/or oscillations appear to be related to the TVC duty cycle as observed from a comparison of slag pool depth and Thrust Vector Control (TVC) commands in Figure 5.1-4. For example, the large excursion centered at $T+61$ seconds occurs at the same time as a TVC step command. Cause and effect of TVC commands on pool dynamics is not attempted here, although results of a Fourier analysis of pool level dynamics as imaged are given in Section 5.2.

\subsection{Slag Dynamics}

The individual strip analysis gives us the opportunity to obtain not only average pool depth, but also to determine pool oscillation modes and frequencies. Pool level time histories for each of the strips are given in Figures 5.2-1 and 5.2-2. These traces provide finer definition of pool level excursions, and are a better choice for Fourier analysis than the average result for either 3 or 5 strips. We have done Fourier analysis for the time period $T+80$ seconds to $T+140$ seconds and find peaks in the fequency spectra near $1 / 4$ $\mathrm{Hz}, 1 / 2 \mathrm{~Hz}$ and $1 \mathrm{~Hz}$ (see Figures 5.2-3 and 5.2-4). Pool level dynamics can also be

\footnotetext{
${ }^{1}$ private communication from Mark Brosmer. The Aerospace Corporation, El Segundo, CA
} 
plotted in bar chart form for the 5 strips, and this is done for the time period $\mathrm{T}+124$ to $\mathrm{T}+142$ seconds in Figures 5.2-5, -6, and -7 .

\subsection{Slag Ejection}

Data tapes were reviewed visually for major slag ejection events. These events were judged to be discernible only from the video single frame data because they appear to occur in such a short time interval, e.g. less than 1 to 2 frames (1/30 to $1 / 15$ second). We must also remember that only a small portion of the aft dome region is imaged on the RTR screen, so that many slag ejection events would not be in the field of view and are never imaged. Slag ejection events that were observed in the video image appear as dark plumes that rise from the slag pool, proceed upward along the contour edge of the nozzle, and then disappear at the top of the nozzle. Only two slag ejection events were positively identified from visually reviewing the video data. A relatively large and unmistakable slag ejection event occurs at approximately $T+127.1$ seconds, while a smaller less obvious ejection event was judged to occur at $T+93.5$ seconds. The mass of material involved in these two ejection events has not been determined. Correlation with pressure spikes at these times was also not attempted here.

\subsection{Slag Density}

Density of the slag pool was not a requirement of RTR, but was considered to be a desirable if it could be extracted from the RTR data. We have concluded that significant additional analysis would be required to determined slag density from the RTR data. The method to do this would involve using pool levels and intensity profiles as determined from the RTR data at specific times. Monte Carlo radiation transport calculations would be needed to simulate the intensity profile using a 3-dimensional model of the test configuration and the correct $9-\mathrm{MeV}$ bremsstrahlung source spectrum. Several different slag densities would be used as input for repeated calculations to bound the intensity profile. A best fit of the intensity profile would be used to determine slag density. A test would be needed with our high energy Linac source to simulate pool geometry with a thick slab of aluminum, and the same calculational analys is would be used to determine bias and uncertainties associated with this analysis method.

\subsection{Test Article Effects}

Thermoluminescent device (TLD) chips had been placed on the $135^{\circ}$ actuator and on the $225^{\circ}$ actuator prior to the first exposure in December-1992. They were removed after the final post test exposures in February-1993. The total exposure dose on the $135^{\circ}$ actuator (TLD no. 920187) was 0.42 Roentgen, and the total exposure dose on the $225^{\circ}$ actuator (TLD no. 920190) was 7.25 Roentgen. These are far below the 1000 Roentgen level normally considered to be the threshold for onset of radiation damage in silicon devices, and considerably below the conservative limit of 200 Roentgen desired for this test.

\subsection{Test Environment Measurements}

The accelerometer signals ${ }^{2}$ were originally recorded on tape (with a frequency response of $0-5 \mathrm{kHz}$ ). During playback, the accelerometer signals were AC-coupled, low-pass filtered at 50 and $500 \mathrm{~Hz}$ and some also at $5 \mathrm{kHz}$, then digitized, stored in memory. The measurement results were plotted as a function of time, and they were also plotted in cascade or waterfall format (in RMS magnitude value) as a function of frequency. A report covering these measurement, which includes the time history, and cascade and waterfall frequency charts, is provided under separate documentation ${ }^{3}$.

\footnotetext{
2 Channels 1 through 9: Endevco 2250AM1-10, amplified from $10 \mathrm{mV} / \mathrm{g}$ to $500 \mathrm{mV} / \mathrm{g}$.

3 unpublished LLNL report, Bart Costerus, "Test Report of Sound and Vibration Environment of X-ray Equipment during Static Test Firing of a Titan IV Motor", March 25, 1993.
} 
A dummy accelerometer was used to verify data integrity 4 . It showed no spurious signals due to the $x$-ray beam, sound, or vibration, beyond the noise of the data processing and recording system.

Table 2 summarizes the results of the test environment acceleration measurements.

Table 2. Test environment measurements maximum acceleration results.

\begin{tabular}{|c|c|c|c|c|}
\hline \multirow{3}{*}{ Location } & \multirow{3}{*}{$\begin{array}{l}\text { Frequency } \\
\text { Range }(\mathrm{Hz})\end{array}$} & \multicolumn{3}{|c|}{ Maximum Acceleration } \\
\hline & & Vertical & North-South & East-West \\
\hline & & (g) & (g) & (g) \\
\hline Camera & $3-50$ & 0.3 & 0.2 & 0.6 \\
\hline Platform & $3-500$ & 0.3 & 0.3 & 0.7 \\
\hline X-Ray & $3-50$ & 0.3 & 0.1 & 0.5 \\
\hline Source & $3-500$ & 1.0 & 0.2 & 0.6 \\
\hline \multirow{3}{*}{$\begin{array}{l}\text { North } \\
\text { Snubber }\end{array}$} & $3-50$ & 0.6 & 0.8 & 2.2 \\
\hline & $3-500$ & 3.2 & 3.2 & 4.8 \\
\hline & $3-5000$ & 6.4 & 4.6 & 7.1 \\
\hline \multirow{3}{*}{$\begin{array}{l}\text { Trailer } \\
\text { Equipment }\end{array}$} & \multirow{3}{*}{$\begin{array}{l}3-50 \\
3-500 \\
\end{array}$} & \multirow{3}{*}{$\begin{array}{l}0.4 \\
1.2 \\
\end{array}$} & Fore-Aft & Transverse \\
\hline & & & 0.3 & 0.5 \\
\hline & & & 1.5 & 0.8 \\
\hline
\end{tabular}

The microphone signal was processed in a B\&K model 2606 amplifier and recorded. During playback, the signal ${ }^{5}$ was processed in an Ono Sokkui CF-350 spectrum analyzer. The indicated sound level inside the acoustic enclosure ${ }^{6}$ of the $x$-ray source was $149 \mathrm{~dB}$ without weighting, and $119 \mathrm{~dB}(\mathrm{~A})$ with $\mathrm{A}$-weighting However, a post-test inspection indicated that the microphone extension cable was damaged. This perhaps explains why the gain of the B\&K microphone amplifier had to be increase significantly during the final pre-test and end-to-end calibration (using a piston-type microphone calibrator), and consequently, the reported sound levels and graphs may be in error.

The expected level outside the sound enclosure was $164 \mathrm{~dB}, 7$ and the enclosure itself provided a theoretical attenuation of $24 \mathrm{~dB}^{8}$ and a crudely measured attenuation of 20 $\mathrm{dB}$, both at $100 \mathrm{~Hz}$.

\footnotetext{
4 Channel 10, Endevco 2250AMl, zero $\mathrm{mV} / \mathrm{g}$, amplified with gain of 50 .

$50.154 \mathrm{~V}$-rms $=140 \mathrm{~dB}$.

${ }^{6}$ plywood with up to 6 layers of 1 -inch 584xx series foam/barrier composites by Tech Products Corp, Dayton, $\mathrm{OH}$.

$7167 \mathrm{~dB}$ for two motors (i.e. $164 \mathrm{~dB}$ for one motor).

8 attenuation $=20 \log (F)+20 \log (D)-33=24 \mathrm{~dB}$, where $F=$ frequency $(100 \mathrm{~Hz})$, and $\mathrm{D}=$ density including plywood $(7 \mathrm{lb} / \mathrm{sq} \mathrm{ft})$.
} 


\subsection{Motor Lift-Off}

Although a motor lift-off measurement was not an objective of RTR, the image data contained this information. Following geometric conversion of screen image, and using the images of near and far pins of the SRMU motor case, the beam centerline position was determined as described in Appendix A2 as well as motor lift-off. RTR results for motor lift-off are compared to axial load cell data ${ }^{9}$ in Figure 5.7-1.

\subsection{DATA ANALYSIS}

\subsection{RTR Data Reduction Methods}

\subsubsection{Image Processing}

Every frame of the original optical disk recording for the camera-2 data channel was digitized from $T+20$ to $T+260$ seconds. The RS-170 output signal from the optical disk recorder was input under computer control to a PC video image processing board for 8-bit digitization. The digitized images were stored in 512 by 512 by 8 -bit frame buffers. Each video frame was read-in and digitized six times, and then an average was taken to reduce the statistical noise introduced by digitization. The digitized images thus obtained were stored in PC memory as frame records. The frame records were later transferred to our computer network and stored on hard disks for access by workstations.

Image processing software was used to extract just the screen image with a surrounding border from the digitized images. Pixels along the narrow dimension of the screen image were then resampled to produce nearly dimensionally square pixels. Resampling was necessary to give a dimensionally correct image display since the 3:2 video aspect ratio had been distorted to $1: 1$ in the 512 by 512 digitization. Finally, the digitized images were rotated $90^{\circ}$ to correct for the fact that the cameras were mounted on their side. Although image digitization and resampling resulted in pixel dimensions of approximately $0.1 \mathrm{inch} / \mathrm{pixel}$ in both screen width and length dimensions, actual conversion (pixel dimension as a function of screen position) resulted from use of fiducials in the screen image as described in Appendix A2. Frame dimensions for the extracted, resampled, and rotated frames, which included an image of the screen with a border, were 390 pixels wide by 422 pixels long. Total disk storage space for the extracted digitized frame records for the time period $T+20$ to $T+260$ seconds was approximately $2.6 \mathrm{~Gb}$.

From the digitized frame records, two separate frame-averaged files were constructed: (1) 30 -frame averages at one second intervals, and (2) 5 -frame averages at 1/6 second intervals. The frame-averaged records are contiguous, and each record is centered about the time given for that record. Dimensional calibration was done with the 30-frame averages, and pool level determination was done with the 5-frame averages.

\subsubsection{Dimensional Calibration}

Using the 30-frame average records, locations of fiducials in the image were used to obtain both vertical and horizontal calibration curves. Horizontal calibration (in/pixel) was determined to be nearly a constant, independent of screen location, while vertical calibration was determined to be a linear function (see Appendix A2). The horizontal calibration, $0.1004 \mathrm{in} / \mathrm{pixel}$, was used to convert horizontal pixel number to horizontal screen location (inches) relative to screen centerline. The vertical calibration, 0.1284 $3.544 \mathrm{e}-5 *$ pixel no. (in/pixel), was used to convert vertical pixel number to vertical screen

\footnotetext{
${ }^{9}$ private communication from Glenn Bergman., Hercules Inc.
} 
location (inches) relative to beam centerline. Image locations of fastener pins in the aft skirt motor case were used to determined motor lift-off as a function of time. The exact centerline of the beam in the image was determined from a superposition of the near (to the screen) and far single row of fastener pins near the center of the screen image as the motor settled at about $T+131$ seconds. Using the vertical conversion factor near the center of the screen, 0.1206 inches/pixel (screen centerline is at pixel no. 219), the beam centerline was determined to be 0.84 inches above screen centerline.

\subsubsection{Pool Level Determination}

The pool level was determined for five vertical strips in the screen image (e.g. see Figure 3.3-4) from the 5-frame average records according to the method described in Appendix A1. Each strip was 30 pixels wide, started at pixel number 75 (numbered from the top of the extracted image) and was 330 pixels long. As described in Appendix A1, the image was first normalized for camera gain and offset by regression analysis, then the transmission image was constructed by taking the log difference image with the selected reference frame. Next, the cumulative intensity was determined along each of the five strips, and finally pool level was determined as the pixel location corresponding to the $3 \%$ order statistic (i.e., pixel location corresponding to $3 \%$ of the integrated attenuation vector). This method was repeated at a $10 \%$ order statistic for both the 330 length strip and for a 270 length strip. The shorter strip length analysis is not appropriate for early times when the pool level is below the 270 -strip minimum detectable level, as discussed in Section 6.2.2, but is included here as a consistency check for later times.

Since the pool is semi-transparent to the $x$-ray beam (half-value thickness estimated to be 7.2 inches), a judgment was needed as to whether the $3 \%$ or $10 \%$ order statistic result was more representative of the top edge of the pool. As discussed in Section 6.2 below, the $3 \%$ order statistic result was chosen as being a more conservative and more accurate estimate. Pool levels determined by this method were checked for internal consistency among the five strips used for each strip length, between the averages of the two strip lengths (330 and 270) and the two order statistics (3\% and 10\%), and against best estimate values at selected times from: (1) visual estimates of pool level from image displays on the work station monitor, (2) line traces of intensity along the strip, and (3) differential filter analysis to determine steepest slope locations. When using the differential filter method, gradients associated with structural features in the motor case must be distinguished from the gradients associated with pool level. This can be done by visual inspection of individual strips of individual frames. For our purposes, the steepest gradient or steepest slope from the differential method did not lend itself to automated pool level determination, and was used only for checks on the order statistic method.

\subsubsection{Geometric Projections}

Geometric projections of the top outer edge of a level slag pool (i.e.. interface of pool surface and inner contour of aft dome insulator) onto the screen were calculated as a function of vertical screen location relative to the beam centerline for different motor liftoff conditions, as described in Appendices A2 and A3. Motor lift-off conditions used in these calculations ranged from 0.0 to 1.8 inches in increments of 0.2 inches. Linear regression fits were made to the calculated results to interpolate intermediate conditions of motor lift-off for each of the five strip regions. This provided conversion relationships, as described in Appendix A2, to convert from screen location of the projected top-of-pool image to pool depth (i.e., pool level relative to datum-A, the lowest point of the inner insulator contour) for any motor lift-off condition. 


\subsection{Pool Level Uncertainty}

\subsubsection{Order Statistic Analysis}

The 3\% and 10\% 330-strip order statistic analyses are compared in the difference plot of Figure 6.2-1 to show the effect of different order statistics for the same strip length. The $3 \%$ order statistic gives a higher pool level as compared to the $10 \%$ result by about 1.0 inch in the time range $T+60$ to $T+125$ seconds. At times greater than $T+125$ seconds, the difference increases to as much as 2.0 to 2.5 inches. The $3 \%$ order statistic analysis is expected to give a larger value for pool depth than the $10 \%$ analysis. That the difference between the $3 \%$ and $10 \%$ analyses is fairly constant from $T+60$ to $T+125$ seconds, and then increases after $T+125$ seconds, is a result of both the order statistic method and the physical distribution of top-of-pool material. The surface of the pool is better defined before $\mathrm{T}+125$ seconds when internal motor pressure is high, and less well defined after $T+125$ seconds when internal motor pressure decreases and the pool becomes more active (e.g. when the pool appears to enter a more active boiling mode). Based on our observations of sharpness of the image terminus that defines the top-of-pool interface, the $3 \%$ order statistic method is estimated to contribute an uncertainty to pool level results of approximately \pm 0.5 inch before $T+125$ seconds, and as much as \pm 1.0 inch after $T+125$ seconds.

\subsubsection{Strip Length Comparisons}

The 270-strip and 330-strip 10\% analyses are compared in Figure 6.2-2, and the difference plot for these two analyses is given in of Figure 6.2-3 to show the effect of different strip lengths using the same order statistic. The image threshold varies with motor lift-off condition, with higher lift-off providing lower image threshold. For the 270-strip analysis at $T+70$ seconds, corresponding to a lift-off of 1.6 inches for example, pool level image threshold is 10.5 inches. For the 330-strip analysis for the same conditions, pool level image threshold is 6.2 inches. We note that the closer the pool level is to the 270-strip threshold, the greater the deviation from the 330-strip analysis. For cases where the 270-strip analysis gives a pool level just above it own threshold (e.g. at $\mathrm{T}+70$ seconds), the 270 -strip analysis is approximately 2.0 to 2.5 inches above the 330strip analysis. When the 270-strip analysis gives a result for pool level 1.5 inches above its own threshold (e.g. at $\mathrm{T}+80$ seconds), the deviation from the 330-strip analysis is approximately 1.5 to 2.0 inches. When the 270-strip analysis gives a result more than 3.0 inches above its own threshold (e.g. at times greater than $\mathrm{T}+90$ seconds), the 270-and 330-strip analyses agree within 0.2 inches. From these comparisons, we conclude that the 270-strip analysis overestimates pool level at times earlier than T+90 seconds due to an image threshold effect, i.e. because the strip either excludes or does not include enough of the pool terminus image for low pool levels. At times greater than $\mathrm{T}+90$ seconds, when pool level estimates are 3.0 or more inches above the 270-strip threshold, there is no bias overestimate. When pool level is 2 inches above strip threshold a bias overestimate by as much as 1 inch results, and when pool level is near threshold a bias overestimate by as much as 3 inches results.

Time and resources did not allow us to repeat the 270-strip analysis using a 3\% order statistic. However, we would expect comparison of the analyses for the two different strip-lengths with a $3 \%$ order statistic to be nearly the same as those given here for $10 \%$. The 330-strip 3\% order statistic was used for final results as being a more accurate pool level estimator, but caution is in order that this analysis probably also overestimates pool level when estimated results are within 3 inches of the 330-strip threshold. This occurs between $T+67$ and $T+75$ seconds where estimated pool level is 2 to 3 inches above threshold, and at times earlier than $T+58$ seconds. In the time range $T+67$ to $T+75$ seconds, the pool level may be overestimated by as much as 0.5 inches due to this image threshold effect based on comparisons at $10 \%$. At times earlier than $\mathrm{T}+58$ seconds, 
however, the pool level is observed above threshold only momentarily. For this time period, the results should be used only as an upper bound on pool level, and are probably overestimates of that by 1 to 3 inches.

\subsubsection{Strip Average Comparisons}

A comparison of the results obtained by averaging strips 2 thru 4 to that of averaging strips 1 thru 5 for the 330-strip 3\% analysis is given as a difference plot in Figure 6.2-4. Only small differences in estimated pool depth are noted, generally less than 0.25 to 0.5 inches over the entire time span $T+40$ to $T+160$ seconds except for a few outliers at times earlier than $\mathrm{T}+60$ seconds. The standard deviation for the three-strip averages (strips 2 thru 4) and five-strip averages (strips 1 thru 5) are given in Figure 6.2-5. For the three strip averages, the standard deviation is 0.2 inches in the time range $T+60$ to $T+70$ seconds, 0.3 inches from $T+70$ to $T+90$ seconds, and 0.15 inches from $T+90$ to $T+160$ seconds. The standard deviation for the five-strip average is greater than three-strip average by about $10 \%$ over the entire time range.

\subsubsection{Projection Uncertainties}

The sharpness of the image terminus corresponding to top of pool is determined by differences in attenuation of $x$-rays projected along paths just above the pool, and with small changes in angle of incidence, just through the top of the pool. For an ideal flat pool with a depth of 16 inches, for example, a difference in incidence angle of the $x$-ray beam from top-of-pool to a projection with a path length of a half-value thickness through the pool material ( 7.2 inches) would correspond to a vertical increment on screen image of 0.6 inches ( 5.0 pixels), as described in Appendix 3. The change in screen image intensity for this vertical screen increment would be a $50 \%$ reduction, assuming no scatter or background and linear conversion of $x$-ray flux to screen intensity. For this same pool depth, 16 inches, a difference in incidence angle producing a 10\% change in intensity would correspond to a vertical screen increment of just 0.09 inches (less than 1 pixel). Since we can easily resolve $10 \%$ changes in image intensity, and since geometric magnification (as discussed in Appendix 3 ) of pool terminus image is about $25 \%$ for this pool depth, our ability to resolve pool level using $10 \%$ image contrast would be about 0.07 inches at 16 inch pool depth. Similar considerations for pool depths of 8,10, and 12 inches provide pool level resolution estimates of $0.19,0.11$ and 0.09 inches, respectively. Camera resolution, approximately 0.12 inches per pixel in the vertical direction, and our ability to do subpixel pool image terminus estimation would appear to be the limiting factors and not image unsharpness due to projection through pool material in the idealized case (flat pool and no scatter).

As observed in the real-time image data, the pool level is probably never instantaneously flat. The top-of-pool terminus may be formed by projection through the crest of a wave in the body of the pool, a meniscus at the edge of the pool, material plumes above the pool, or a graded density at the top of the pool. To determine pool depth, the logarithm of the ratio of each foreground data image to a background data image is first determined. This result for each pixel-strip data set is the log-difference image from which attenuation vectors are constructed. One method to determine top-of-pool would be to determine the relative screen location corresponding zero intercept of the attenuation vector, i.e. location on the screen corresponding to zero projected mass. A more robust method to determine pool level, as done here, is to take the cumulative attenuation vector and apply an order statistic, i.e. determine the relative screen location corresponding to the $3 \%$ or 10\% cumulative level, as discussed in Appendix A1. The order statistic method always overestimates pool level for the ideal case (e.g. flat pool and no scatter), but is not as sensitive to variations from the ideal case (e.g. scatter noise, changing background, and non-flat pool surface). 
A few of the data sets that were analyzed for determining which order statistic to use are shown in Figures 6.2-6 thru 6.2-8. For the data at $T+50$ seconds, as shown in the top portion of Figure 6.2-6, the zero intercept for the attenuation vector is pixel no. 289.3. As shown in the lower portion of Figure $6.2-6$, the $3 \%$ order statistic result is 284.6 , slightly less than the zero intercept result ( 4.7 pixels or 0.6 inches) giving higher pool level by 0.4 inches, and the $10 \%$ order statistic result is 297.7 , slightly greater than the zero intercept result ( 8.4 pixels or 1.01 inches) giving lower pool level by 0.8 inches. At $T+60$, Figure $6.2-7$, the zero intercept for the attenuation vector is pixel no. 189.8 , while the $3 \%$ order statistic result is 196.3 giving lower pool level by 0.6 inches, and the $10 \%$ order statistic result is 207.7 giving lower pool level by 1.7 inches. At $T+70$ seconds, Figure 6.2-8, where the image contains significant motor case features in the region of interest, the zero intercept for the attenuation vector from what we judge to be the pool terminus image is pixel no. 180.4 , while the $3 \%$ order statistic result is 183.8 giving a lower pool level by 0.3 inches, and the $10 \%$ order statistic is 202.5 giving a lower pool level by 2.1 inches. After comparing a number of data sets like this, we chose the $3 \%$ order statistic as our best pool level estimator for enabling automated computer data analysis. The 3\% order statistic always gives a higher pool level than the $10 \%$ order statistic, conservative in that sense, and also provides closer agreement to results from the zero intercept method.

\subsubsection{Combined Uncertainties}

The $3 \%$ order statistic analysis appears to be biased toward lower pool level as compared to zero intercept results by approximately -0.5 inches at times earlier that $T+90$ seconds, and by -0.2 inches at times greater than $T+90$ seconds. An opposite bias toward higher pool level due to threshold effects is estimated to be +0.2 inches in the time range $T+58$ to $T+67$ seconds, +0.5 inches in the time range $T+67$ to $T+75$, and +0.2 inches at times greater than $\mathrm{T}+75$ seconds. At times earlier than $\mathrm{T}+58$ seconds, the results are upper bounds only, and may be an over estimate (i.e., toward higher pool level) by as much as 1 to 3 inches. The two biases appear to nearly cancel each other, and an uncertainty of \pm 0.5 inches is assigned to the combined offsetting biases. The uncertainty corresponding to statistical variations from the averaged strip data (strips 2 thru 4) was determined to be \pm 0.15 to \pm 0.3 . Resolution of the imager is estimated at \pm 0.2 inches. When uncertainties are combined, the resultant uncertainty for pool level results is estimated to be \pm 1 inch.

\subsection{CONCLUSIONS}

The successful completion of this test demonstrates that real-time radiography can be implemented in a vertical static firing test configuration and produce quality data under adverse test conditions. The issues of extreme g-shock, vibration, and acoustic levels can be successfully mitigated. High output linear accelerator $x$-ray generators and large area real-time imaging arrays can be assembled and applied to the diagnosis of solid rocket motor performance. High confidence levels were obtained through application of robust and redundant data acquisition system components. The high energy and high output linear accelerator, essential for x-ray penetration of large solid rocket motors, was customized and maintained by skilled electronic and mechanical support teams. The success of this project depended on quick response to U.S. Air Force criteria by securing a multidisciplinary team to address and meet the numerous technical challenges. In addition to the RTR requirements met, environmental, personnel dosimetry, radiation site survey, safe operational, and site procedural requirements were met. 


\section{ACKNOWLEDGMENTS}

We would like to acknowledge Captain Tom Williams, USAF, for constant encouragement and support of this work, and other USAF and civilian personnel at SMC/MES and Edwards AFB for making our participation in this test possible. We would also like to acknowledge Bob Snodgress, Tom White, Floyd Rickman, and Ron Edstrom, Martin-Marietta Corporation; Mike Baron, Glenn Bergman, Jeff Foote, Dave Parsley, Gary Spencer, Chris Robbins, Jeff Vosburgh, and Jack Nuttall, Hercules; Ricardo Gorecki, TRW; Mark Brosmer, Gary Hawkins, Mary Quinn, and Joe Vanna, The Aerospace Corporation; Reggie Ching, John Sykes and other Phillips Lab and Lampson personnel for on-site cooperation and assistance. We also wish to acknowledge the assistance of Varian personnel Dan Bingham, Greg Blandin, and Dave Huffman.

LLNL personnel we would like to recognize are Frank Drobnick, Greg Bianchini, and Tom Woehrle for design fabrication and on-site installation, and the many people that worked in their crews; Paul Gschweng, test stand hardware design; Jim Fugina, Bill Stigman, Dave Warwas, and Larry Griffith, Linac and support electronics; Don Bitz, Al Knabe, N. Nguyen, and Rich Ring, Test Measurements Data Acquisition; Dave Elsea and Don Tucker, RTR Data Acquisition electronics; Jim Winstanley, Gary Mansfield, and Larry Auman, Health Physics (site survey and dosimetry); Willie Thompson and Ben Paredes, on-site test team, and Tricia Torry and Harry Howe, Hazards Control; Earl Updike and Gerry Sobczak, NDE radiographers and on-site test crew ; Lin Hester, and Gene Ford, NDE radiographers, and Jerry Haskins, Dick Ryon and Derrill Rikard NDE Radiation Applications Group for valuable technical contributions; Earl Kelly and Dick Sites, procurement coordinators; Gordon Krauter, John Shingleton, Patty Billy for safety reviews and safety procedures; Jim Campbell, Mechanical Engineering Department office and Susan Springer, Engineering Sciences Division office; Jane DeAnda and Karen Lindsay NDE Section secretaries; and Satish Kulkarni Nondestructive Evaluation Section Leader and RTR Project Manager. Many others at LLNL not mentioned here also contributed to the success of this project to whom we owe our thanks. 


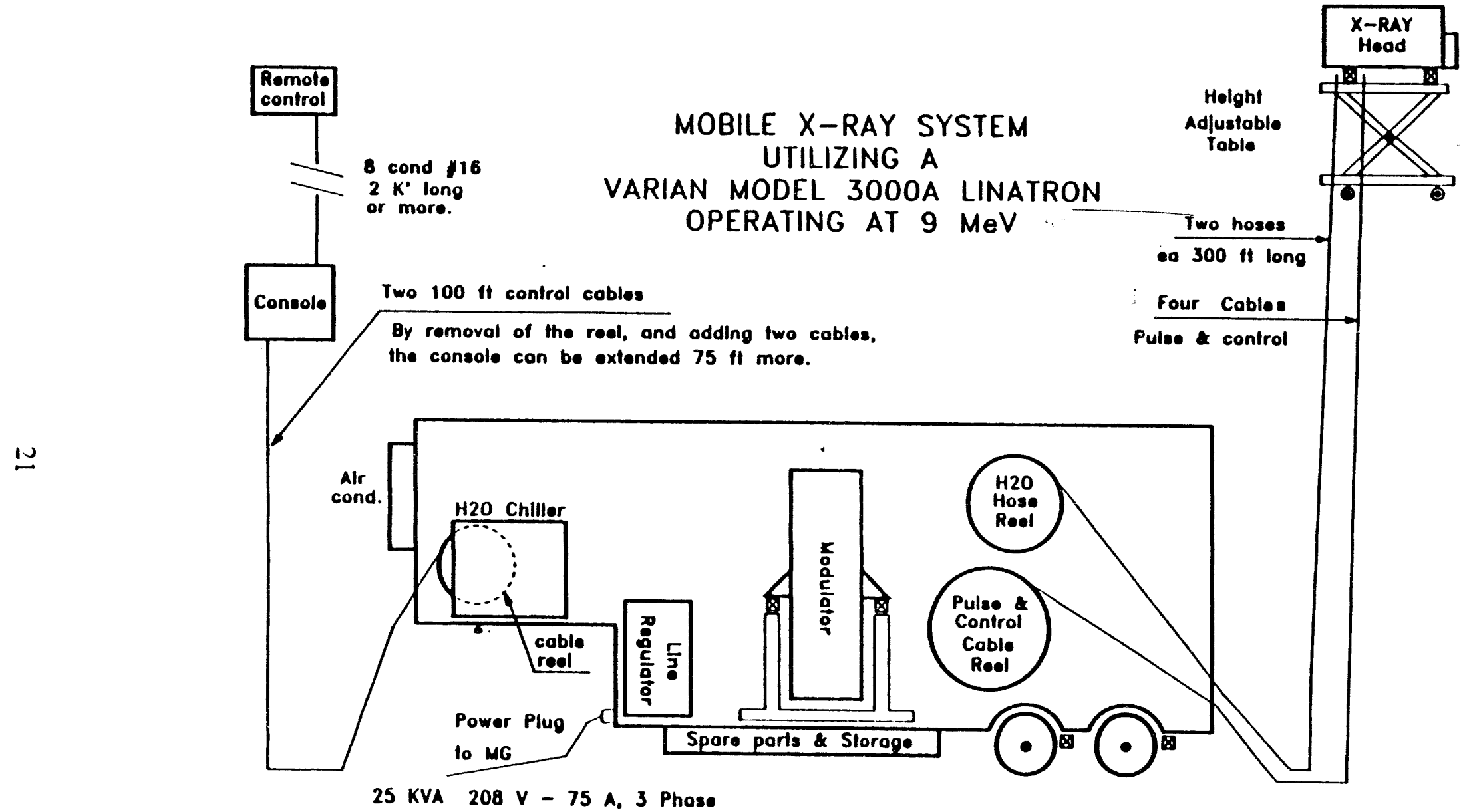

25 KVA 208 V - 75 A. 3 Phose

The traller ls 32 ft long, 11 if 10 In hlgh, \& 8 if wide.

Alr support

Figure 3.1-1. Linac equipment layout showing trailer, $x$-ray tube head and console. 


\section{SCREEN LAYOUT}

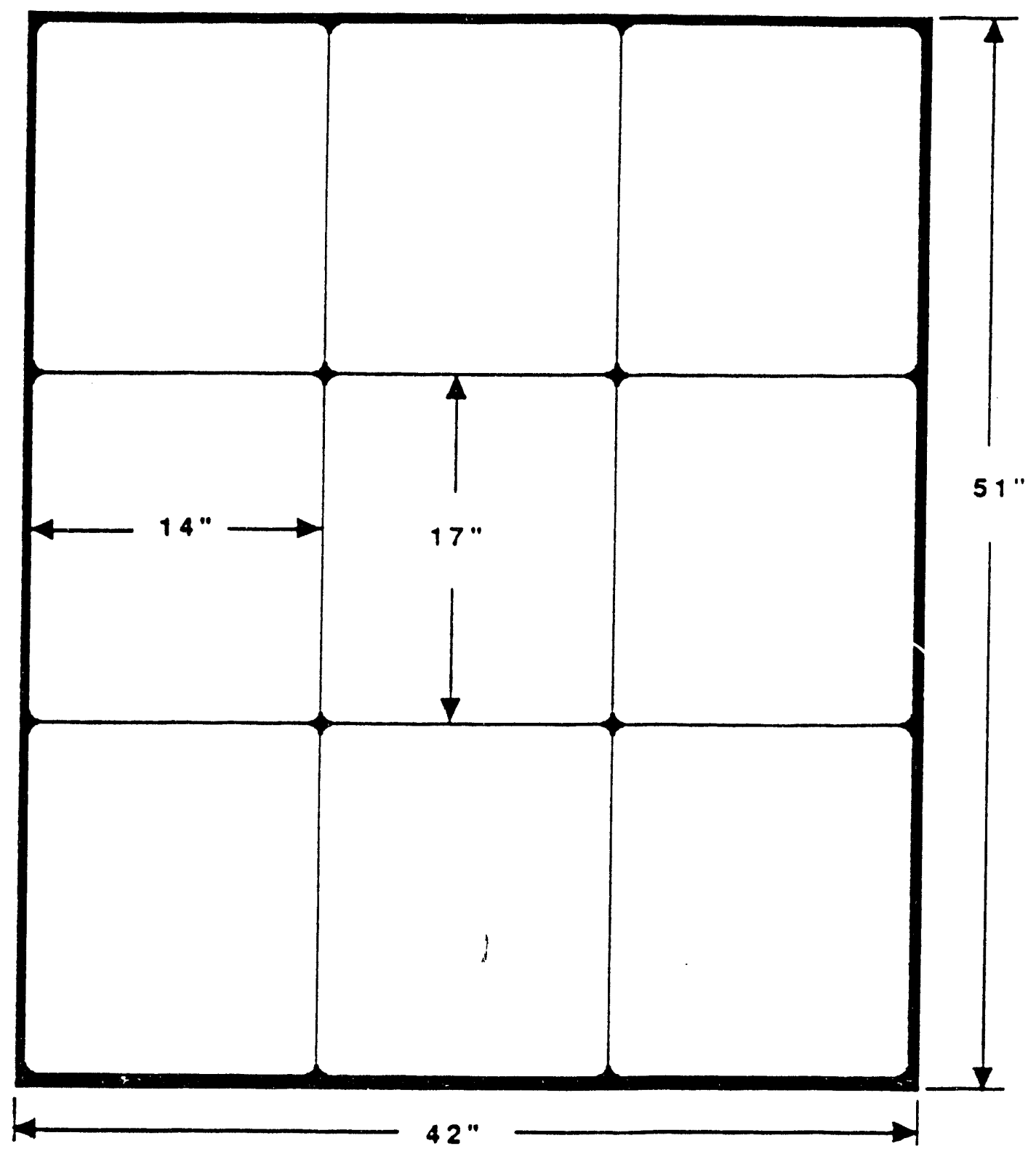

Figure 3.1-2. Screen layout showing nine each 14 by 17 inch standard screens laid up in a mosaic array with fiducials at interstices. 

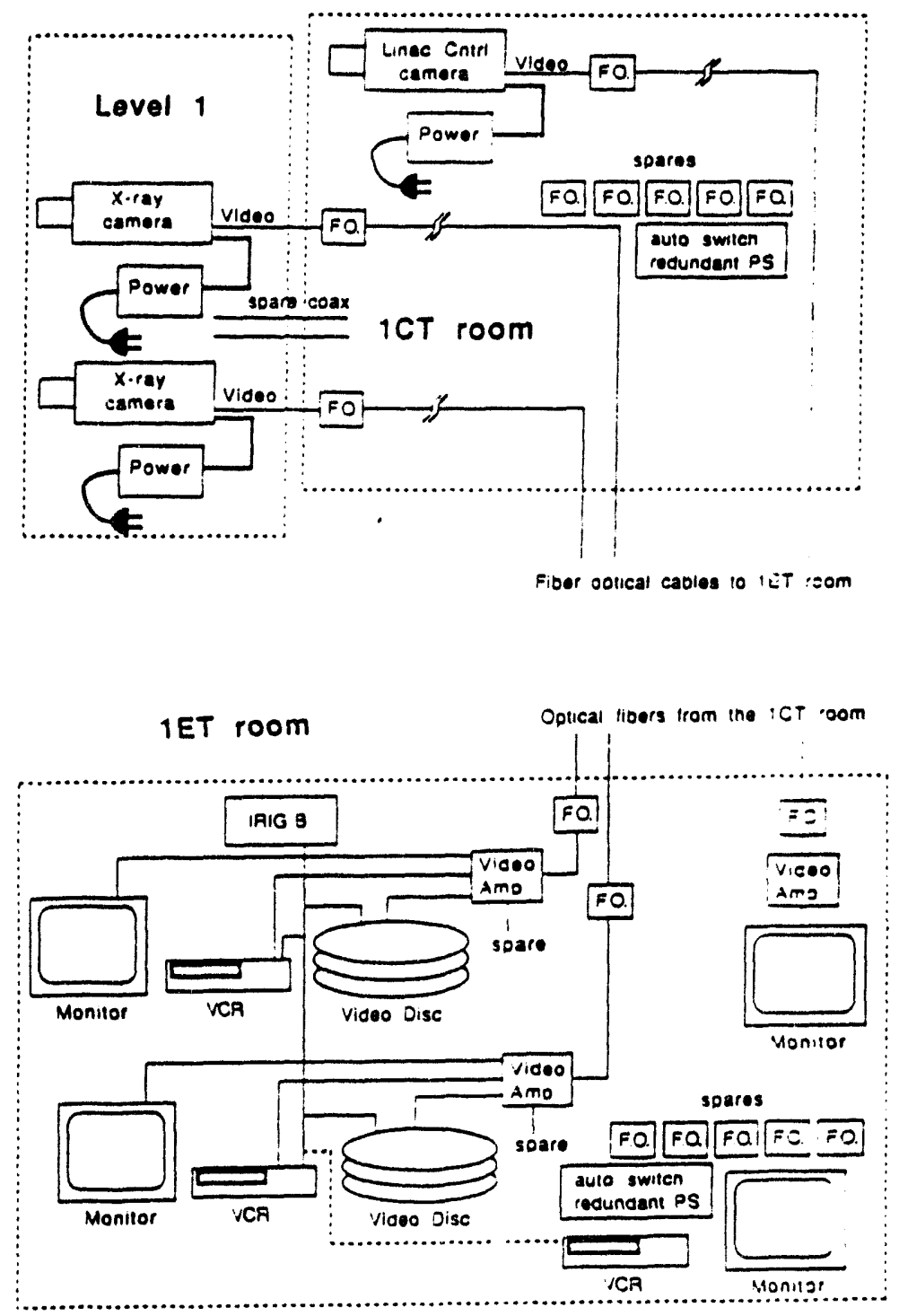

Figure 3.1-3. Data acquisition system block diagram. 


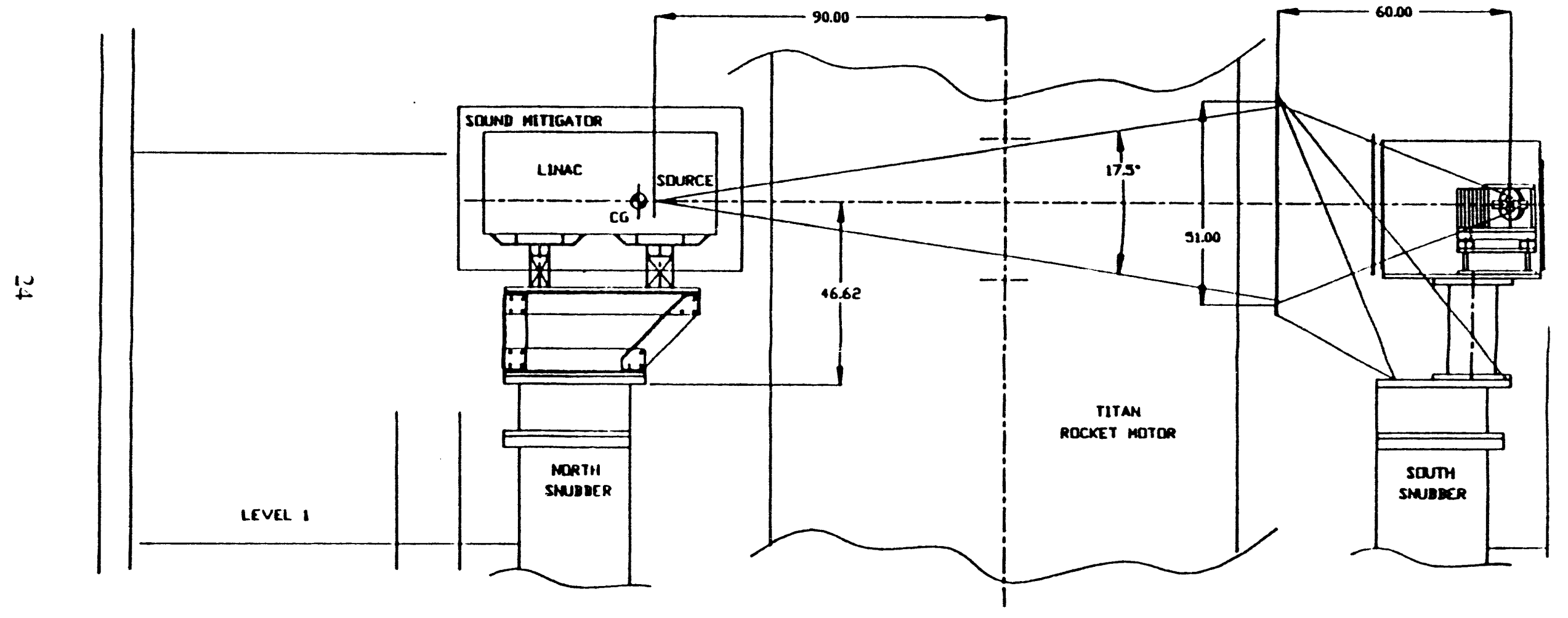

Figure 3.2-1. E:(puipment layout in lest stand - side view. 
||

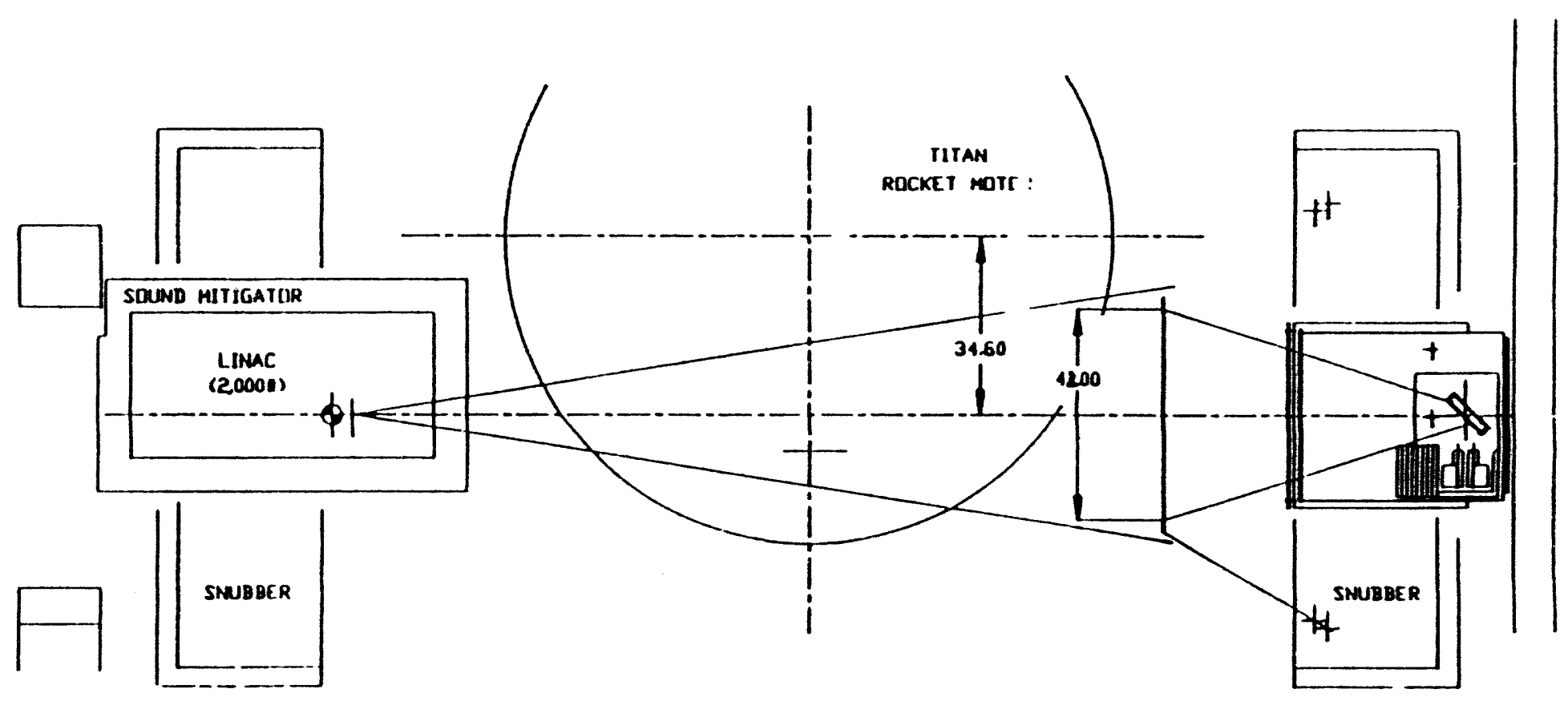

lighure 3.2-2. liguipment layout in lest stand - overhead view. 


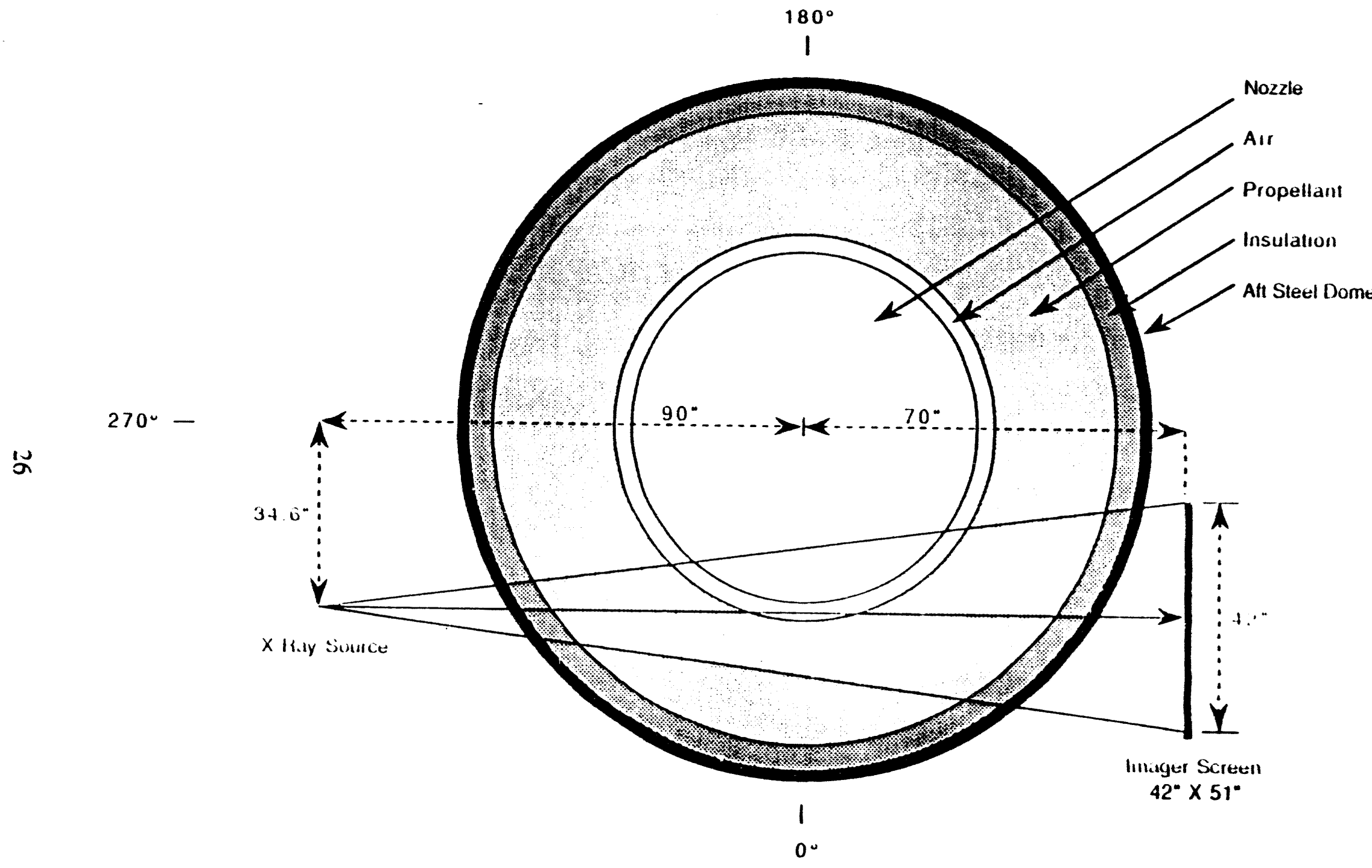

$-90$

ligurce 3.3-1. R'TR and 'litan SRMU afl dome cross-section plan view. 


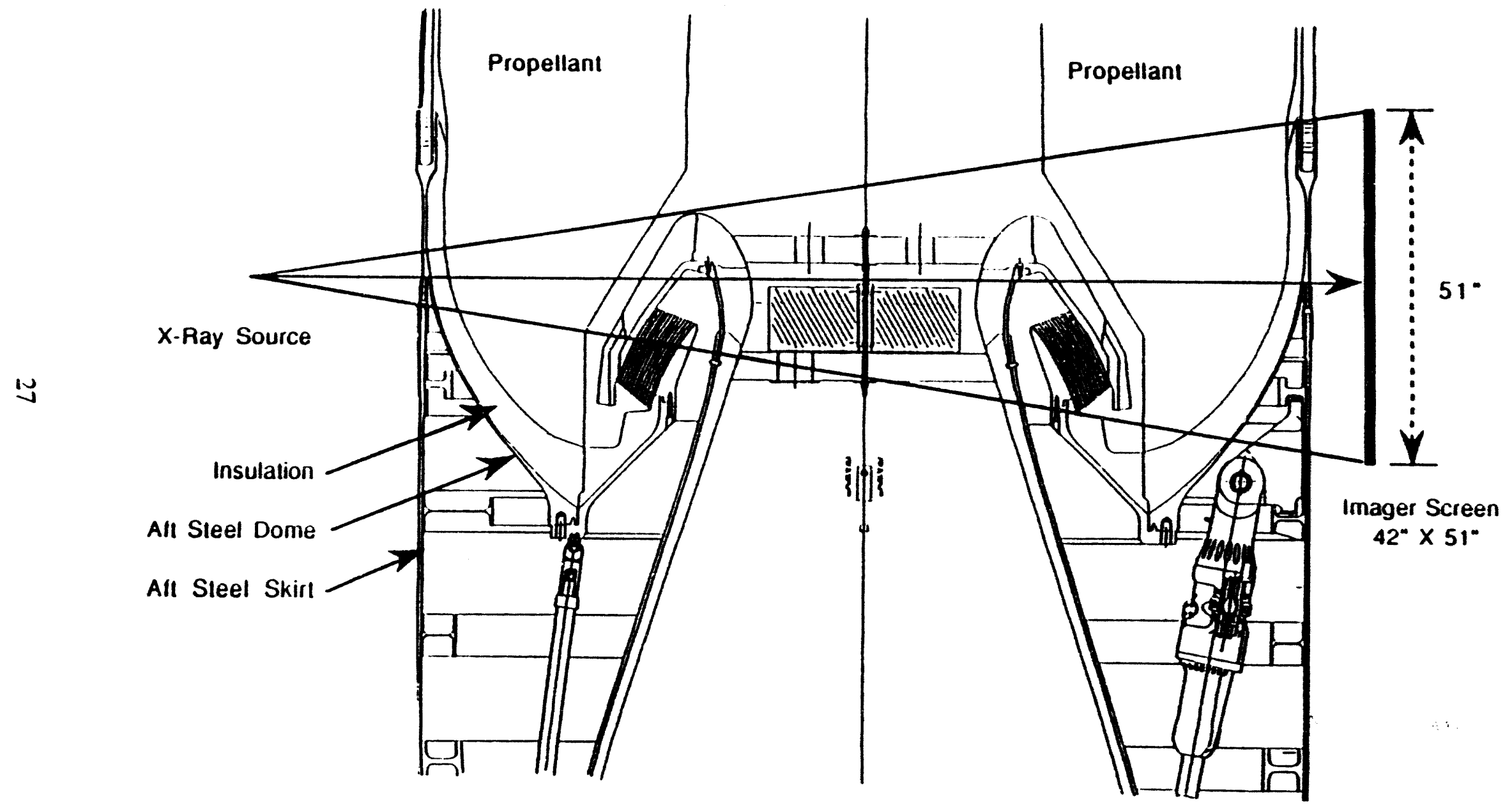

lighure 3.3-2. R'TR and Tilan SRMU alt dome cross-section elevalion view. 


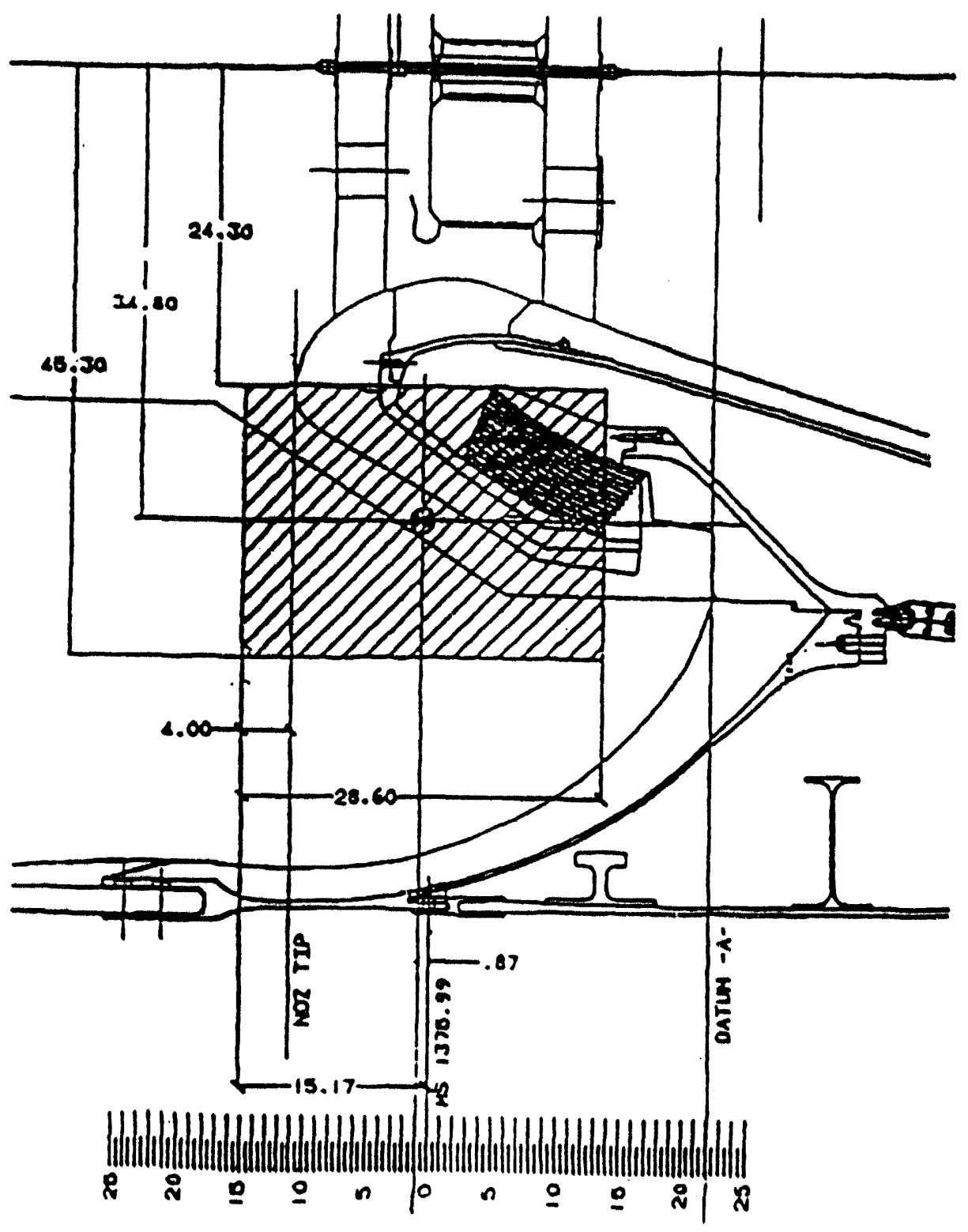

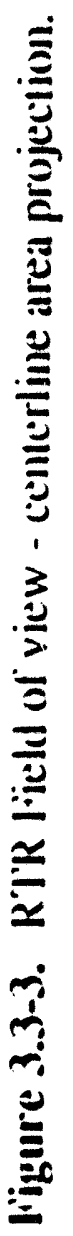




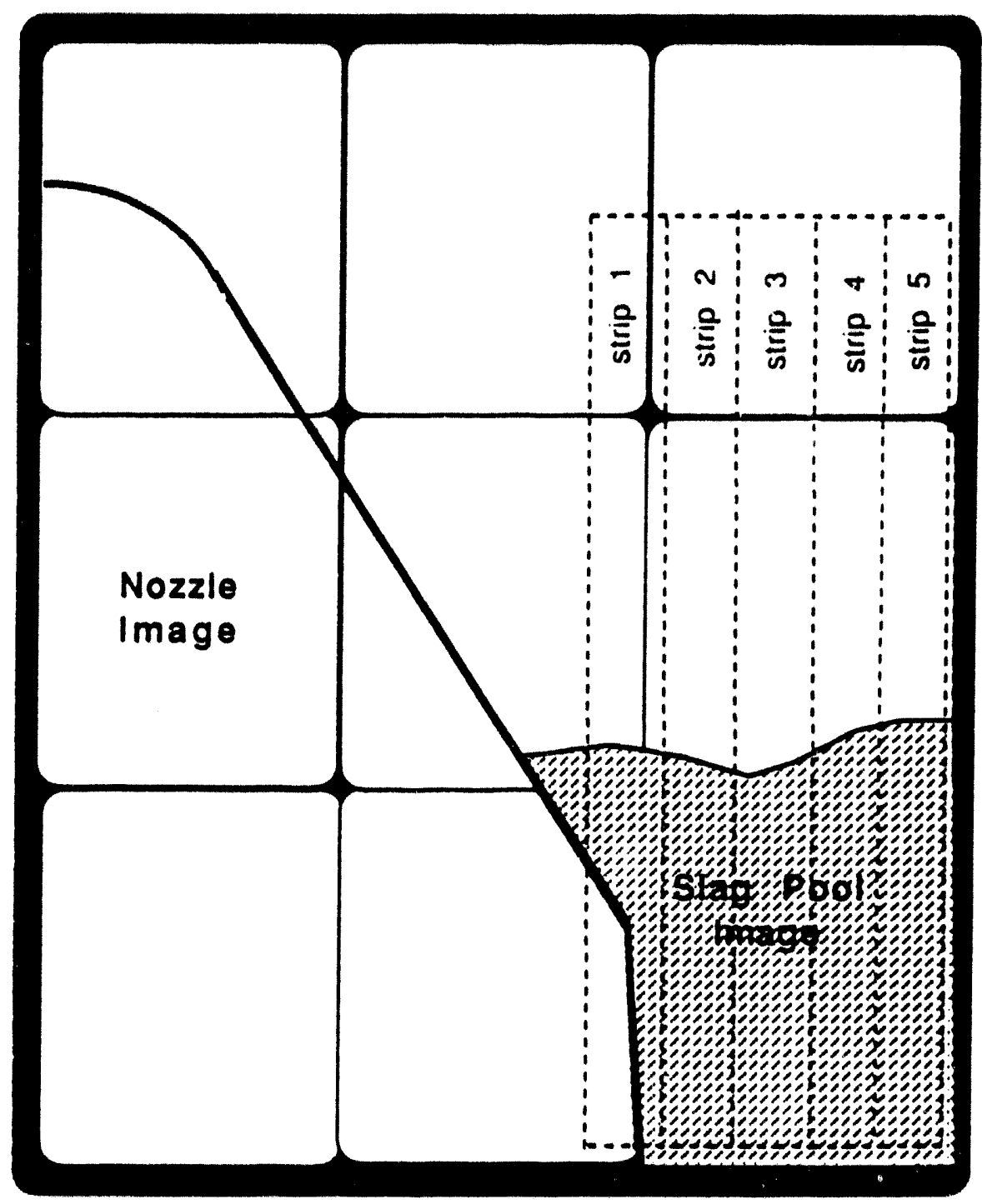

Figure 3.3-4. Image screen with nozzle and slag pool images represented together with pixel strip locations used for pool depth analysis. 


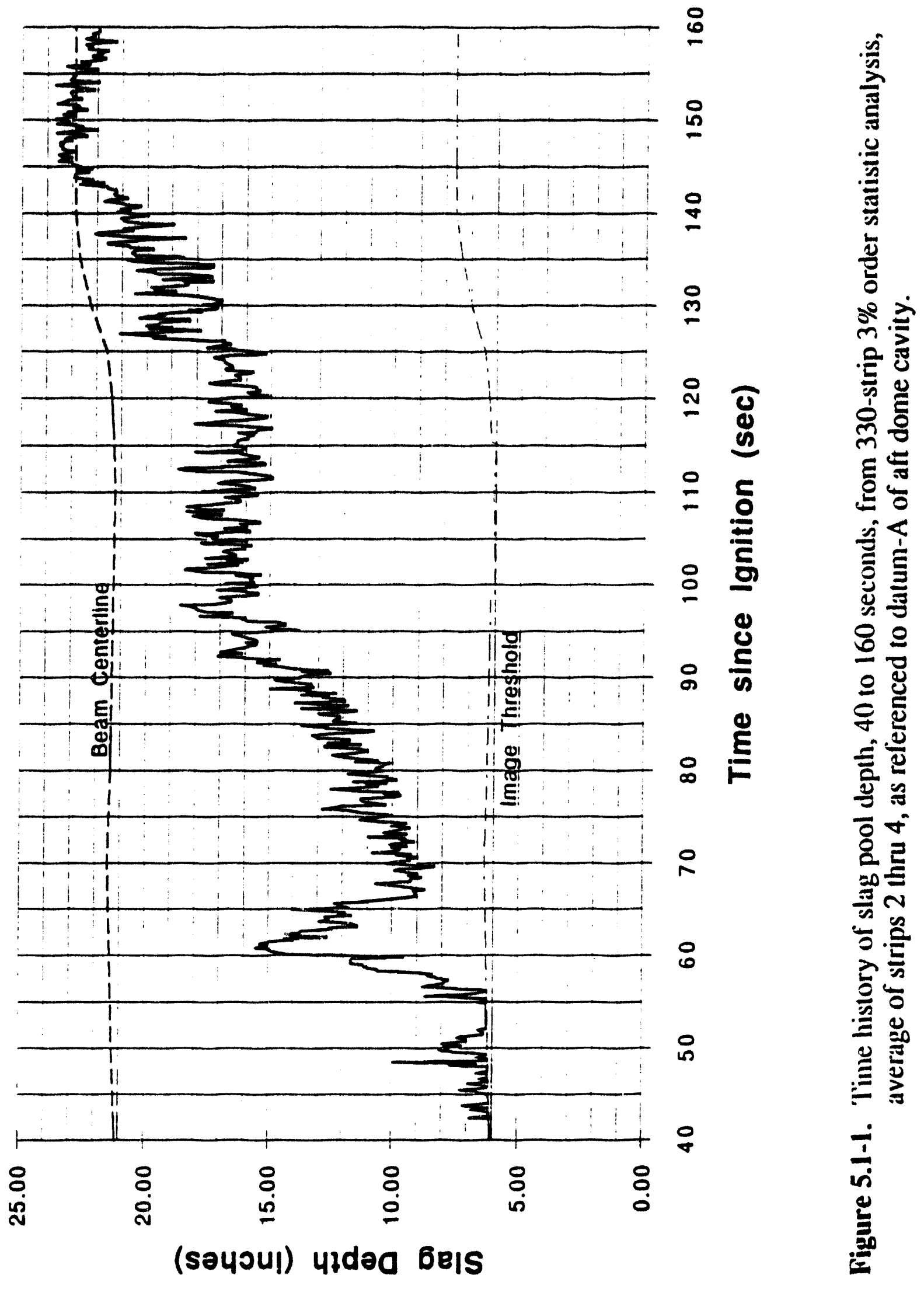




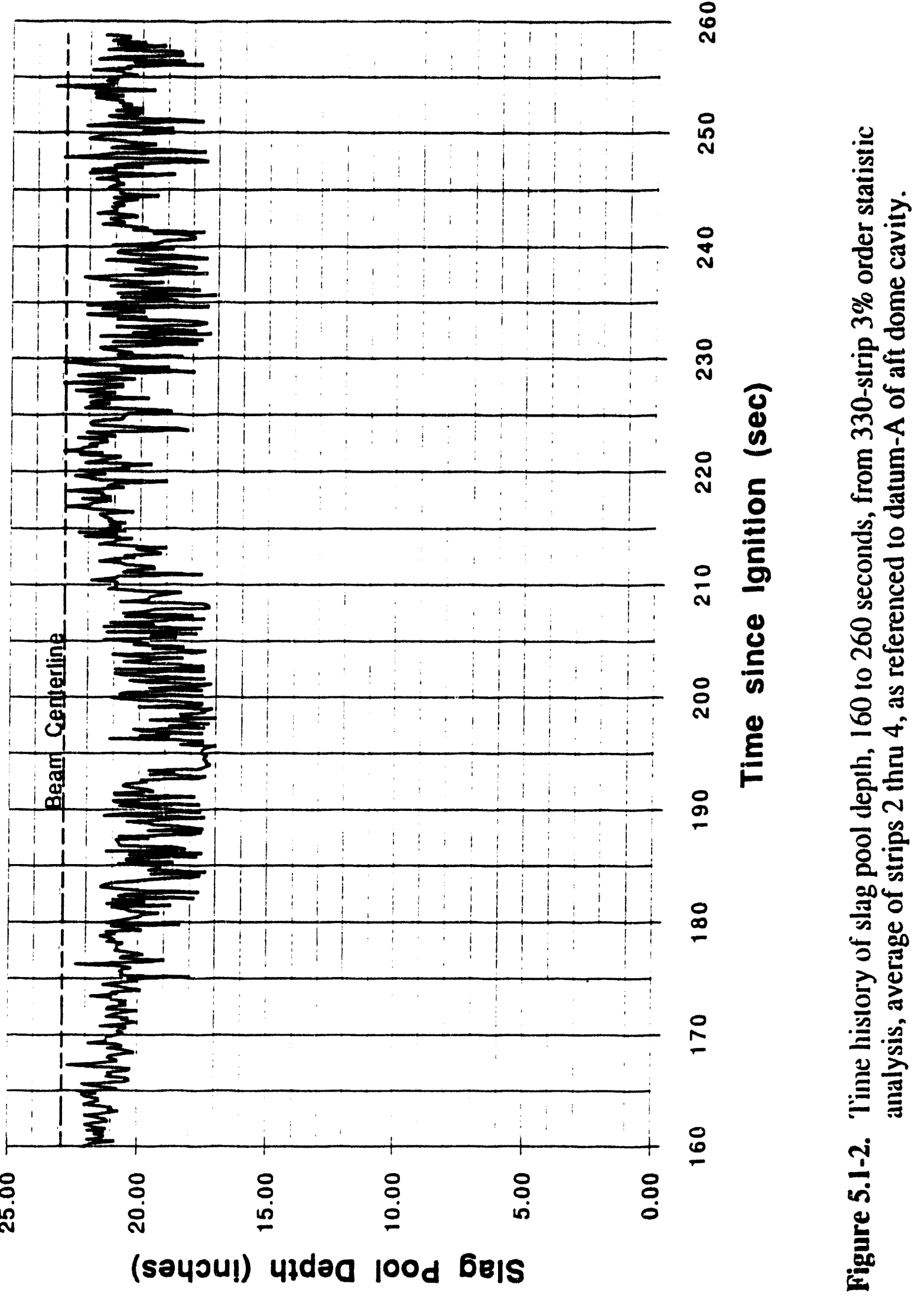




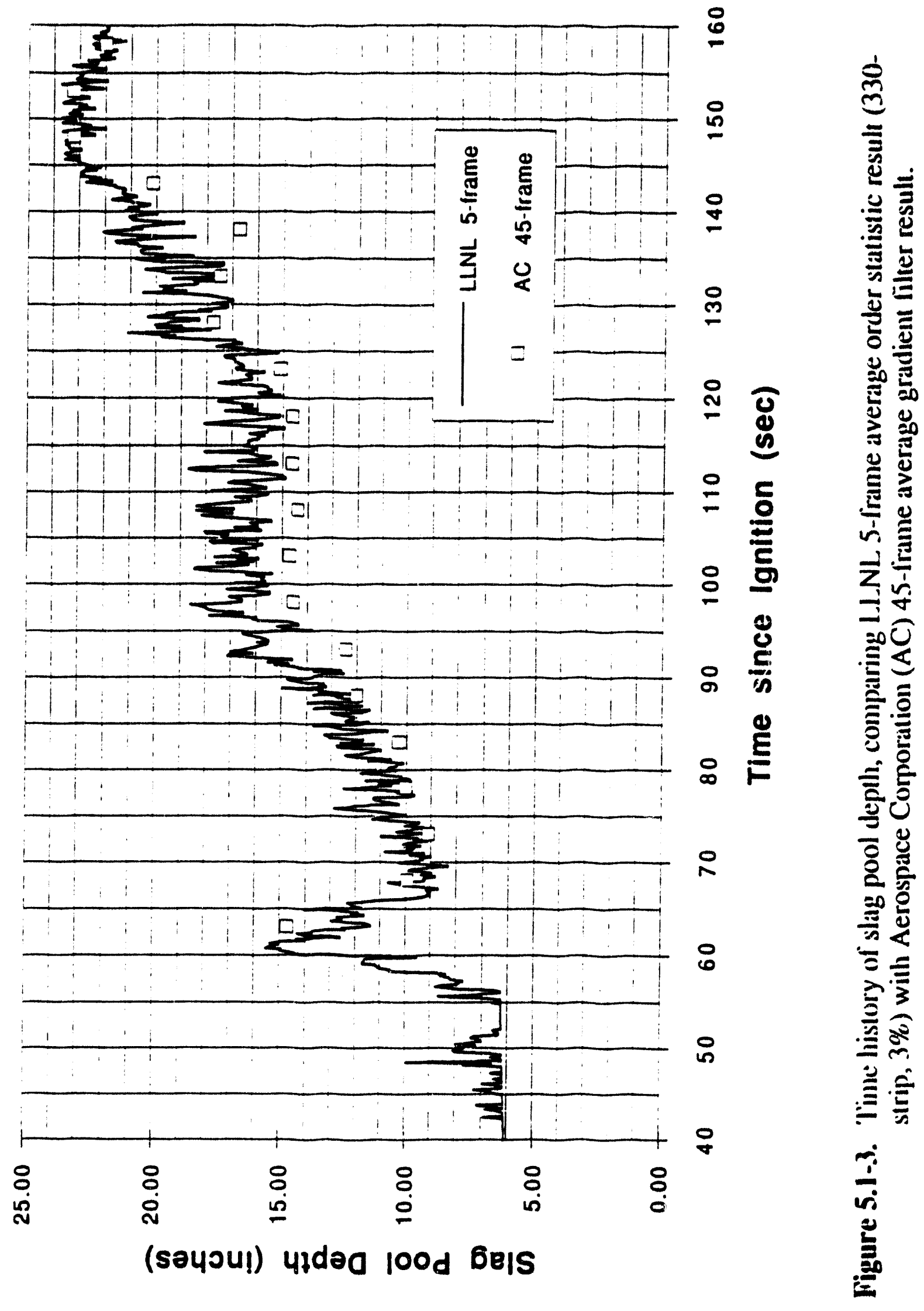


(sә2,6әр) puemuоo $ว \wedge \perp$

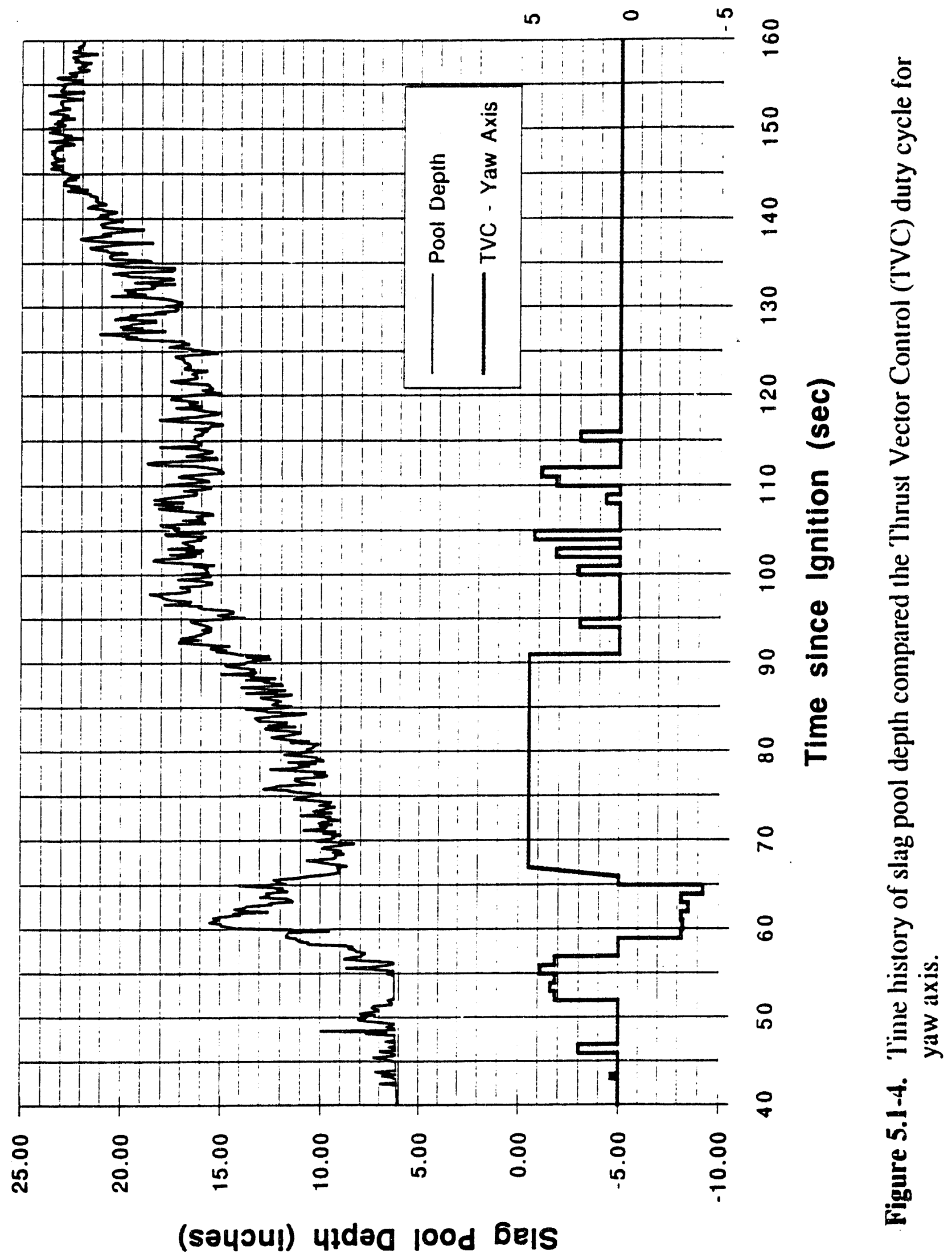




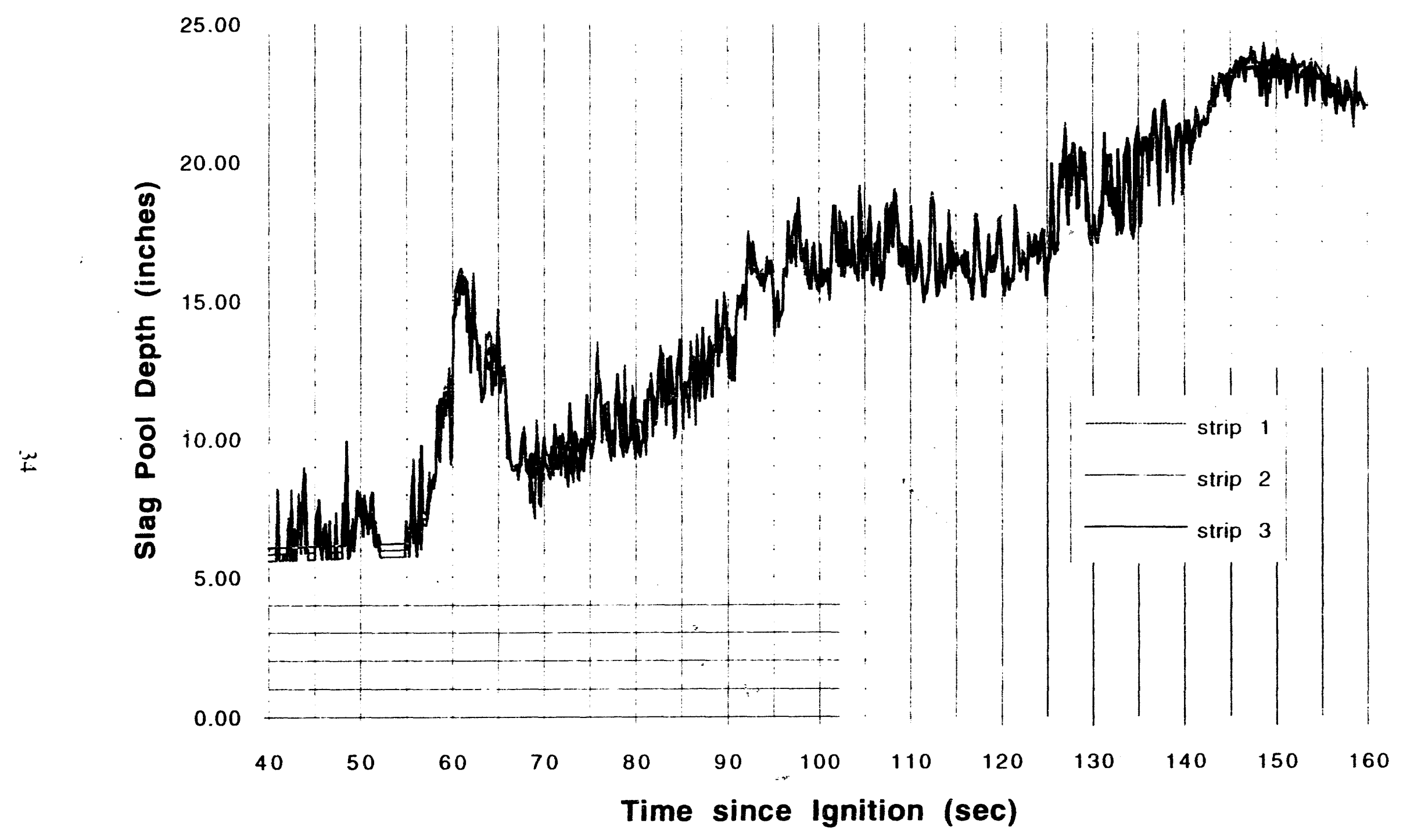

Figure 5.2-1. Time history of slag pool depth for strips 1 thru 3 from 330-strip 3\% order statistic analysis. 


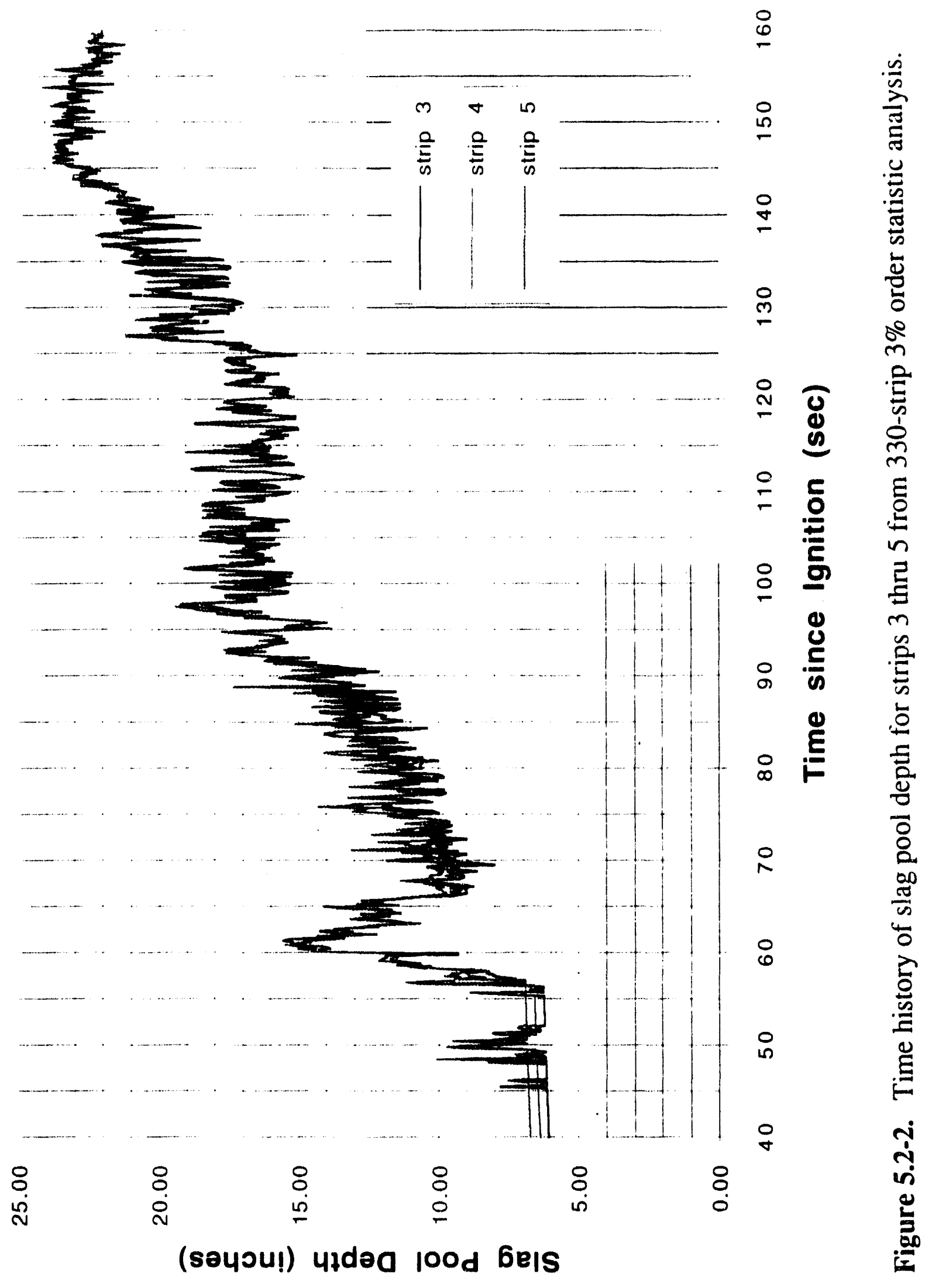




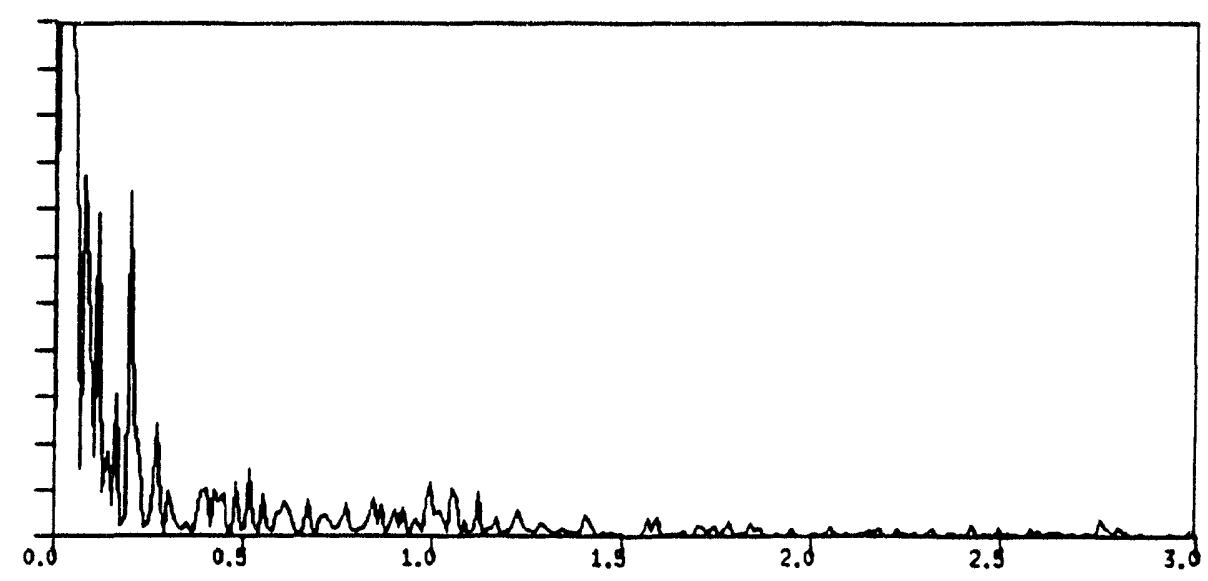

strip

no. 1

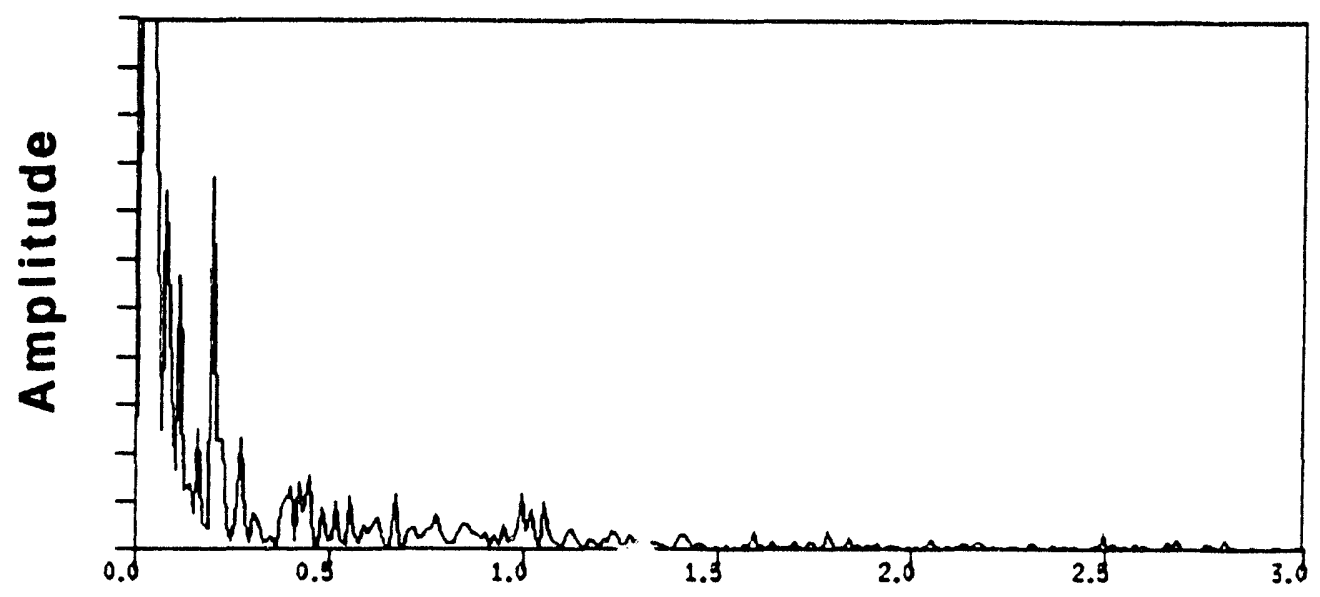

strip

no. 2

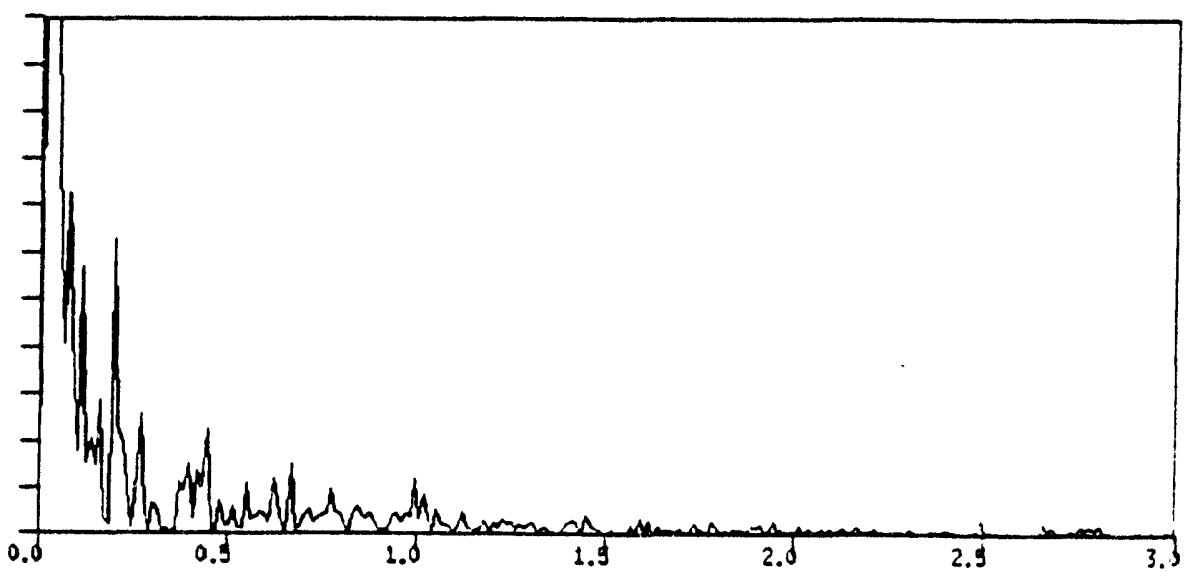

strip

no. 3

Cycles/Second

Figure 5.2-3. Amplitude spectrum from Fourier analysis of strips 1,2 , and 3 for the time period 80 to 140 seconds. 


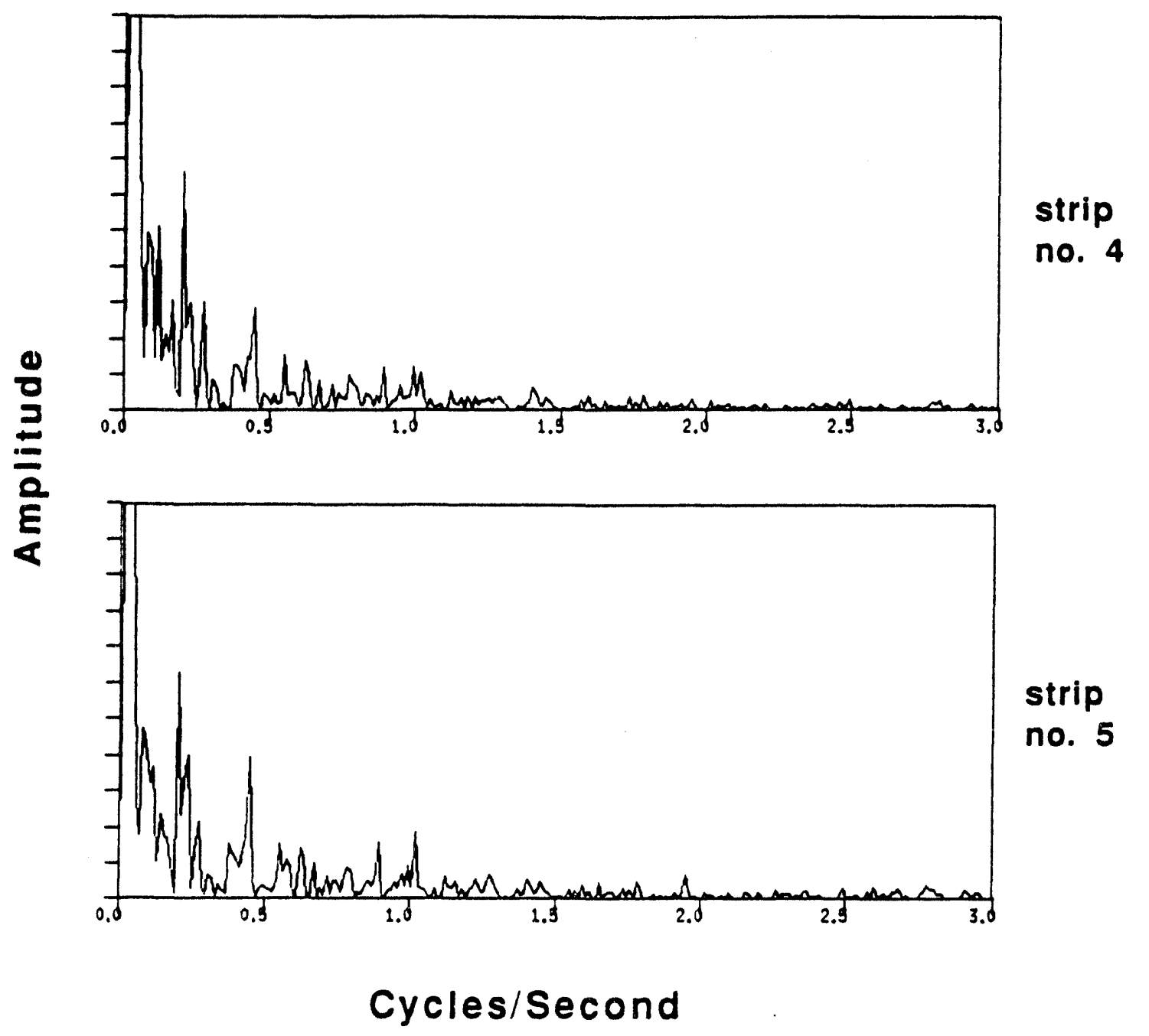

Figure 5.2-4. Amplitude spectrum from Fourier analysis of strips 4 and 5 for the time period 80 to 140 seconds. 

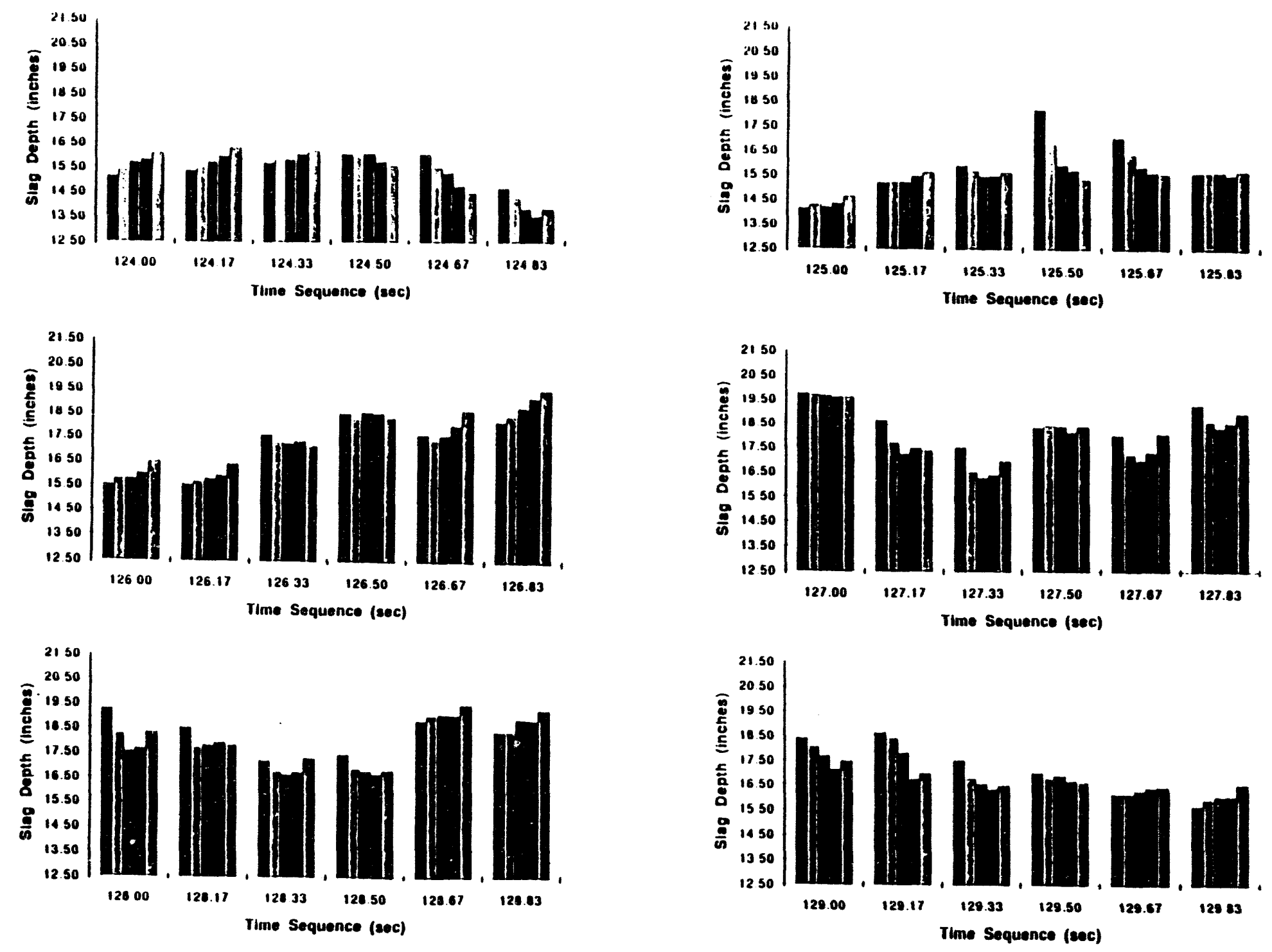

Figure 5.2-5. Barr chart time sequence of slag pool depth for strips 1 thru 5 (left to right in each chart), indicating slosh and wave modes, from $T+124$ to $T+130$ at $1 / 6$ second intervals. 

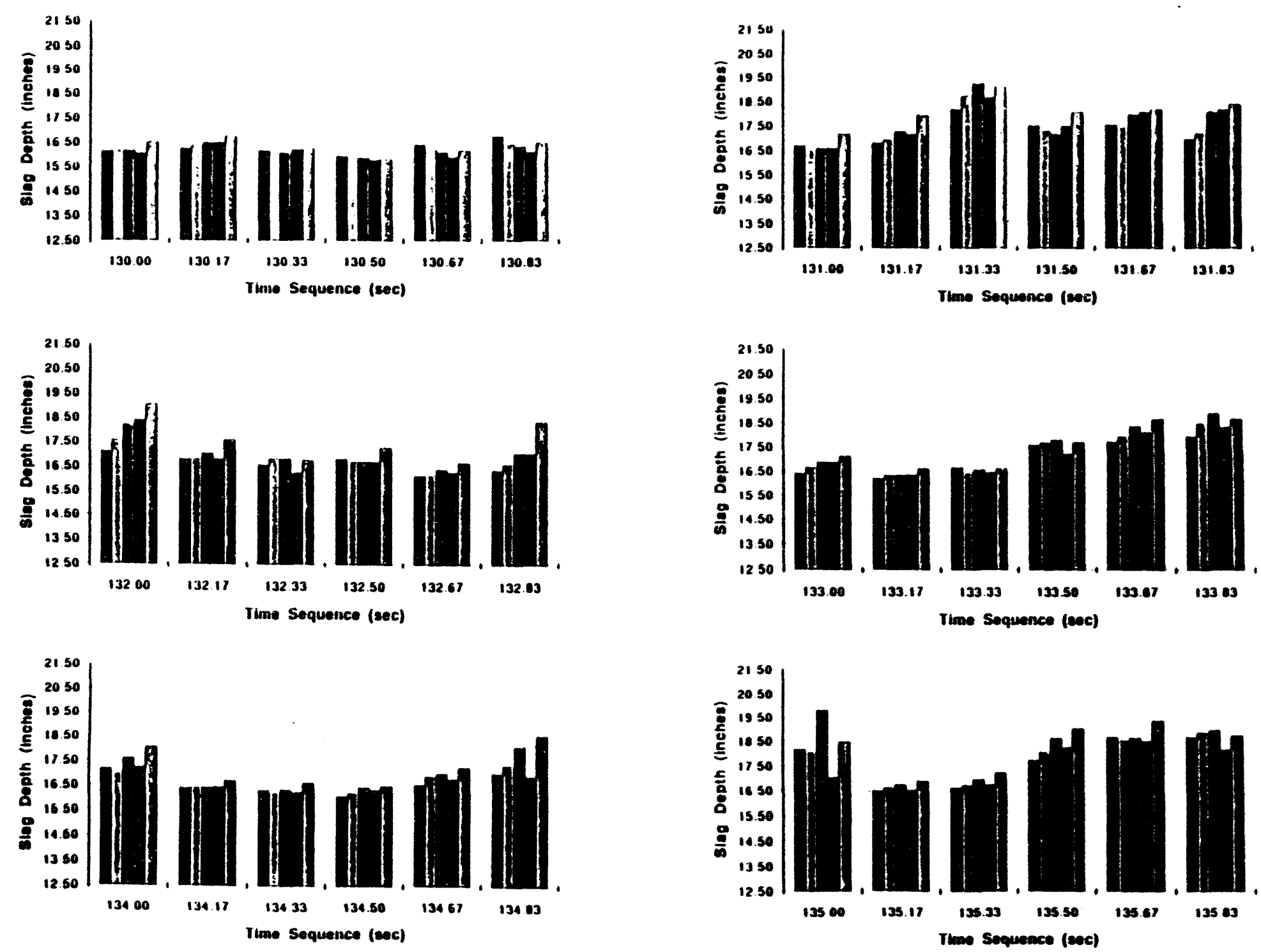

Figure 5.2-6. Bar chart lime sequence of slag pool depth for strips 1 thru 5 (left to right in each chan), indicating slosh and wave modes, from $T+130$ to $T+136$ at $1 / 6$ second intervals. 

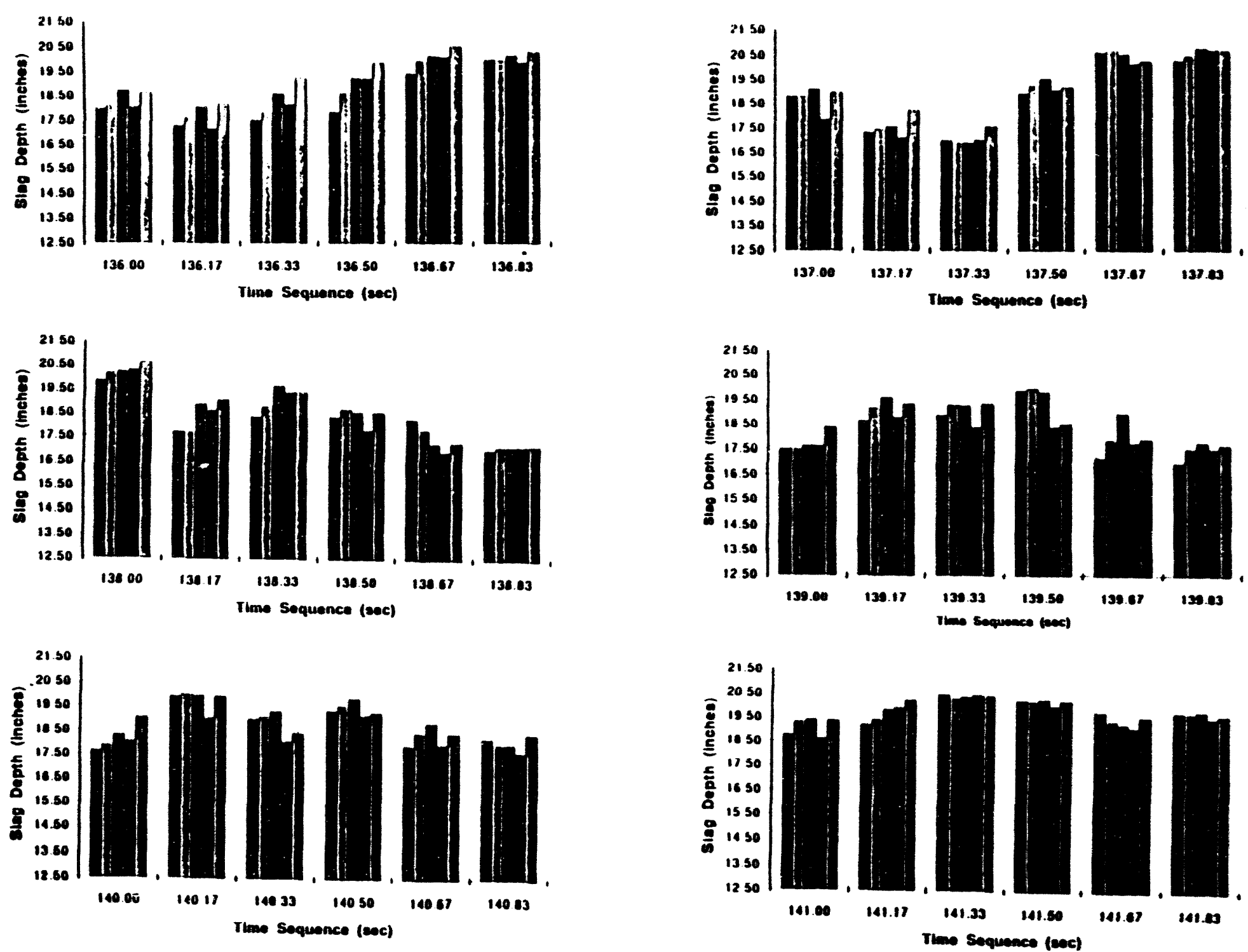

Figure 5.2-7. Bar chant lime sequence of slag pool depth for strips 1 thru 5 (left to right in each chart), indicalling slosh and wave modes, from $\mathrm{T}+136$ to $\mathrm{T}+142$ at $1 / 6$ second intervals. 
를

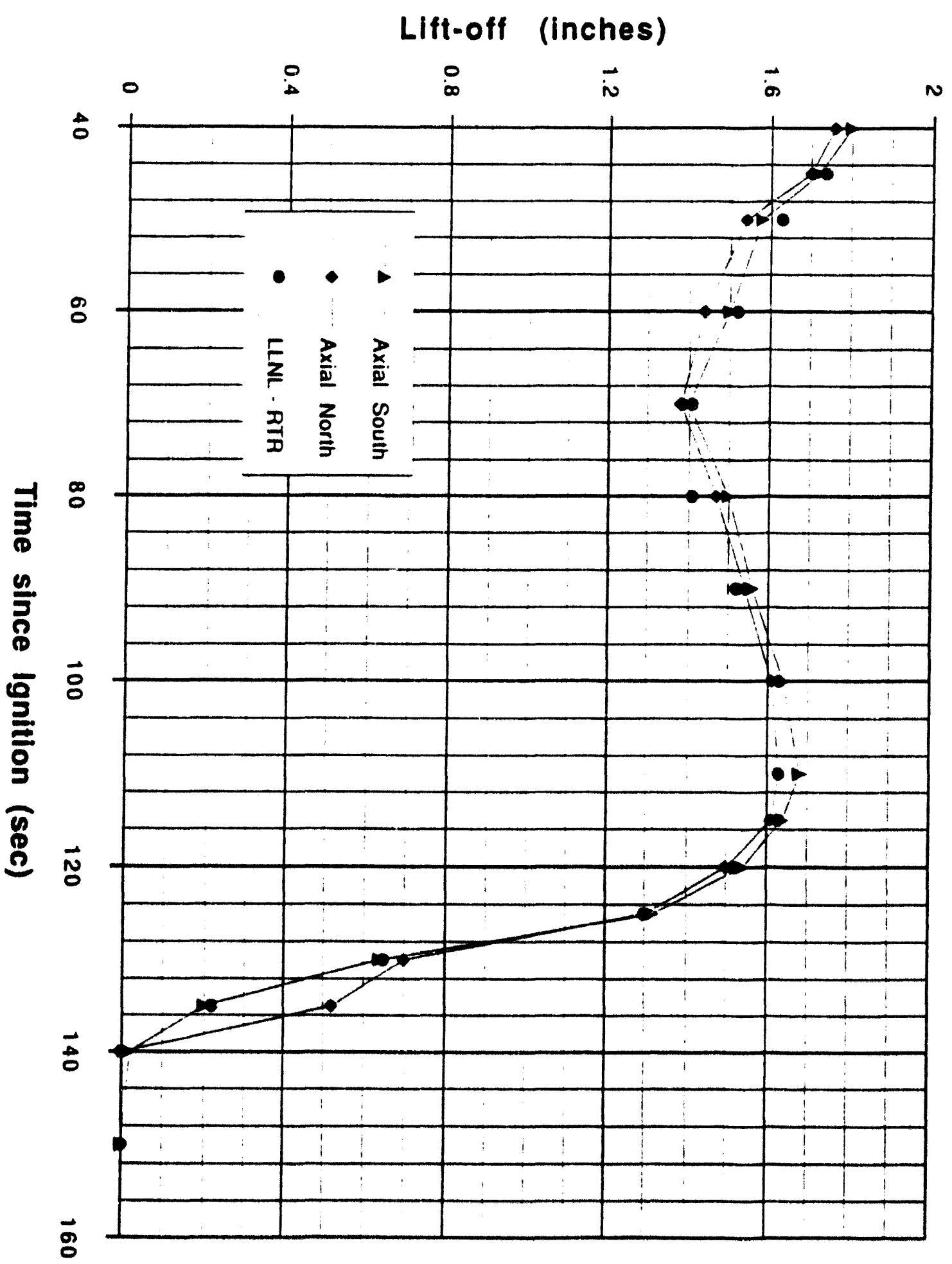

4 

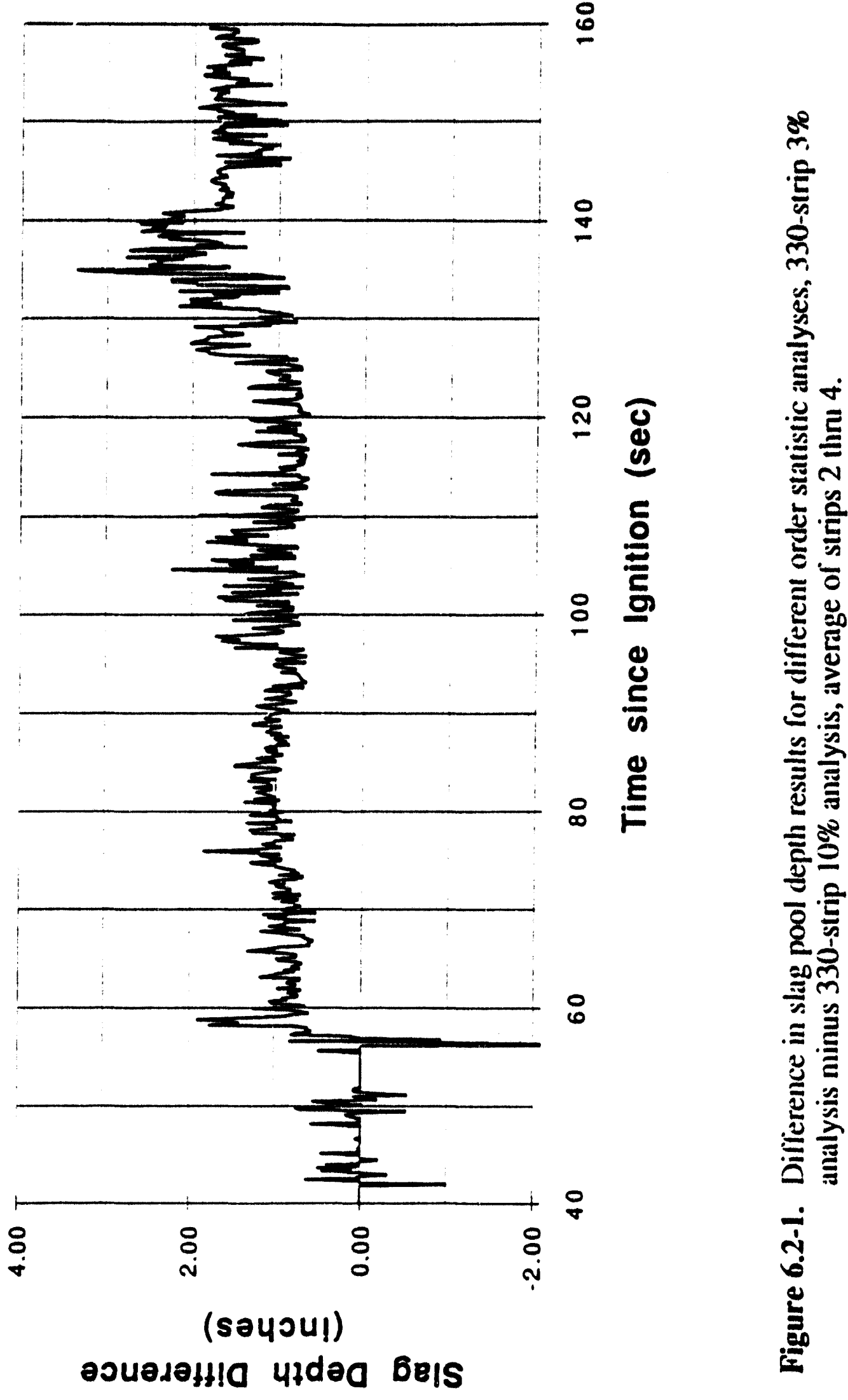

ํ. 


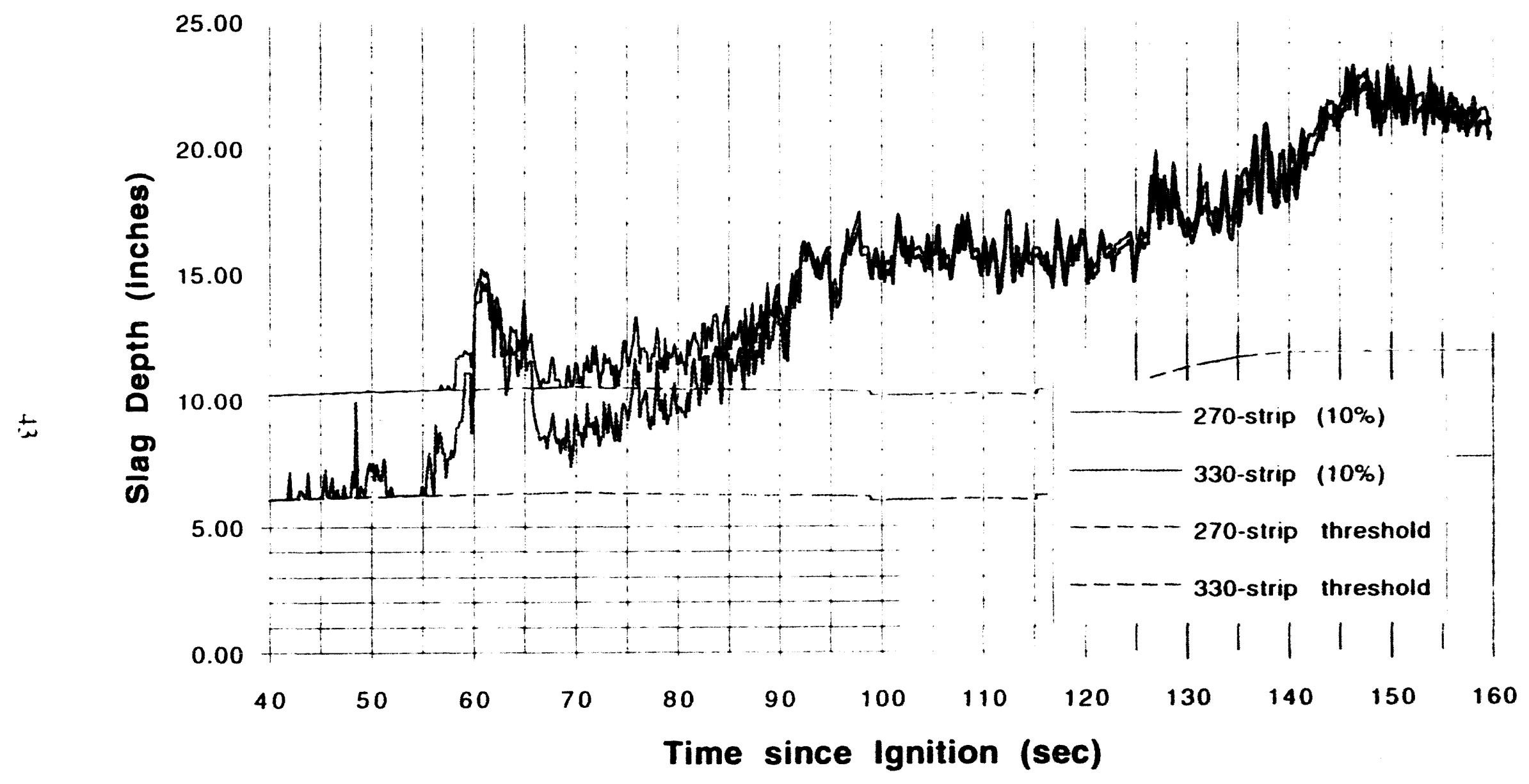

Figure 6.2-2. Comparison of slag pool depth results for different strip length analyses, 270-strip and 330strip $10 \%$ order statistic analysis. 


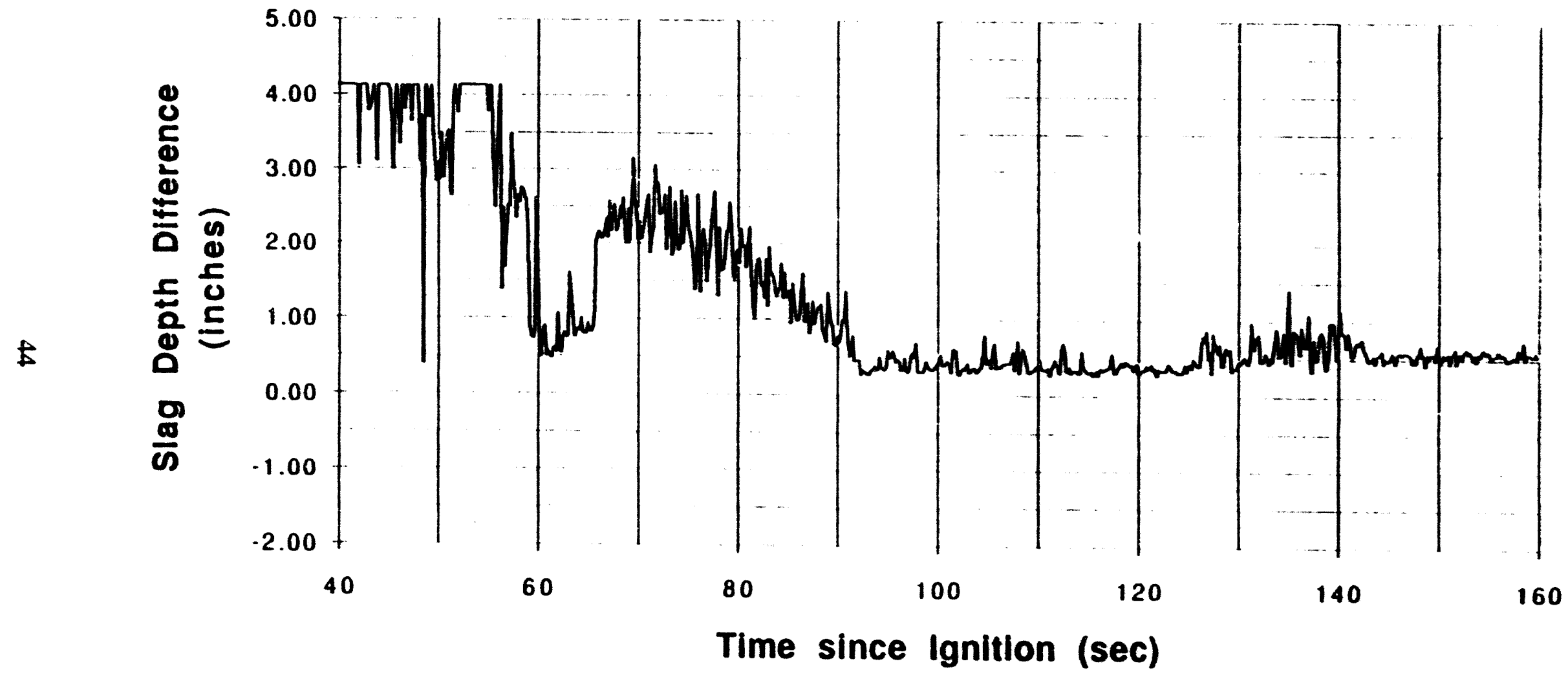

Figure 6.2-3. Dilference in slag pool depth results for different strip lengths, 270-strip 10\% analysis minus 330-strip 10\% analysis, average of strips 2 thru 4. 


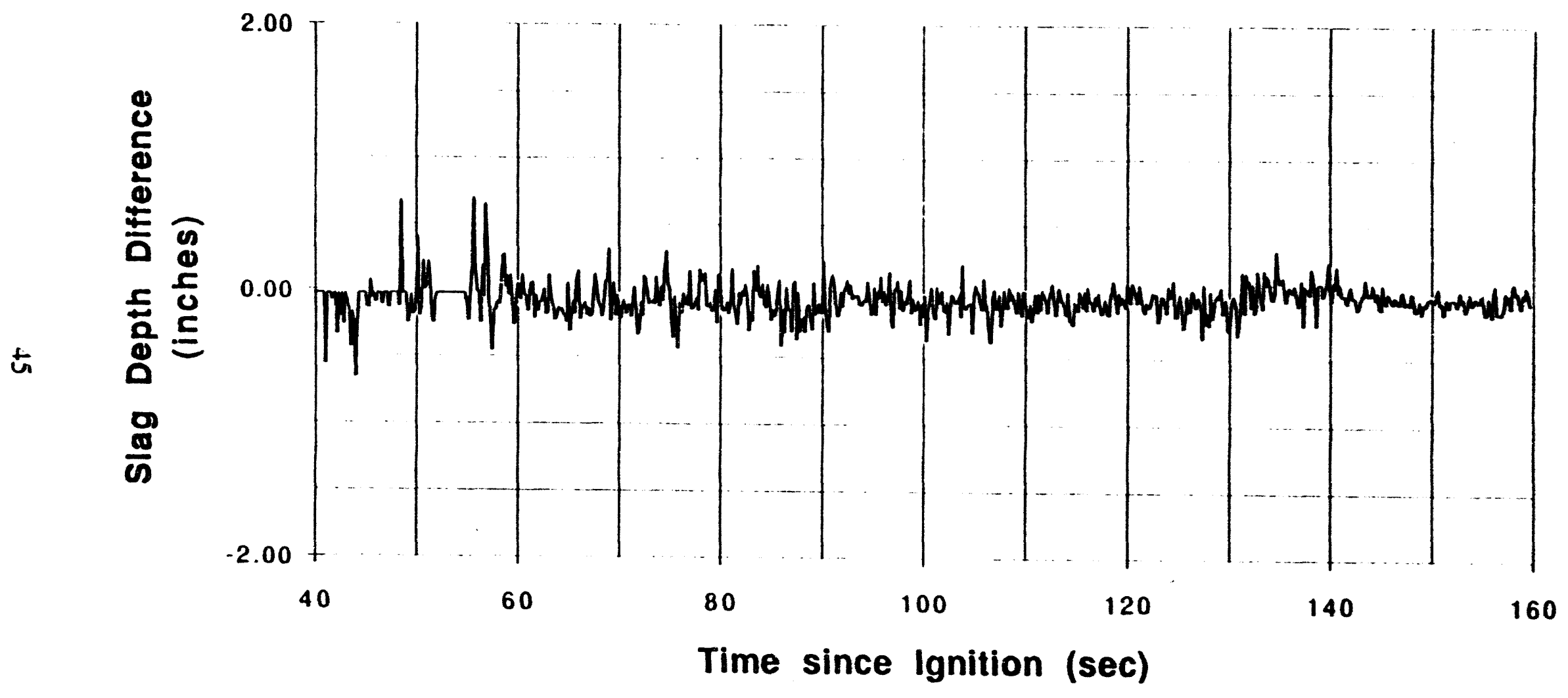

Figure 6.2-4. Difference in slag pool depth results for different strip averages, average of strips 2 thru 4 minus average of strips 1 thru 5 , for 330 -strip length $3 \%$ order statistic analysis. 


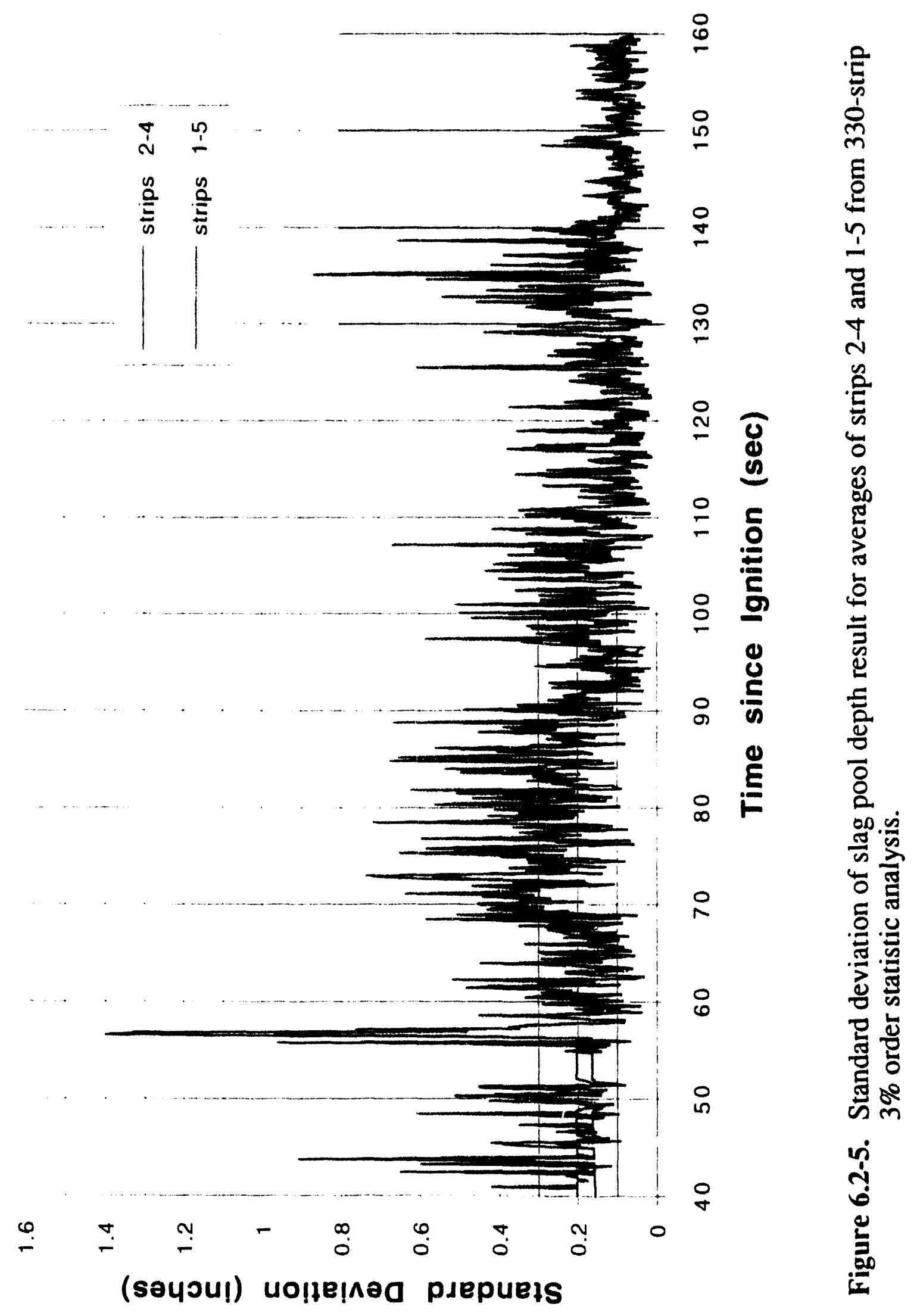


$2.50-$
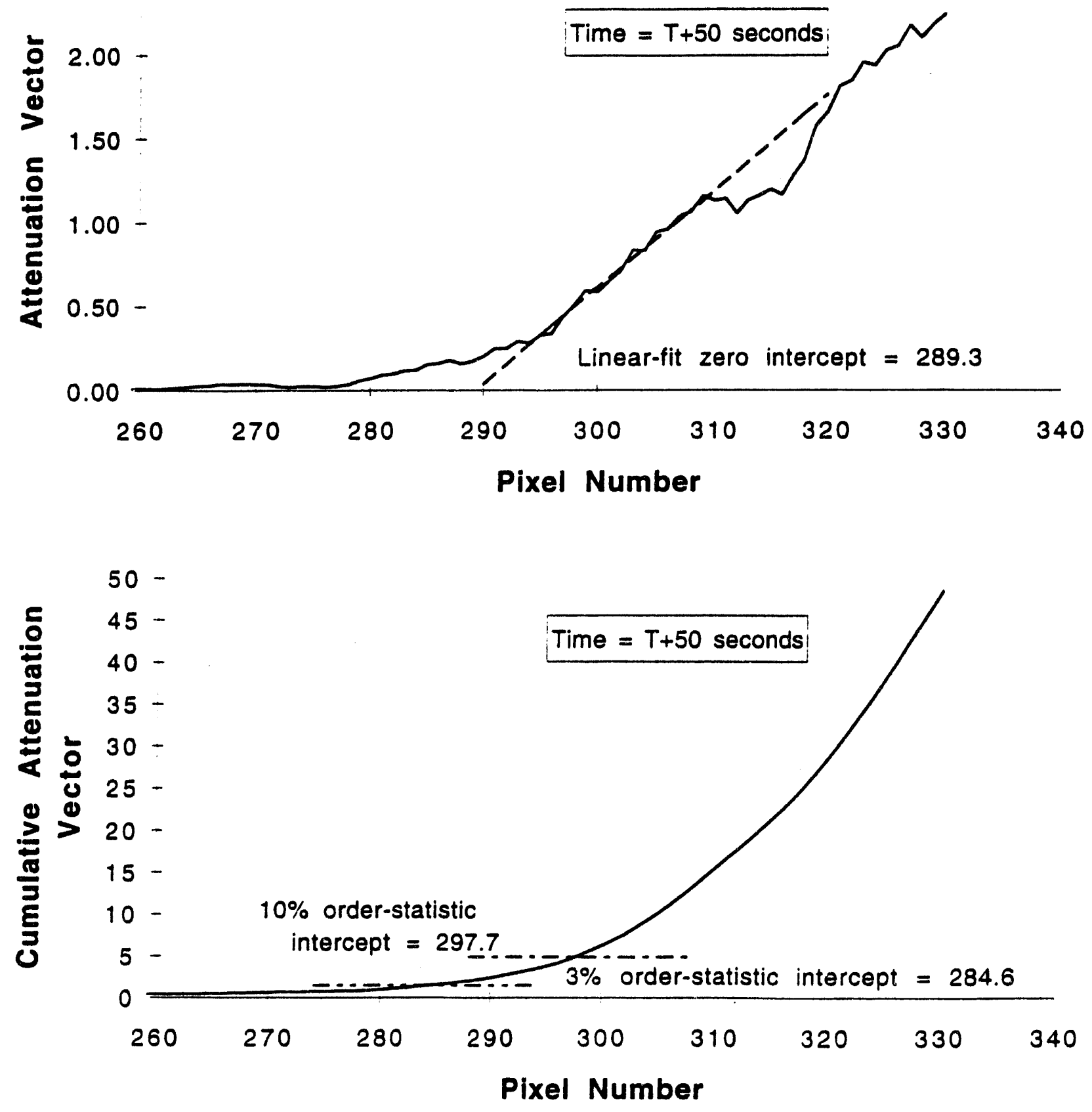

Figure 6.2-6. Attenuation vector (top) and cumulative attenuation vector (bottom) vs. pixel number from average of strips 2 thru 4 at $T+50$ seconds indicating pool level results for zero intercept, $3 \%$ and $10 \%$ order statistic. 

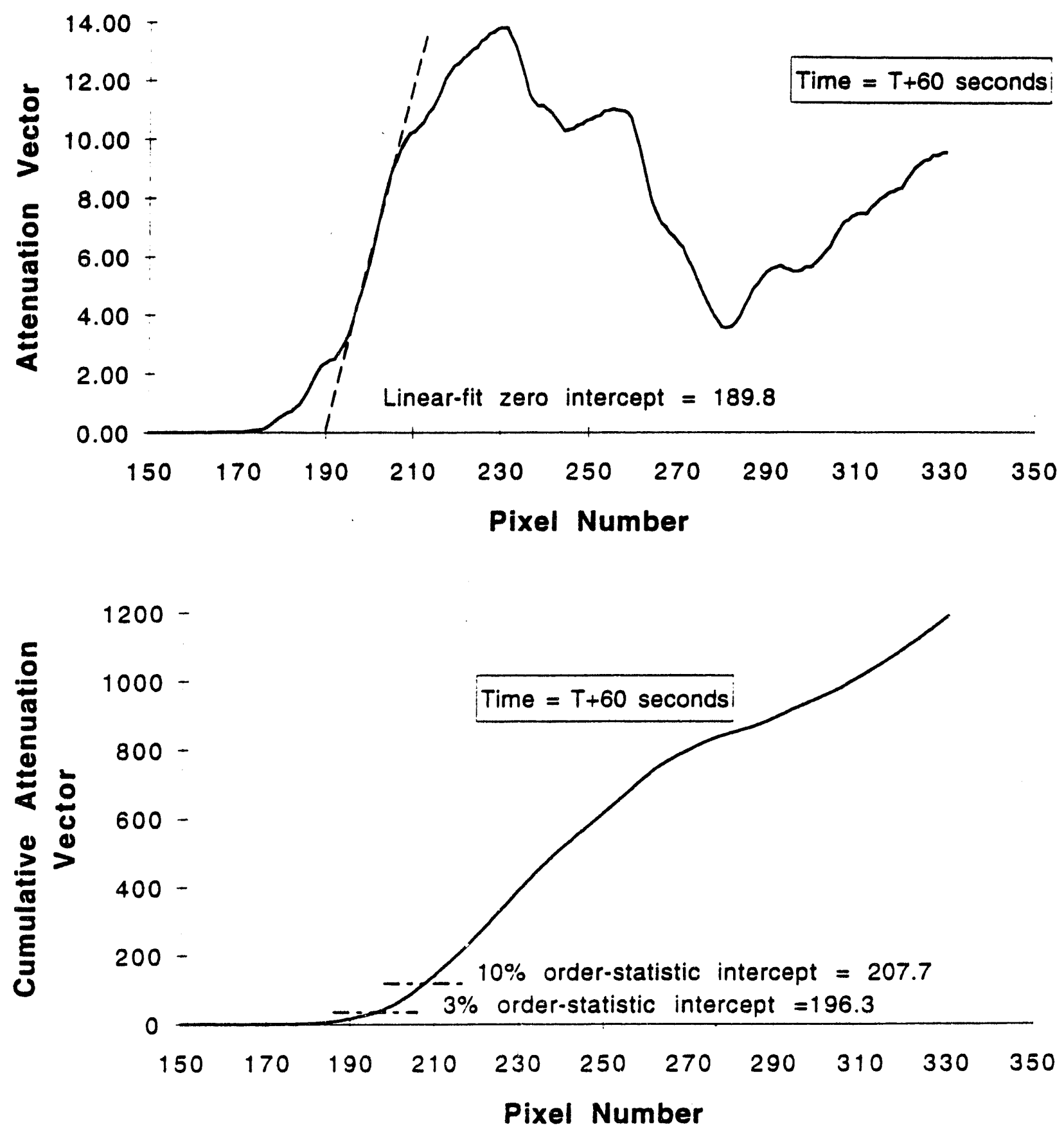

Figure 6.2-7. Attenuation vector (top) and cumulative attenuation vector (bottom) vs. pixel number from average of strips 2 thru 4 at T+60 seconds indicating pool level results for zero intercept, $3 \%$ and $10 \%$ order statistic. 
12.00
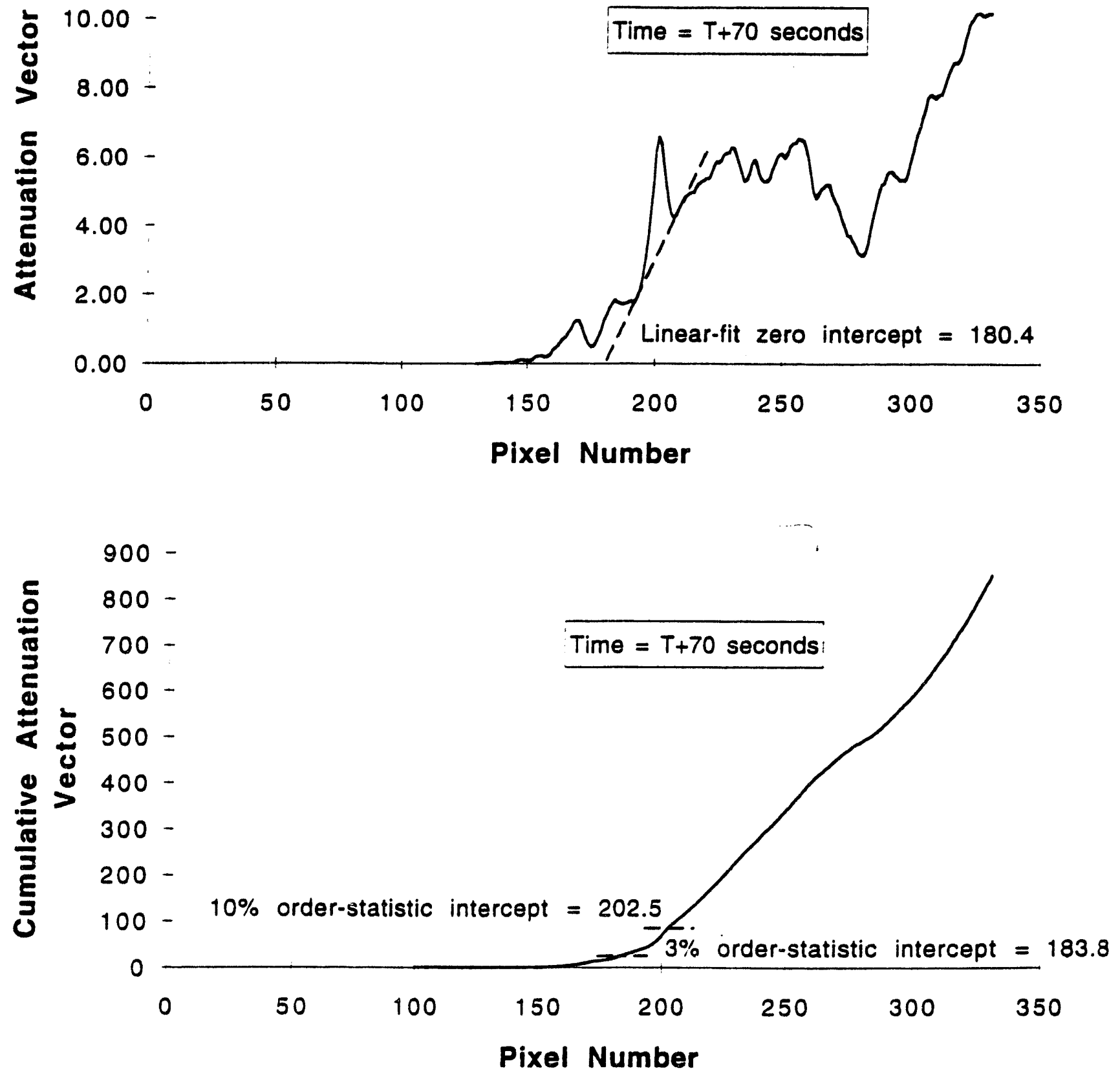

Figure 6.2-8. Attenuation vector (top) and cumulative attenuation vector (bottom) vs. pixel number from average of strips 2 thru 4 at $T+70$ seconds indicating pool level results for zero intercept, $3 \%$ and $10 \%$ order statistic. 


\section{APPENDIX A1: PROCEDURES FOR PROCESSING DATA}

There are two distinct operations in our processing procedures: i) using different images in the total sequence real-time data to calculate the attenuation image, and ii) analyzing the attenuation image to obtain measures of pool level, total mass in the field of view, and accumulated mass. The analysis of pool level, total mass, etc., depends upon a sound calculation of the attenuation image, and we discuss this operation first.

\section{I - Calculating the Attenuation Image}

Our approach follows standard radiometric procedures when applied to real-time radiographic data - follow the imaging chain back to the interaction between the penetrating radiation and the object to uncover properties of the object field. We seek information concerning just some, not all, of the object space imaged by the $\mathrm{x}$-ray beam. Also, our data acquisition hardware was chosen because of its ability to dynamically track the changing events in the rocket motor, but this can become an obstacle to the analysis. Our procedures attempt to perform two tasks; i) account for the changing disposition of the data collection hardware, and ii) isolate the attenuation due to the part of the object space of interest, (the slag pool).

In this detection system, three processes constitute the imaging chain which results in a measurement of the $x$-ray fluence at some pixel location on the detected image; i) the process of the interaction of the penetrating radiation and the object space which generates a transmission image, ii) the process whereby the transmission fluence is converted into visible light (the scintillation process), iii) the process of recording the visible light image with an intensified-CCD camera. Although our procedures will be applied to the data in the reverse order of the imaging chain, we will describe a few rudiments of these processes in the order mentioned above.

Denote the fluence centered at a point $d$ on the scintillator screen as $N(d)$, where we describe $\mathbf{N}(\mathbf{d})$ as follows:

$$
\mathrm{N}(\mathbf{d})=\int \mathrm{N}_{\mathrm{T}}(E, \mathbf{d}) \mathrm{d} E
$$

Although we will not discuss the composition of $\mathrm{N}_{\mathrm{T}}(E, \mathbf{d})$ in detail, there are three major components to $\mathrm{N}_{\mathrm{T}}\left(E\right.$, d); i) $\mathrm{N}_{\mathrm{P}}$, the 'primary' $\mathrm{x}$-rays, ii) $\mathrm{N}_{\text {SO }}$, scattered $\mathrm{x}$-rays emanating from the object of interest, and iii) $\mathrm{N}_{\text {SB }}$ background scattered $\mathrm{x}$-rays which arise from scatter events outside the section of object space we are interested in. While it is true that the trajectories of these three types of fluence are quite different, to a first order we represent the transmission image as following the trajectory of the primary beam:

$$
\int \mathrm{N}_{\mathrm{T}}(E, \mathbf{d}) \mathrm{d} E=\int \mathrm{N}_{\mathrm{T} 0}(E, \mathrm{~d}) \exp \left(-\int \mu(E, Z, r, \mathbf{v}) \delta\left(\left(\mathbf{s}+\mathrm{l}_{\mathrm{d}} \mathbf{u}_{\mathrm{d}}\right)-\mathbf{v}\right) d \mathbf{v}\right) \mathrm{d} E
$$

where the equation for the ray path is $\mathbf{s}+l_{d} \mathbf{u}_{d}$, where $\mathbf{s}$ is the position of the source relative to the object rotation, $l_{d}$ the distance from source to detector, $\mathbf{u}_{\mathrm{d}}$ the direction cosines of the path between source and detector, and $\int \mu(E, Z, r, v)$ denotes the object function, the values of the function being the linear attenuation coefficient averaged over the energy spectrum.

It is the goal of these procedures to say as much as possible about the object function, which in radiography is projected onto the detector plane. If a measurement of $\mathrm{N}_{\mathrm{TO}}(E, \mathrm{~d})$ can be obtained, a background subtraction in the log scale can be performed to obtain the transmission image, and then the attenuation image, as follows: 


$$
\begin{aligned}
& \int \mathrm{T}_{\mathrm{P}}(E, \mathrm{~d}) \mathrm{d} E=\left(\int \mathrm{N}_{\mathrm{T}}(E, \mathbf{d}) / \int \mathrm{N}_{\mathrm{T} 0}(E, \mathrm{~d})\right) \\
& \left.\quad=\exp \left(-\int \mu(E, Z, r, \mathbf{v}) \delta\left(\mathbf{s}+l_{\mathrm{d}} \mathbf{u}_{\mathrm{d}}\right)-\mathbf{v}\right) d \mathbf{v}\right) \mathrm{d} E \\
& \int \mathrm{A}_{\mathrm{P}}(E, \mathbf{d}) \mathrm{d} E=-\ln \left(\mathrm{T}_{\mathrm{P}}(E, \mathbf{d})=\int \mu(E, Z, r, \mathbf{v}) \delta\left(\left(\mathbf{s}+l_{\mathrm{d}} \mathbf{u}_{\mathrm{d}}\right)-\mathbf{v}\right) d \mathbf{v} \mathrm{d} E\right.
\end{aligned}
$$

For radiographic analysis, the attenuation image is much closer to the object function than the raw recorded image. Changes in pixel value (attenuation) reflect changes in the object function, as integrated down a particular trajectory of the $\mathrm{x}$-ray beam. The linear attenuation coefficient is the product of the chemical formula and the density, and these two components must be accounted for in analyzing the image.

The operation of the scintillator generates a brightness where the number of visible light photons is proportional to the $\mathrm{x}$-ray fluence. Representing the visible light photons as $\mathrm{NV}(\mathrm{d})$, and the scintillation operation as SC, then:

$$
\mathrm{NV}(\mathbf{d})=\operatorname{SC}\left(\int_{\mathrm{N}_{\mathrm{T}}}(E, \mathrm{~d}) \mathrm{d} E\right)
$$

The scintillation function is also a function of energy, different energy photons will result in differing amounts of visible light. We will look past this aspect for the purposes of this analysis.

Imaging of the visible fluence is performed with an intensified-CCD camera with antiblocming and automatic gain control. The net result of this hardware is a sensor which adjusts dynamically to the light level presenting itself at the back of the scintillator. There are two sets of dynamic adjustments, first, the image intensifier gain, which makes the most of the available light in focus for the camera. Second, the gain, and offset in the CCD camera, which is considered to be less of a factor than the image intensifier operation. Representing these operations as functions $\mathrm{II}_{t}$, and $\mathrm{CS}_{\mathrm{t}}$ (where the subscript $\mathrm{t}$ has been added to reflect and image acquired at a certain data acquisition speed) the recorded digital number in a single pixel can be represented as,

$$
\operatorname{DRN}(\mathbf{d})=\operatorname{CS}_{\mathrm{t}}\left(\Pi_{\mathrm{t}}\left(\operatorname{SC}\left(\int_{\mathrm{N}_{\mathrm{T}}}(E, \mathbf{d}) \mathrm{d} E\right)\right)\right)
$$

In order to measure the operation of $\mathrm{CS}_{\mathrm{t}}, \mathrm{II}_{\mathrm{t}}$ some measurement of the camera signal must be made which isolates the operation of the intensifier and camera read out.

Information concerning the object is best evaluated from the attenuation image, but in order to obtain this data a background correction must be performed. As is true in many situations outside the laboratory, a 'true' background image could not be acquired in the dynamic sequence of events being imaged. Attempting this type of analysis requires that a nominal 'background' image be selected from the sequence of images acquired. The difficulty with this approach is the dynamics of the camera response, which adjusts to each light level for each acquired frame.

The radiographic images contain data on a number of important structural elements of the rocket motor, but in this analysis the interest is focused on that part of the object occupied by the slag pool. With this interest, a number of different regions of the image can be utilized to measure the response of the camera. Figure Al-1 shows the two regions which are candidates for performing the scaling operation between the background image and the particular image to be converted. In both of these regions the intensifier gain and camera response are emphasized due to a lack of primary radiation, or in the case of region \#1, the camera was not viewing the scintillator material. Comparing 
different images for these two regions will provide some measure of the difference in the operation of the intensifier and camera.

We applied regression and simple ratio or log difference techniques to calculate scaling factors for both regions and determined that regression techniques applied to region \#2 was the most precise for the time period between 100 and 150 seconds. We used different frames for the background image throughout the experiment, each background frame averaged for 5 single frames. For data up to $53 \mathrm{sec}$, we used the 5-frame average of the image at 45 seconds as background. For the data between 55 and 70 we used the image at 54 seconds. For all the data after 70 seconds we used the image at 69 seconds. Using these images as background, and the linear regression techniques, we transformed all of the 5-frame averaged data into attenuation units as indicated in equation (4).

\section{Calculating pool level. mass in field of view, and other statistics}

All of these quantities are calculated from the attenuation image. In each case we assume the pixels in the attenuation image have the significance in equation (4) - the ray sum through the material with the background image subtracted. We have chosen our background to emphasize the identification of pool mass in field of view, and pool level. The measurement of pool level or pool mass can be performed directly on the attenuation since the pixels are in the units of the linear attenuation coefficient.

Pool level is measured at 5 different positions across the horizontal axis of the real time image. In pixel numbers a 30 by 330 strip at locations $(240,75),(270,75),(300,75)$, $(330,75)$, and $(360,75)$. Each of these 30 by 330 strips is summed into a vector, and that vector is integrated down the height of the image, from top (no pool) to bottom (where the pool should be). This procedure was repeated for strips 270 pixels long which does not provide pool level for early times, less than 55 seconds, because the pool level is too low, but provided a comparison on this method for later times. To provide an analysis that could be automated and that could eventually lead to a determination of density from the intrinsic data, and one that is different from gradient filter processing already used by others, our determination of "in the pool' proceeds from an integration of the vector from the strips, integrating from top to bottom, and identifying the position 'in the pool' as synonymous with the 10 percent order statistic in the integration. That is, when the integration has proceeded to accumulate 10 percent of the proportional mass, ther that pixel location is taken as the determination top of the pool. Admittedly, this approach may understate the pool level by some small amount, but it was deemed useful, due to the noteworthy robustness of order statistic estimators. Figure A1-2 contains two plots for the 270 pixel length analysis; i) the 5 vectors (the summed strips) in different strips down the height of the image, and ii) the corresponding integrated vectors from these summed vectors for the identification of pool level. All of this data was calculated from the data at 100 seconds. The attenuation image at this time presented in Figure A1-3. Total pool mass in field of view is the total mass integrated for the entire strip. 


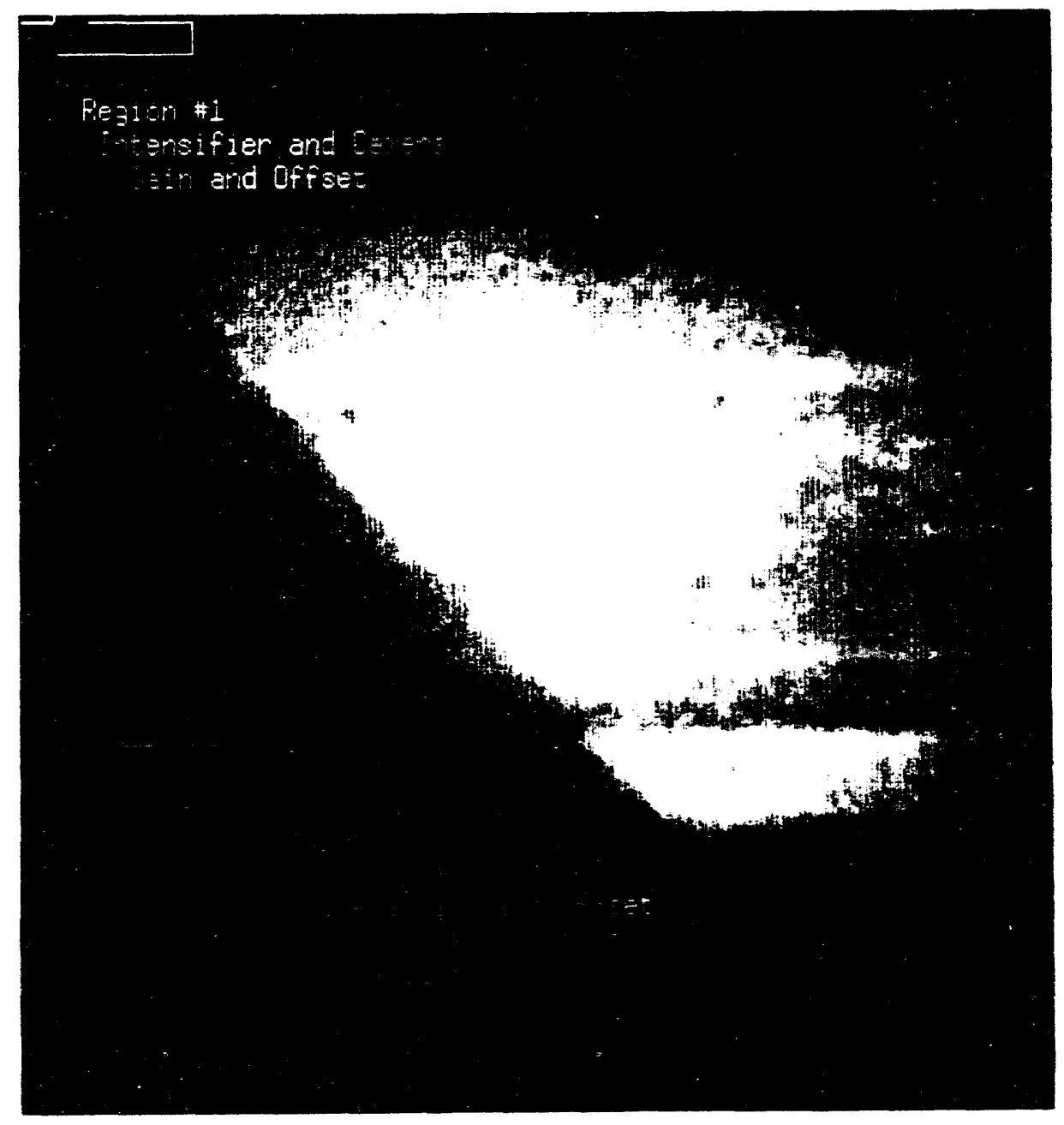

Figure A1-1. Five-frame RTR image showing two regions which are candidates for performing the scaling operation between the background image and the image to be converted. 

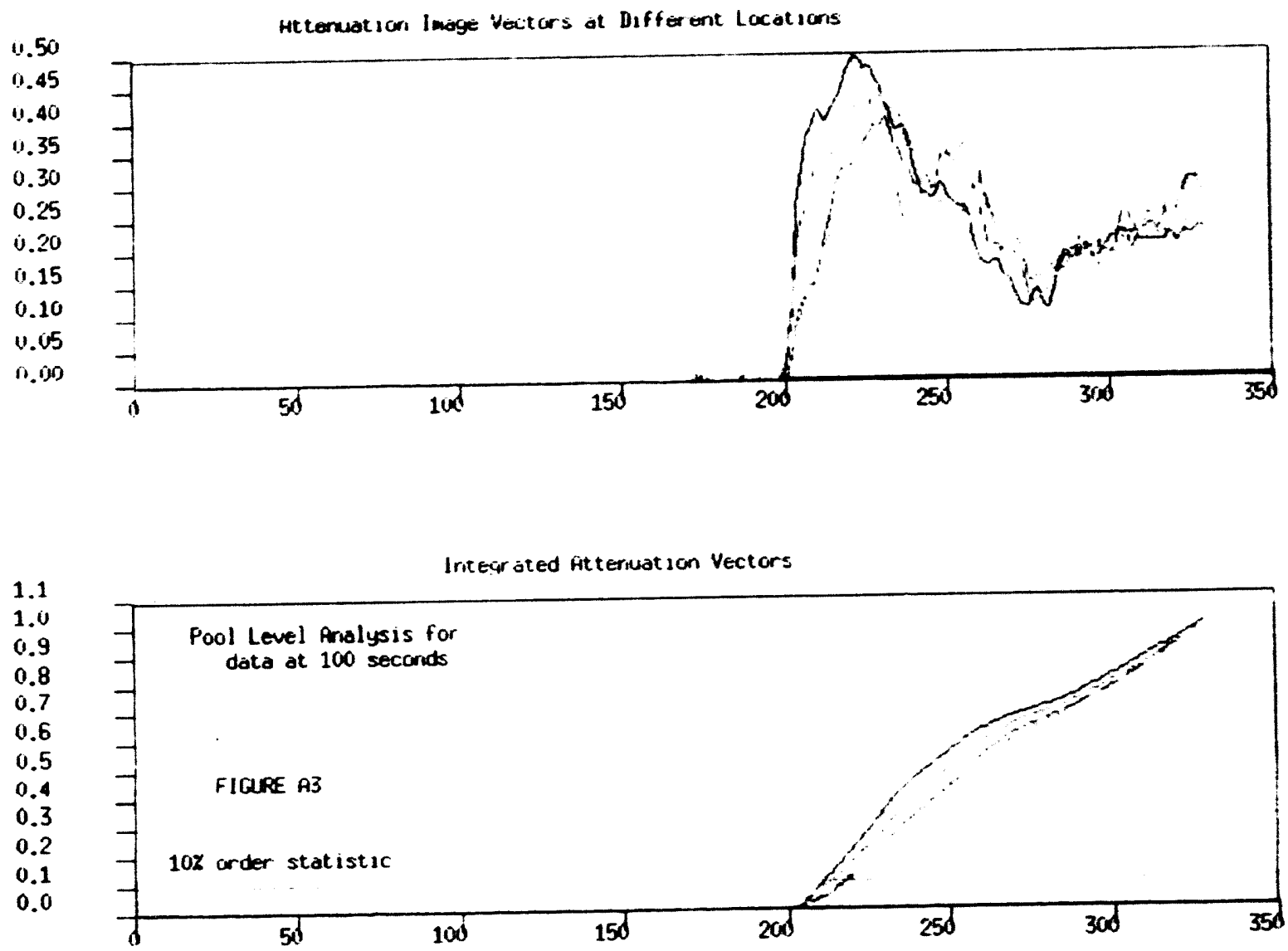

Figure A1-2. Vector plots from the 270-strip analysis: a) upper plot - attenuation vectors for different strips as a function of vertical pixel location, and b) lower plot - integrated attenuation vectors. 

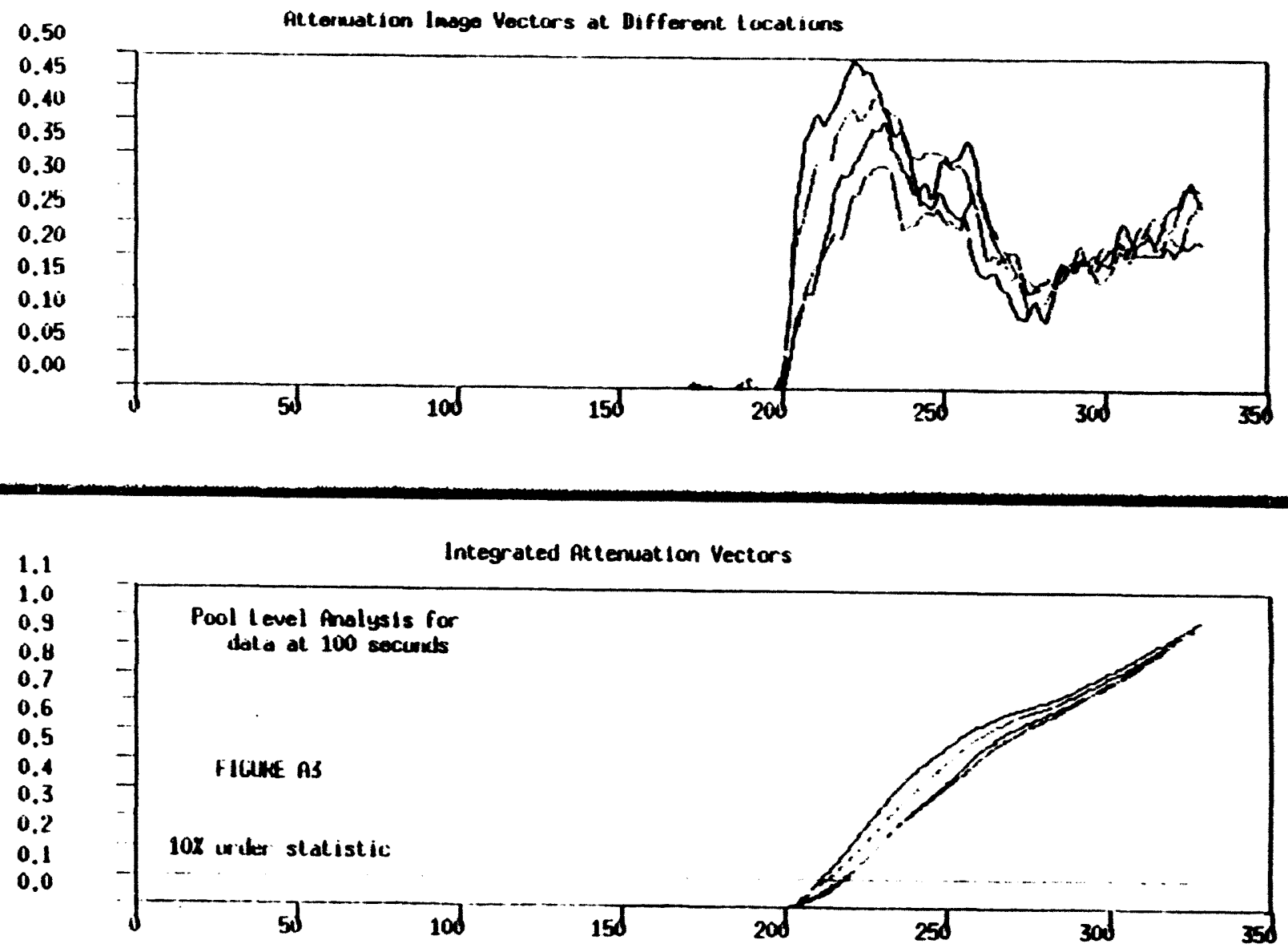

Figure A1-2. Vector plots from the 270-strip analysis: a) upper plot - attenuation vectors for different strips as at finction of vertical pixel location, and b) lower plot - integrated attenuation veclors. 


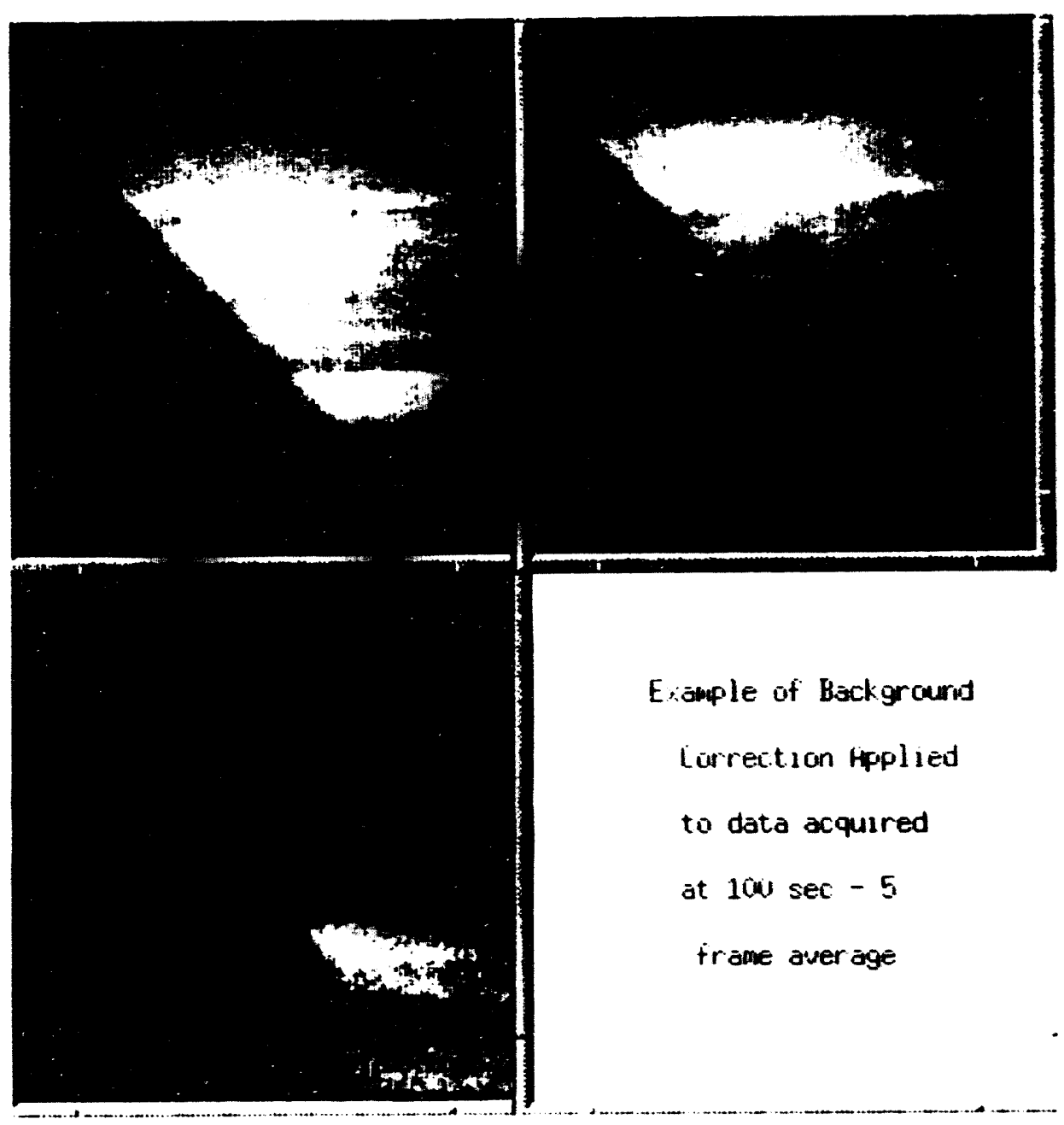

Figure A1-3. Example of background corrected image: a) upper left - background image at $69 \mathrm{sec}$ ), b) upper right - RTR image at $100 \mathrm{sec}$, c) lower left - background corrected image at $100 \mathrm{sec}$. 


\section{APPENDIX A2. GEOMETRIC CONVERSION OF SCREEN IMAGE TO POOL LEVEL}

1. Image screen consists of 9 panels each 17 inches high by 14 inches wide. Each frame is digitized, and then a portion of the frame image is extracted that includes the screen image and a minimal border around the screen image The extracted image includes the top and two vertical sides of the screen, but does not include the bottom of the screen which is cut-off in the frame image. Center of screen is located 34.6 inches from centerline of motor.

2. The pool level analysis is done using $\mathbf{5}$ strips in the digitized image. Strip length (vertical) is 330 pixels each, ranging from pixel no. 75 to 405 . Top of screen, taken at right-center seam, is pixel no. 12. Bottom of screen is not included in the image as noted above. Bottom of image, taken at right-center seam, is pixel no. 413 . Bottom of image is estimated to be 2.75 inches above bottom of screen based on screen calibration data. Pixel coordinates of fiducials are given in Table 1.

Table A2.1. Pixel numbers corresponding to screen fiducials and bottom of image.

\begin{tabular}{|l|l|l|}
\hline Location & $\begin{array}{l}(\mathrm{X}, \mathrm{Y}) \text { - Coordinates at } \\
\text { Left Center Seam }\end{array}$ & $\begin{array}{l}(\mathrm{X}, \mathrm{Y}) \text { - Coordinates at } \\
\text { Right Center Seam }\end{array}$ \\
\hline Top of Screen & 122,17 & 260,12 \\
\hline Top of Center panel & 125,152 & 264,148 \\
\hline Bottom of Center panel & 129,292 & 269,290 \\
\hline Bottom of Image & $\mathrm{xxx}, \mathrm{yyy}$ & $\mathrm{xxx}, 413$ \\
\hline Bottom of Screen & not imaged & not imaged \\
\hline
\end{tabular}

$\mathrm{X}=$ horizontal screen location

$Y=$ vertical screen location

$\mathrm{xxx}, \mathrm{yyy}=$ not resolved

Screen centroid is at vertical pixel no. 220.5 and horizontal pixel no. 196.8. From coordinate values of fiducials we note that the screen image is not in true alignment (square) with axes of digitized image. Based on fiducial values, horizontal calibration is 0.1004 inches/pixel. Vertical calibration is $0.1255 \mathrm{in} /$ pixel for top row of panels, and $0.1206 \mathrm{in} / \mathrm{pixel}$ for center row of panels. Calibration for bottom row of panels was not obtained because fiducial images that would locate bottom of screen are cut off. Based on difference of top row and center row calibrations, the calibration slope (in/pixel) is not a constant but has a linear relationship of the form: slope $=\mathrm{a} 0+\mathrm{al} * \mathrm{v}$, where $v$ is pixel no. Constants obtained for straight line fit of slope are: $a 0=0.1284$, $\mathrm{al}=-3.544 \mathrm{e}-5$. We have verified that there is no lens distortion in the image using the 60 inch optical path as was used in the RTR imager for QM2. We conclude that the top to bottom distortion in the RTR QM2 data is linear and is probably caused by a slight tilt of camera or mirror relative to the screen.

3. Strip width (horizontal) is 30 pixels for each strip. Pixel ranges for each strip and normal distances from center of each strip to both the screen centerline and $90^{\circ}$ $270^{\circ}$ plane through the motor centerline are given in Table 2. 
Table A2.2. Pixel ranges and normal distances for each of 5 strips.

\begin{tabular}{|l|l|l|l|l|l|}
\hline & strip 1 & strip 2 & strip 3 & strip 4 & strip 5 \\
\hline $\begin{array}{l}\text { horizontal range } \\
\text { (pixel nos.) }\end{array}$ & $240-269$ & $270-299$ & $300-329$ & $330-359$ & $360-389$ \\
\hline $\begin{array}{l}\text { distance from center-of- } \\
\text { screen (inches) }\end{array}$ & 5.82 & 8.84 & 11.85 & 14.86 & 17.87 \\
\hline $\begin{array}{l}\text { distance from centerline } \\
\text { of motor (inches) }\end{array}$ & 40.42 & 43.44 & 46.45 & 49.45 & 52.47 \\
\hline
\end{tabular}

4. Beam centerline was determined from superposition of near and far pins of SRMU motor case during settling of motor and end of burn. Beam centerline near center of the screen is pixel no. 227. This is approximately 0.78 inches below the center of the screen. Because the screen image is not square with the frame image, the pixel nos. corresponding to vertical position of beam centerline are slightly different for each strip. These are given in Table 3.

Table A2.3. Pixel numbers corresponding to beam centerline for each of 5 strips.

\begin{tabular}{|l|l|l|l|l|l|}
\hline & strip 1 & strip 2 & strip 3 & strip 4 & strip 5 \\
\hline $\begin{array}{l}\text { Beam Centerline } \\
\text { (pixel no.) }\end{array}$ & 225.8 & 225.1 & 224.5 & 223.8 & 223.2 \\
\hline
\end{tabular}

5. Conversion from pixel number to vertical position relative to beam centerline is accomplished with equation of slope (in/pixel) from para.1 and beam centerline position for each strip from para.2. A second order polynomial equation is fit to these values for each strip. Equation is of the form $\mathrm{z}=\mathrm{a} 0+\mathrm{a} 1^{*} \mathrm{v}+\mathrm{a} 2^{*} \mathrm{v}^{\wedge} 2$, where $\mathrm{z}$ is vertical location (inches) with respect to beam centerline and $v$ is pixel number. Coefficients from polynomial fit are given in Table 4.

Table A2.4. Coefficients for second order polynomial equation for converting pixel number to screen location relative to beam centerline.

\begin{tabular}{|c|c|c|c|}
\hline strip no. & $\mathrm{a} 0$ & $\mathrm{al}$ & $\mathrm{a} 2$ \\
\hline 1 & 28.089 & -0.1284 & $1.772 \mathrm{e}-5$ \\
\hline 2 & 27.983 & -0.1283 & $1.773 \mathrm{e}-5$ \\
\hline 3 & 27.910 & -0.1283 & $1.772 \mathrm{e}-5$ \\
\hline 4 & 27.826 & -0.1283 & $1.772 \mathrm{e}-5$ \\
\hline 5 & 27.753 & -0.1283 & $1.771 \mathrm{e}-5$ \\
\hline
\end{tabular}

6. Convert from screen position ( $w /$ beam $\mathrm{CL}$ ) to pool level:

6.a. For all pool levels below beam centerline, intersection of pool surface with inner insulator contour nearest screen is assumed to form the top-of-pool image on the screen. For this assumption to be valid, propellant burn-back front must be higher than calculated pool level. Table 5 gives intercept of propellant front with inner insulator contour from Aerospace Corp. burn-back chart (note: interpolation is used for 
times 40 and 50 seconds). Based on these values, our assumption is valid for pool depths less than 8.9 inches at 40 seconds, less than 13.4 inches at 50 seconds, and less than 19.7 inches at 60 seconds .

Table A2.5. Intercept of propellant front with inner insulator contour.

\begin{tabular}{|c|c|c|}
\hline $\begin{array}{c}\text { Time since } \\
\text { ignition }(\mathbf{s e c})\end{array}$ & $\begin{array}{c}\text { Propellant front relative } \\
\text { to insulator definition }\end{array}$ & $\begin{array}{c}\text { Propellant front relative } \\
\text { to sta0 (datum } \mathrm{A} \text { ) }\end{array}$ \\
\hline 0 & 11.125 & 0.0 \\
\hline 30 & 16.2 & 5.1 \\
\hline 40 & 20.0 & 8.9 \\
\hline 50 & 24.5 & 13.4 \\
\hline 60 & 30.8 & 19.7 \\
\hline
\end{tabular}

6.b. Inner contour insulator radii corresponding to pool depths $0,2,4, \ldots, 28$ inches are interpolated from insulator contour definition drawing. Drawing definition and interpolation values are given in Table 6.

Table A2.6. Insulator contour radii and corresponding pool depths.

\begin{tabular}{|c|c|c|c||c|c|}
\hline station & $\begin{array}{c}\mathrm{X}-\text { height } \\
\text { (in) }\end{array}$ & $\begin{array}{c}\text { Y-radius } \\
\text { (in) }\end{array}$ & $\begin{array}{c}\text { Pool Depth } \\
\text { (in) }\end{array}$ & $\begin{array}{c}\text { Pool Depth } \\
\text { (in) }\end{array}$ & $\begin{array}{c}\text { Interpolated } \\
\text { radius (in) }\end{array}$ \\
\hline 0 & 11.125 & 40.454 & 0 & 0 & 40.450 \\
\hline 1 & 12.121 & 43.289 & 0.996 & 2 & 45.395 \\
\hline 2 & 13.324 & 45.813 & 2.199 & 4 & 48.267 \\
\hline 3 & 15.213 & 48.387 & 4.088 & 6 & 50.500 \\
\hline 4 & 17.225 & 50.610 & 6.100 & 8 & 52.336 \\
\hline 5 & 19.445 & 52.627 & 8.320 & 10 & 53.916 \\
\hline 6 & 21.825 & 54.453 & 10.700 & 12 & 55.290 \\
\hline 7 & 24.346 & 56.076 & 13.221 & 14 & 56.491 \\
\hline 8 & 26.993 & 57.487 & 15.868 & 16 & 57.545 \\
\hline 9 & 29.736 & 58.700 & 18.611 & 18 & 58.430 \\
\hline 10 & 32.552 & 59.734 & 21.427 & 20 & 59.210 \\
\hline 11 & 35.440 & 60.539 & 24.315 & 22 & 59.894 \\
\hline 12 & 38.403 & 61.002 & 27.278 & 24 & 60.451 \\
\hline 13 & 41.394 & 61.236 & 30.269 & 26 & 60.802 \\
\hline 14 & 44.391 & 61.308 & 33.266 & 28 & 61.058 \\
\hline
\end{tabular}

6.c. Intercepts of inner insulator contour radii with source-to-strip centroid vectors are determined in beam centerline plane as shown in Figure A2-1. The intercept coordinates are given in Table 7 , where $X, Y$ coordinates of motor centerline are $(0,0)$, source is located at $(-90,-34.6)$, and screen centroid is located at $(+70,-34.6)$, all dimensions in inches. Entries in Table 7 that read \#NUM! indicate undefined values, i.e. no intercept. 


\begin{tabular}{|c|c|c|c|c|c|}
\hline $56^{\circ} I^{\circ}$ & to Et & 08.09 & 92 & $\varepsilon$ & \\
\hline 26.15 & $9 s^{2} 2 t$ & St:09 & $\overline{b i}$ & $\bar{\varepsilon}$ & \\
\hline $88^{\circ} 15$ & 08 '1t & 68.65 & 22 & $\varepsilon$ & \\
\hline Es'T & $58^{\circ} 0 t$ & 12.65 & 02 & $\varepsilon$ & \\
\hline$\angle L^{\prime} I T$ & $9 L^{\prime} 6 \varepsilon$ & $E D^{\circ} 8 S$ & 81 & $\varepsilon$ & \\
\hline $0 L^{\prime} \mid \mathrm{t}$ & $158 \varepsilon$ & $S S^{\prime} L S$ & 91 & $\varepsilon$ & \\
\hline 29.15 & $869 \varepsilon$ & 66.95 & $D 1$ & $\varepsilon$ & \\
\hline $2510^{-}$ & $1 \bar{I}^{\prime} \mathrm{s} \varepsilon$ & 62.55 & 21 & $\bar{\varepsilon}$ & \\
\hline $0 t^{\circ} 1 t^{-}$ & ZाहE & $26^{\circ} E S$ & 01 & $\varepsilon$ & \\
\hline $90^{\circ} 1 t^{-1}$ & $29^{\circ} 0 \varepsilon$ & $\triangle E^{\prime \prime 2 S}$ & 8 & $\bar{\varepsilon}$ & \\
\hline 6015 & $S S^{\prime} L 2$ & OS'OS & 9 & $\mathcal{E}$ & \\
\hline$\angle 8^{\circ} 0 t$ & $0 S^{\prime} \varepsilon Z$ & $\angle 28 D^{\circ}$ & 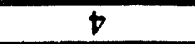 & $\varepsilon$ & \\
\hline ESOt & $1 t^{\circ} \angle 1$ & $0 t^{\prime} s t$ & $z$ & $\varepsilon$ & \\
\hline iK几N\# & iK几N\# & Stot & 0 & $\varepsilon$ & $a \cdot \forall$ \\
\hline $90^{\circ} \mathrm{Zb}$ & $10.5 t$ & $08^{\circ} 09$ & 92 & 2 & \\
\hline$\varepsilon 0^{\prime} Z^{-}$ & $s s^{2} t$ & St09 & $\nabla 2$ & 2 & \\
\hline 6615 & $18^{\circ} \mathrm{Et}$ & 68.65 & $\overline{z z}$ & $\overline{2}$ & \\
\hline 66.15 & $06^{\circ} 27$ & 12.65 & 02 & $\overline{2}$ & \\
\hline $88^{\prime} \mathrm{It}^{-}$ & 58.16 & $\varepsilon \nabla^{\prime} 8 S$ & 81 & $\bar{z}$ & \\
\hline $28^{\prime} 10^{-}$ & $t 9^{\circ} 0 t$ & $\overline{S S L S}$ & 91 & 2 & \\
\hline$D L^{\circ} 10^{\circ}$ & $816 \varepsilon$ & $60^{\circ} 9 S$ & 51 & 2 & \\
\hline 59.16 & $80^{\circ} \angle \mathcal{E}$ & 62.55 & 21 & 2 & \\
\hline ES'It & $6 \nabla^{\circ} S \varepsilon$ & $26 \mathrm{ES}$ & 01 & $\tau$ & \\
\hline $00^{\prime} 15$ & $\left.\mathcal{E}\right|^{\prime} \mathcal{E} \mathcal{E}$ & $t \varepsilon^{\prime} Z S$ & 8 & 2 & \\
\hline$\sigma^{\prime} 1 b^{-}$ & SZOE & OS'OS & 9 & 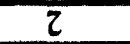 & \\
\hline $50^{\circ} 10^{\circ}$ & ES92 & $\angle 285$ & $t$ & 2 & \\
\hline${ }^{\circ} L^{\circ} O t$ & SI'IL & $0 t^{\prime} s t$ & 2 & $z$ & \\
\hline $86^{\circ} 6 \varepsilon^{-}$ & SEL & stot & 0 & $\bar{Z}$ & $5-\forall$ \\
\hline $95^{\prime} 6 \varepsilon^{-}$ & 0596 & $08^{\circ} 09$ & 92 & 1. & \\
\hline $7 S^{\prime} 6 E^{-}$ & $89^{\circ} 50$ & $55^{\prime} 09$ & $\overline{t z}$ & $T$ & \\
\hline $7 S^{\prime} 6 E^{-}$ & $89.5 \phi$ & 68.65 & 22 & 1 & \\
\hline $0 S^{\prime} 6 E^{-}$ & $08^{\circ}$ & 1265 & 02 & 1 & \\
\hline$\angle t^{\circ} 6 \mathcal{E}^{-}$ & $8 L^{\prime} E t$ & $E+8 S$ & 81 & 1 & \\
\hline $20^{\circ} 6 \varepsilon^{\circ}$ & $19^{2} 2 t$ & $S S L S$ & 91 & $I$ & \\
\hline$\angle E^{\prime} 6 \varepsilon^{-}$ & $02^{\prime} 15$ & $6 b^{\prime} 95$ & $D I$ & $I$ & \\
\hline $1 \varepsilon^{\prime} 6 E^{-}$ & $\angle S^{\prime} 6 \varepsilon$ & 62.55 & 21 & $I$ & \\
\hline $6 Z^{\prime} 6 \varepsilon^{\circ}$ & $\angle 9^{\prime} \angle \mathcal{E}$ & $26^{\circ} E S$ & 01 & 1 & \\
\hline $916 \varepsilon^{-}$ & IDSSE & $\overline{D E} Z S$ & 8 & 1 & \\
\hline $90^{\circ} 6 \varepsilon^{-}$ & $0 L^{\prime} Z \varepsilon$ & $O S^{\prime} O S$ & 9 & 1 & \\
\hline $768 E^{\circ}$ & 2262 & $\angle 278$ & $t$ & 1 & \\
\hline $9 L^{\circ} 8 E^{\circ}$ & $\varepsilon E^{\prime} t \tau$ & $00.5 t$ & $\tau$ & $T$ & \\
\hline$\angle E^{\prime} 8 E^{-}$ & टSहा & $5 t^{\circ} 0 t$ & 0 & 1 & $\bar{\theta}-\bar{v}$ \\
\hline$(\mathrm{UI}) I_{\mathrm{K}}$ & (UI) $\mid X$ & $\begin{array}{c}\text { (u!) sn!̣py } \\
\text { Joje|nsul }\end{array}$ & (u!) पगdळ्व & dب̣ns & uolloכlo.d \\
\hline
\end{tabular}

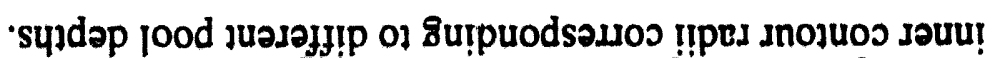

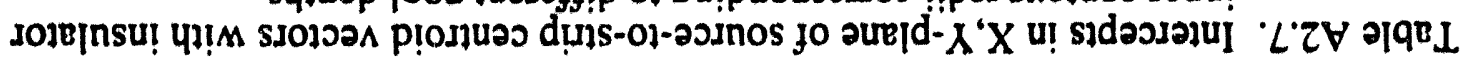


Table A2.7 (cont.).

\begin{tabular}{|c|c|c|c|c|c|}
\hline$\overline{A-E}$ & 4 & 0 & 40.45 & \#NUM! & \#NUM! \\
\hline & 4 & 2 & 45.40 & 12.78 & -40.28 \\
\hline & 4 & 4 & 48.27 & 20.04 & -40.68 \\
\hline & 4 & 6 & 50.50 & 24.54 & -40.93 \\
\hline & 4 & 8 & 52.34 & 27.86 & -41.11 \\
\hline & 4 & 10 & 53.92 & 30.53 & -41.26 \\
\hline & 4 & 12 & 55.29 & 32.75 & -41.38 \\
\hline & 4 & 14 & 56.49 & 34.61 & -41.40 \\
\hline & 4 & 16 & 57.55 & 36.21 & -41.57 \\
\hline & 4 & 18 & 58.43 & 37.52 & -41.65 \\
\hline & 4 & 20 & 59.21 & 38.65 & -41.71 \\
\hline & 4 & 22 & 59.89 & 39.63 & -41.76 \\
\hline & 4 & 24 & 60.45 & 40.42 & -41.81 \\
\hline & 4 & 26 & 60.80 & 40.92 & -41.83 \\
\hline A-F & 5 & 0 & 40.45 & \#NUM! & \#NUM! \\
\hline & 5 & 2 & 45.40 & 6.03 & -39.91 \\
\hline & 5 & 4 & 48.27 & 15.91 & -40.45 \\
\hline & 5 & 6 & 50.50 & 21.11 & -40.74 \\
\hline & 5 & 8 & 52.34 & 24.78 & -40.94 \\
\hline & 5 & 10 & 53.92 & 27.67 & -41.10 \\
\hline & 5 & 12 & 55.29 & 30.03 & -41.23 \\
\hline & 5 & 14 & 56.49 & 32.01 & -41.34 \\
\hline & 5 & 16 & 57.55 & 33.69 & -41.43 \\
\hline & 5 & 18 & 58.43 & 35.07 & -41.51 \\
\hline & 5 & 20 & 59.21 & 36.26 & -41.58 \\
\hline & 5 & 22 & 59.89 & 37.28 & -41.63 \\
\hline & 5 & 24 & 60.45 & 38.11 & -41.68 \\
\hline & 5 & 26 & 60.80 & 38.62 & -41.71 \\
\hline
\end{tabular}

6.d. Vertical distance, $\mathrm{zl}$, from beam centerline plane to inner insulator surface corresponding to in-plane intercept points from para. 6.c is determined by geometry for lift-off conditions $0.0,0.2,0.4, \ldots, 1.8$ inches. Corresponding vertical screen locations, $z 2$, relative to beam centerline are determine from geometry. Second order polynomial equations relating $\mathrm{z} 1$ to $\mathrm{z} 2$ are determined for each of the lift-off conditions above $(0.0,0.2, \ldots, 1.8$ inches). Pool depth is given by the relationship (22.885 abs(zl) - lift-off), where 22.885 is the vertical height (inches) of the beam centerline above sta0 (datum $\mathrm{A}$ ) at 0.0 inches lift-off . Relationship of pool depth to screen location (with respect to beam centerline) is second order polynomial, depth $=\mathrm{a} 0+$ $\mathrm{a} 1 * z 2+\mathrm{a} 2 * z 2^{\wedge} 2$, with polynomial coefficients for different lift-off conditions as given in Table 8. Values of pool depth for intermediate lift-off conditions are determined by linear interpolation. 
Table A2.8. Coefficients of second order polynomial $\left(y=a 0+a 1^{*} x+a 2^{*} x^{\wedge} 2\right)$ relating pool depth $(y)$ to screen location with respect to beam centerline $(x)$.

\begin{tabular}{|c|c|c|c|c|c|c|c|c|c|}
\hline strip & $\begin{array}{c}\text { lift-off } \\
\text { (in) }\end{array}$ & $\mathrm{a} 0$ & $\mathrm{a}$ l & $\mathrm{a} 2$ & strip & $\begin{array}{c}\text { (ift-off } \\
\text { (in) }\end{array}$ & $\mathrm{a} 0$ & $\mathrm{a} 1$ & $\mathrm{a} 2$ \\
\hline 1 & 1.8 & 21.1060 & 0.8718 & 0.0054 & 4 & 1.8 & 21.1133 & 0.8382 & 0.0059 \\
\hline 1 & 1.6 & 21.3148 & 0.8743 & 0.0054 & 4 & 1.6 & 21.3236 & 0.8408 & 0.0060 \\
\hline 1 & 1.4 & 21.5175 & 0.8759 & 0.0054 & 4 & 1.4 & 21.5281 & 0.8424 & 0.0060 \\
\hline 1 & 1.2 & 21.7266 & 0.8780 & 0.0054 & 4 & 1.2 & 21.7416 & 0.8457 & 0.0060 \\
\hline 1 & 1.0 & 21.9314 & 0.8792 & 0.0054 & 4 & 1.0 & 21.9521 & 0.3482 & 0.0060 \\
\hline 1 & 0.8 & 22.1395 & 0.8818 & 0.0054 & 4 & 0.8 & 22.1637 & 0.8506 & 0.0060 \\
\hline 1 & 0.6 & 22.3495 & 0.8845 & 0.0055 & 4 & 0.6 & 22.3702 & 0.8525 & 0.0060 \\
\hline 1 & 0.4 & 22.5552 & 0.8859 & 0.0055 & 4 & 0.4 & 22.5816 & 0.8550 & 0.0060 \\
\hline 1 & 0.2 & 22.7696 & 0.8889 & 0.0055 & 4 & 0.2 & 22.7944 & 0.8574 & 0.0060 \\
\hline 1 & 0.0 & 22.8542 & 0.8479 & 0.0031 & 4 & 0.0 & 22.8536 & 0.8089 & 0.0033 \\
\hline 2 & 1.8 & 21.1100 & 0.8623 & 0.0056 & 5 & 1.8 & 21.1189 & 0.8261 & 0.0063 \\
\hline 2 & 1.6 & 21.3175 & 0.8645 & 0.0056 & 5 & 1.6 & 21.3321 & 0.8291 & 0.0063 \\
\hline 2 & 1.4 & 21.5212 & 0.8661 & 0.0056 & 5 & 1.4 & 21.5409 & 0.8316 & 0.0063 \\
\hline 2 & 1.2 & 21.7270 & 0.8676 & 0.0056 & 5 & 1.2 & 21.7525 & 0.8343 & 0.0063 \\
\hline 2 & 1.0 & 21.9358 & 0.8700 & 0.0056 & 5 & 1.0 & 21.9591 & 0.8360 & 0.0063 \\
\hline 2 & 0.8 & 22.1449 & 0.8723 & 0.0056 & 5 & 0.8 & 22.1740 & 0.8392 & 0.0063 \\
\hline 2 & 0.6 & 22.3546 & 0.8748 & 0.0056 & 5 & 0.6 & 22.3876 & 0.8419 & 0.0063 \\
\hline 2 & 0.4 & 22.5626 & 0.8767 & 0.0056 & 5 & 0.4 & 22.5962 & 0.8442 & 0.0063 \\
\hline 2 & 0.2 & 22.7749 & 0.8792 & 0.0057 & 5 & 0.2 & 22.8156 & 0.8476 & 0.0064 \\
\hline 2 & 0.0 & 22.8552 & 0.8372 & 0.0032 & 5 & 0.0 & 22.8501 & 0.7931 & 0.0034 \\
\hline 3 & 1.8 & 21.1117 & 0.8504 & 0.0057 & & Pool Level Above Beam Centerline & \\
\hline 3 & 1.6 & 21.3177 & 0.8525 & 0.0057 & 1 & 0.0 & 22.8937 & 0.2615 & $-6.71 \mathrm{e}-06$ \\
\hline 3 & 1.4 & 21.5242 & 0.8544 & 0.0057 & 2 & 0.0 & 22.8774 & 0.2745 & $-4.66 \mathrm{e}-04$ \\
\hline 3 & 1.2 & 21.7347 & 0.8571 & 0.0058 & 3 & 0.0 & 22.8767 & 0.2815 & $-4.95 \mathrm{e}-04$ \\
\hline 3 & 1.0 & 21.9441 & 0.8590 & 0.0058 & 4 & 0.0 & 22.8769 & 0.2888 & $-5.21 \mathrm{e}-04$ \\
\hline 3 & 0.8 & 22.1499 & 0.8613 & 0.0058 & 5 & 0.0 & 22.8758 & 0.2968 & $-5.52 \mathrm{e}-04$ \\
\hline 3 & 0.6 & 22.3649 & 0.8645 & 0.0058 & & & & & \\
\hline 3 & 0.4 & 22.5724 & 0.8665 & 0.0058 & & & & & \\
\hline 3 & 0.2 & 22.7814 & 0.8684 & 0.0058 & & & & & \\
\hline 3 & 0.0 & 22.8544 & 0.8239 & 0.0033 & & & & & \\
\hline & & & & & & & & & \\
\hline
\end{tabular}




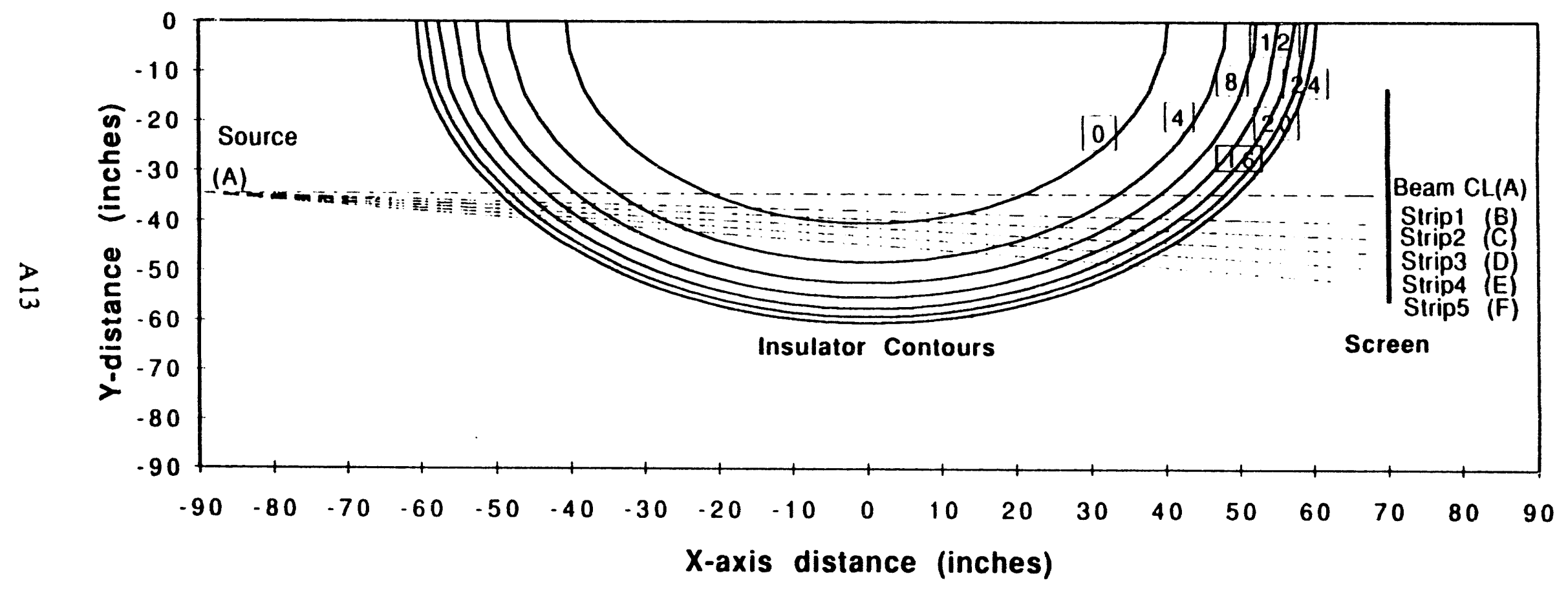

Figure A2-1. Source-to-strip centroid projections in beam centerline plane showing intercepts with inner insulator contours corresponding to pool depths of $0,4,8, \ldots, 24$ inches. 


\section{APPENDIX A3: GEOMETRIC PROJECTIONS AND PATH LENGTHS}

The geometry for analyzing this test is one of an $\mathrm{x}$-ray beam projected through the motor case in straight line projections resulting in a transmitted $\mathrm{x}$-ray image on the imager screen. Since the $x$-ray source and beam centerline are above the top of the pool during the entire test except for a brief period following motor burnout (e.g., see Figure 5.1-1), the pool level is defined by projections as represented in Figure A3-1. The image terminus (e.g. transition form bright to dark corresponding to the top of the pool) for a flat pool is defined by the straight line projection through the outer edge of the slag pool, or inner contour of the insulation, onto the screen. The minimum detectable pool level corresponds to the projection that intersects the bottom of the screen as viewed by the camera.

A change in pool level corresponds to a change in vertical location of the image terminus on the screen. Pool level changes are magnified somewhat in the screen image because of the geometry. Greater geometric magnification occurs at low pool levels since the edge of the pool is farther away from the imager screen due to the shape of the insulator inner contour, and less magnification occurs at higher pool levels.

The sharpness of the image terminus is determined by the angle of incidence of the beam with the pool. At high pool levels, where the image terminus is formed at near grazing incidence with the top of the pool, small changes in angle of incidence result in large changes of $\mathrm{x}$-ray path length through the pool, and hence large changes in attenuation or image brightness. At low pool levels, changes in projected path length through the pool are not as great with changing angle of incidence. In order to assess the effect on sharpness of image terminus, we calculate the screen location increment that corresponds $50 \%$ and $10 \%$ changes in x-ray intensity at the terminus as a function of pool depth. These are given in Table A3.1 at a motor lift-off condition of 0.0 inches Lift-off conditions greater than 0.0 inches result in smaller screen location increments for corresponding $\mathrm{x}$-ray intensity changes since the top of the pool is closer to the beam centerline.

Table A3.1 Screen location increment at image terminus corresponding to $50 \%$ and $10 \%$ changes in $\mathrm{x}$-ray intensity as a function of pool depth at a lift-off condition of $0.0 \mathrm{inch}$.

\begin{tabular}{|c|c|c|c|c|c|}
\hline $\begin{array}{c}\text { Pool } \\
\text { Depth } \\
\text { (in) }\end{array}$ & $\begin{array}{c}\text { Geometric } \\
\text { Magnifi- } \\
\text { cation }\end{array}$ & $\begin{array}{c}\text { Intensity } \\
\text { Change } \\
(\%)\end{array}$ & $\begin{array}{c}\text { Screen } \\
\text { Increment } \\
\text { (in)* }\end{array}$ & $\begin{array}{c}\text { Intensity } \\
\text { Change } \\
(\%)\end{array}$ & $\begin{array}{c}\text { Screen } \\
\text { Increment } \\
\text { (in)* }\end{array}$ \\
\hline 8 & 1.33 & 50 & 1.65 & 10 & 0.25 \\
\hline 10 & 1.30 & 50 & 1.11 & 10 & 0.15 \\
\hline 12 & 1.28 & 50 & 0.86 & 10 & 0.12 \\
\hline 16 & 1.25 & 50 & 0.61 & 10 & 0.09 \\
\hline 20 & 1.22 & 50 & 0.33 & 10 & 0.05 \\
\hline
\end{tabular}

*assumes half-value thickness of 7.2 inches for pool material 


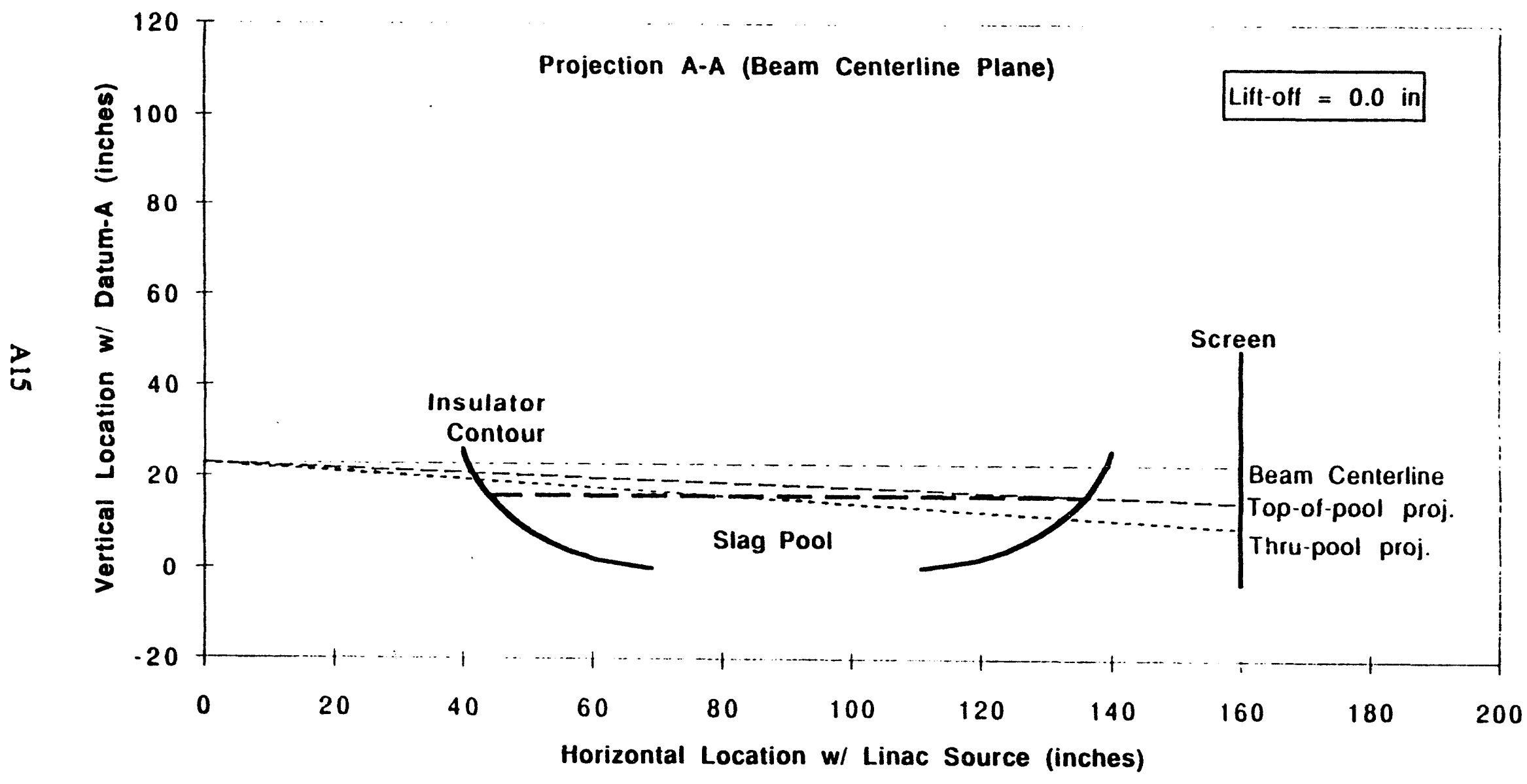

Figure A3-2. Representation of projection in vertical beam centerline showing top-of-pool projection and through pool projection. 


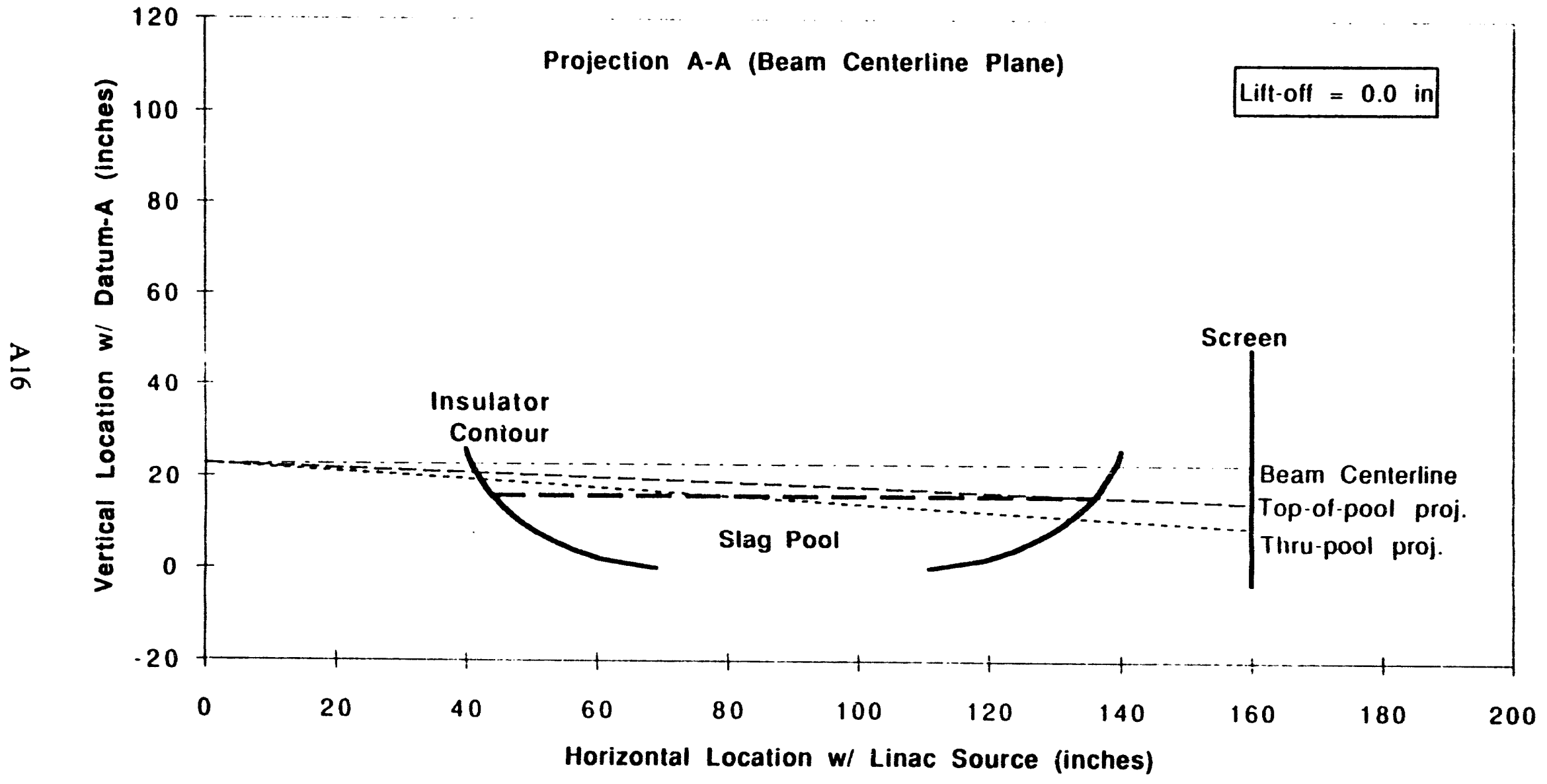

Figure A3-2. Representation of projection in vertical beam centerline showing top-of-pool projection and through pool projection. 


\section{APPENDIX A4: LINAC RADIATION EXPOSURE LOG}

\begin{tabular}{|c|c|c|c|c|c|c|}
\hline DATE & $\begin{array}{c}\text { Time: } \\
\text { BEAM ON }\end{array}$ & $\begin{array}{c}\text { Time: } \\
\text { BEAM OFF }\end{array}$ & $\begin{array}{c}\text { Exposure } \\
\text { Time } \\
\text { (minutes) }\end{array}$ & $\begin{array}{c}\text { DOSE OUT } \\
(\mathrm{rads} / \mathrm{min})\end{array}$ & $\begin{array}{c}\text { Cumulative } \\
\text { time (min) } \\
\text { @ } 3000 \mathrm{rad} \text { Equiv }\end{array}$ & NOTES \\
\hline 15-Dec-92 & 05:07:00 & $05: 09: 00$ & 2.00 & 1000 & 0.67 & \\
\hline 15-Dec-52 & $05: 13: 00$ & $05: 15: 00$ & 2.00 & 2000 & 2.00 & \\
\hline 15-Dec-92 & $05: 19: 00$ & $05: 21: 00$ & 2.00 & 3000 & 4.00 & \\
\hline 15-Dec-92 & $06: 05: 00$ & $06: 07: 00$ & 2.00 & 3000 & 6.00 & \\
\hline 15-Dec-92 & $06: 10: 00$ & $06: 15: 00$ & 5.00 & 3000 & 11.00 & \\
\hline 15-Dec-92 & $06: 19: 00$ & $06: 31: 00$ & 12.00 & 3000 & 23.00 & \\
\hline 15-Dec-92 & $06: 57: 00$ & $07: 06: 00$ & 9.00 & 3000 & 32.00 & \\
\hline 17-Dec-92 & 05:00:00 & $05: 05: 36$ & 0.60 & 3000 & 32.60 & \\
\hline 17-Dec-92 & $05: 27: 00$ & $05: 28: 06$ & 1.10 & 3000 & 33.70 & \\
\hline 17-Dec-92 & $05: 31: 00$ & $05: 32: 18$ & 0.30 & 3000 & 34.00 & \\
\hline 17-Dec-92 & $05: 46: 00$ & $05: 46: 30$ & 0.50 & 3000 & 34.50 & \\
\hline 17-Dec-92 & $06: 00: 30$ & $06: 01: 00$ & 0.50 & 3000 & 35.00 & \\
\hline 17-Dec-92 & $06: 01: 00$ & $06: 02: 18$ & 0.30 & 3000 & 35.30 & \\
\hline 17-Dec-92 & $06: 02: 18$ & $06: 04: 18$ & 2.00 & 3000 & 37.30 & \\
\hline 17-Dec-92 & $06: 06: 00$ & $06: 08: 00$ & 2.00 & 3000 & 39.30 & \\
\hline 17-Dec-92 & $13: 25: 19$ & $13: 27: 19$ & 2.00 & 3000 & 41.30 & FMST-1B \\
\hline 17-Dec-92 & $14: 21: 00$ & $14: 31: 20$ & 10.34 & 3000 & 51.64 & FMST-1B \\
\hline 13-Feb-93 & $16: 47: 45$ & $16: 47: 47$ & 0.03 & 300 & 51.64 & \\
\hline 13-Feb-93 & $16: 48: 16$ & $16: 52: 45$ & 4.48 & 300 & 52.09 & \\
\hline 13-Feb-93 & 16:53:00 & $17: 00: 41$ & 7.68 & 3000 & 59.77 & \\
\hline 13-Feb-93 & $17: 02: 00$ & $17: 03: 08$ & 1.13 & 3000 & 60.90 & \\
\hline 13-Feb-93 & $17: 04: 30$ & $17: 10: 15$ & 5.75 & 3000 & 66.65 & \\
\hline
\end{tabular}




\section{A4: LINAC RADIATION EXPOSURE LOG (cont).}

\begin{tabular}{|c|c|c|c|c|c|c|}
\hline DATE & $\begin{array}{c}\text { Time: } \\
\text { BEAM ON }\end{array}$ & $\begin{array}{c}\text { Time: } \\
\text { BEAM OFF }\end{array}$ & $\begin{array}{c}\text { Time } \\
\text { (minutes) }\end{array}$ & $\begin{array}{l}\text { DOSE OUT } \\
(\mathrm{rads} / \mathrm{min})\end{array}$ & $\begin{array}{c}\text { Cumulative } \\
\text { Time (min) } \\
\text { @ } 3000 \mathrm{rad} \text { Equiv }\end{array}$ & NOTES \\
\hline 14-Feb-93 & $17: 19: 33$ & $17: 29: 33$ & 10.00 & 3000 & 76.65 & \\
\hline $15-F e b-93$ & $11: 22: 11$ & $11: 27: 11$ & 5.00 & 3000 & 81.65 & FMST-1C \\
\hline $15-\mathrm{Feb}-93$ & $12: 53: 17$ & $13: 01: 20$ & 8.05 & 3000 & 89.70 & FMST-1C \\
\hline 16-Feb-93 & $17: 48: 04$ & $18: 01: 34$ & 13.50 & 3000 & 103.20 & \\
\hline $17-\mathrm{Feb}-93$ & $12: 24: 10$ & $12: 26: 10$ & 2.00 & 3000 & 105.20 & \\
\hline $18-F e b-93$ & $10: 21: 18$ & $10: 23: 18$ & 2.00 & 3000 & 107.20 & FMST-2 \\
\hline $18-F e b-93$ & $11: 13: 36$ & $11: 15: 36$ & 2.00 & 3000 & 109.20 & FMST-2 \\
\hline $18-\mathrm{Feb}-93$ & $12: 05: 35$ & $12: 16: 14$ & 10.65 & 3000 & 119.85 & FMST-2 \\
\hline 19-Feb-93 & $12: 34: 45$ & $12: 41: 45$ & 7.00 & 3000 & 126.85 & \\
\hline $21-F e b-93$ & $12: 03: 04$ & $12: 13: 40$ & 10.67 & 3000 & 137.52 & QM-2 \\
\hline $22-\mathrm{Feb}-93$ & $17: 42: 00$ & $17: 52: 00$ & 10.00 & 3000 & 147.52 & Post-Test \\
\hline $22-\mathrm{Feb}-93$ & $18: 57: 00$ & 19:07:00 & 10.00 & 3000 & 157.52 & \\
\hline
\end{tabular}




\section{APPENDIX A5: STATEMENT OF WORK}

\section{RTR Inspection of Titan IV SRMU Static Firing Test}

Task 1. Prepare, transport and install $9 \mathrm{MeV}$ transportable Linac at Rocket Motor Test Stand, Phillips Laboratory, Edwards AFB, CA.

Task 2. Conduct site and radiation surveys and prepare operating procedures

Task 3. Design, fabricate, test and install RTR imager, associated electronics, and data acquisition hardware

Task 4. Design and fabricate vibration isolation equipment for RTR system. Instrument RTR system for vibration data acquisition and analyze data.

Task 5. Perform radiographic inspection of High Energy Firing Unit. (canceled)

Task 6. Conduct radiographic inspection of rocket motor firing and analyze test data.

Task 7. Dismantle equipment after test and transport to LLNL

Task 8. Prepare preliminary and final reports as required by USAF SMC/MES 


\section{APPENDIX A6: ORDER OF EVENTS AND TASK PLANNING}

\begin{tabular}{|c|l|c||}
\hline$\#$ & Task Description & Date \\
\hline I & Motor generator arrives Phillips Lab and is located by Hercules. & $2 / 9 / 93$ \\
\hline & Air Force obtain deionized or distilled water (100 gal) & \\
\hline a & Transports (2) arrive at Phillips Lab 6:00 AM & $2 / 10 / 93$ \\
\hline 2b & Propane bottle removed from Linac Trailer and stored in designated area & \\
\hline 3a & Equipment off loaded from transport vehicle into IC building & \\
\hline 3b & Linac tubehead off loaded from trailer into IC building & \\
\hline 4a & Trailer located by Test Stand, wheels chocked, trailer secured & \\
\hline 4b & Linac visual checks for transportation damage & \\
\hline 4c & Trailer visual checks for equipment damage & \\
\hline 4d & Hercules wires trailer to motor generator & \\
\hline 4e & LLNL begins installation of Linac support and imager mods in Test Stand & \\
\hline & Lampson will be needed to pick the Al plate and Wooden Box into Test Stand & \\
\hline 4f & Linac setup for "Dummy Load" op check in the lC bldg. & \\
\hline 4g & LLNL begins data system checkout ( cabling checkout, equipment inventory) & \\
\hline 5 & Linac operational test using dummy Load ( IC building Restricted Access) & \\
\hline & Barricade using rope "Stay Out" area at least 30 ft circumference around linac & \\
\hline & Perform maintenance operation into dummy load and record results in log & \\
\hline & $\begin{array}{l}\text { Upon satisfactory performance, power down and secure high voltage power } \\
\text { supply }\end{array}$ & \\
\hline 6 & Secure high voltage power supply by: & \\
\hline & turning off high voltage breaker in trailer & \\
\hline & Attaching grounding rods to terminals in high voltage power supply & \\
\hline & Locking up the trailer & \\
\hline & Confirm the vac-ion power supply is plugged into wall receptacle & \\
\hline
\end{tabular}




\section{A6: ORDER OF EVENTS AND TASK PLANNING (cont.)}

\begin{tabular}{|c|c|c|}
\hline \# & Task Description & Date \\
\hline $7 \sqrt{a}$ & Linac Prep for pick/installation into Test Stand & \\
\hline & A)Remove linac from transport framework ( Lampson assist) \& place on floor & \\
\hline & B)Aftach insulating material around linac and tape (2 layers is sufficient) & \\
\hline & C)Confirm water hookup and flow and vac-ion pump working & \\
\hline 76 & Imager and DAS systems check & \\
\hline $7 \mathrm{c}$ & $\begin{array}{l}\text { Environmental Measuring Systems checkout ( Equipment inventory, system } \\
\text { checks) }\end{array}$ & \\
\hline 8 & $\begin{array}{l}\text { Lampson picks linac and places in Test Stand (per TPS "RTR Equipment } \\
\text { Installation") }\end{array}$ & $2 / 11 / 93$ \\
\hline $9 a$ & $\begin{array}{l}\text { Linac installation ( } 0.5 \mathrm{~mW} \text { alignment laser, insulating box, securing, Heater and } \\
\text { duct) }\end{array}$ & \\
\hline & Laser caution signshall be posted on all access doors prior to turning on the laser & \\
\hline & $\begin{array}{l}\text { The laser is not to be turned on until all nonessential personnel are out of the } \\
\text { identified area }\end{array}$ & \\
\hline & $\begin{array}{l}\text { All personnel present while the HeNe laser is on shall wear Approved Laser } \\
\text { Safety goggles }\end{array}$ & \\
\hline & $\begin{array}{l}\text { The laser shall only be turned on for the time required to align the linac to the } \\
\text { SRM }\end{array}$ & \\
\hline $9 b$ & $\begin{array}{l}\text { Lampson locates and secures hose and cable runs from trailer to linac in Test } \\
\text { Stand }\end{array}$ & \\
\hline $9 \mathrm{c}$ & Confirm linac stand-by mode: maintenance checklist & \\
\hline $10 \mathbf{a}$ & Complete Environmental Measuring ?ystem checkouts & $2 / 12 / 93$ \\
\hline $\mathrm{IOb}$ & Complete Imager and DAS checkout & \\
\hline $10 \mathrm{c}$ & Complete linac installation & \\
\hline
\end{tabular}




\section{APPENDIX A7: SUPPORTING DOCUMENTATION}

1. LLNL Operational Safety Procedure No. O-167: Titan IV Field Radiography at Edwards AFB

2. LLNL Operational Safety Procedure No. OS1.01: Repair and Maintenance of Varian $9 \mathrm{MeV}$ Linac

3. LLNL, Internal Memorandum: Gordon Krauter to distribution, "Design and Safety Review of 9 MeV Linac Modification", dated December 7, 1992.

4. LLNL Internal Memorandum: J. Chang to Paul Gschweng, "Vibration and Safety Analysis of Critical RTR Components", dated December 8, 1992.

5. LLNL Engineering Drawing: ENW-84-929, "Transportable X-Ray System Modulator Suspension", dated November 29, 1984. 


\section{APPENDIX A8: RTR TEAM MEMBERS}

Project Leadership

Kenneth Dolan *

Gary Curnow *

Satish Kulkarni

\section{RTR Imager}

Dwight Perkins **

Jerry Haskins

Derrill Rikard

Richard Ryon

Radiography

Gerry Sobczak **

Earl Updike **

Gene Ford

Daniel Green

Linwood Hester

Data Systems

Mark La Chapell **

Donald Tucker *

David Elsea *

Data Analysis

Dan Schneberk

Mike Gorvad

Bill Comfort

Electronics Engineering - Linac

Support

Donald Turner *

Phinas Wallace *

James Fugina *

William Stigman *

Darrell Griffin *

Acoustic/Vibration Isolation

Brad Burdick *

Bart Costerus *

Al Brown *

Thomas Woehrle *

Acoustic/Vibration

Measurements

Donald Bitz *

Al Knabe *

Richard Ring *

Nhan Nguyen
Mechanical Desion/Fabrication

Frank Drobnik *

Greg Bianchini *

Paul Gschweng

Terry Hancock

Mark Johnson

Warren Bell

Joe Conner

Wayne Cooke

Don Fearon

Fred Grabner

Joe Lane

Bill Lewis

Gary Loomis

Greg Maine

Richadd Meager

Ray Swan

Phil Waide

Ben Visser

\section{Hazards Control}

Larry Auman*

James Winstanley *

Gary Mansfield*

Ben Paredes**

Willie Thompson **

Tricia Torry *

Procurement Coord.

Earl Kelley

Dick Sites

Resource Management

Jim Campbell

Susan Springer

\section{Secretarial Support}

Karen Lindsay

Jane DeAnda

Transportation

Gary Cundiff

Andrew Galligan

Earl Nevares

*On-site installatiun/test

** Test Team Member 

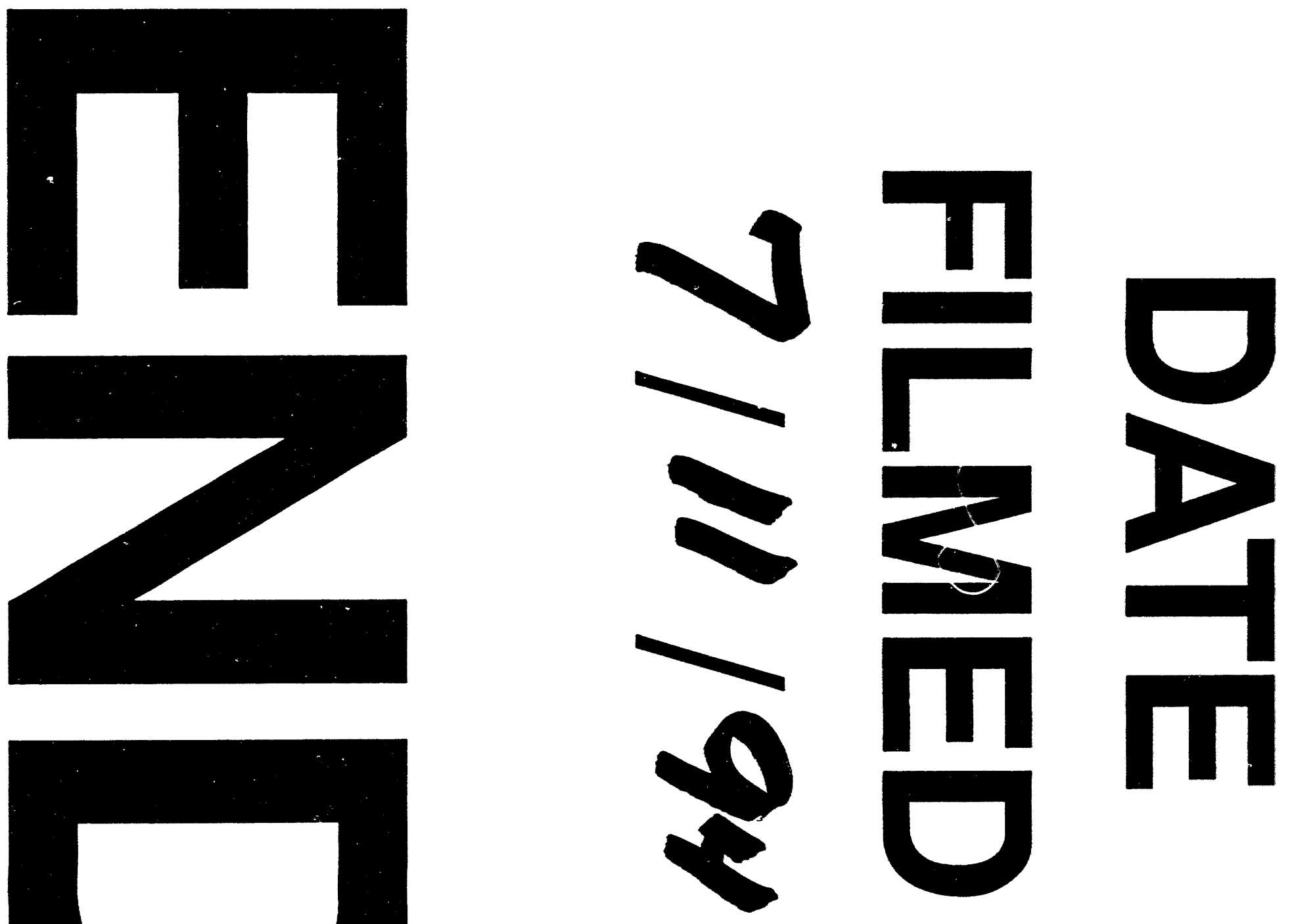

2

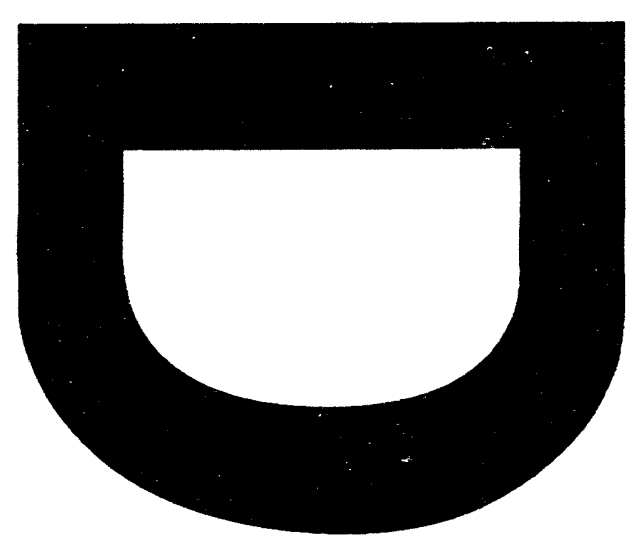

